RADBOUD UNIVERSITY DISSERTATION

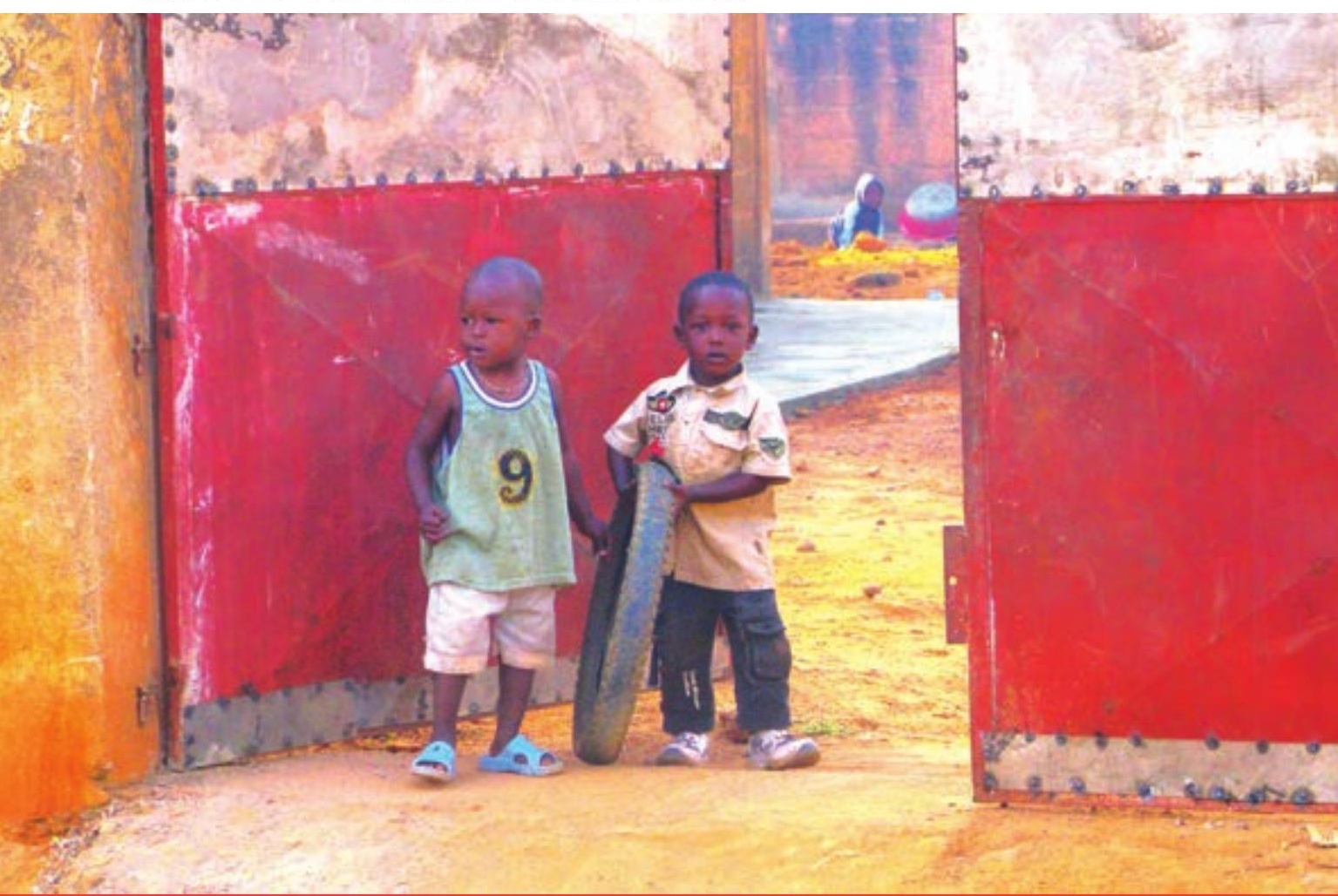

Annemieke Mol Lous

Depression and Play in Early

Childhood 
Depression and Play in Early Childhood 
This research has also been made possible by

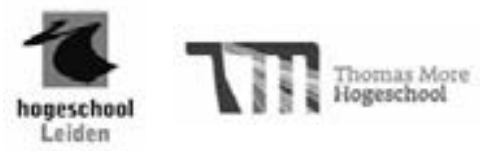

Lay-out: Crius Group, Hulshout

ISBN $\quad 978-90-8555^{-095-2}$

(c) A. Mol Lous/ Amsterdam University Press B.V., Amsterdam 2014

All rights reserved. Without limiting the rights under copyright reserved above, no part of this book may be reproduced, stored or introduced into a retrieval system, or transmitted, in any form or by any means (electronic, mechanical, photocopying, recording or otherwise) without the written permission of both the copyright owner and the author of the book. 


\title{
Depression and Play in Early Childhood
}

\author{
PROEFSCHRIFT \\ ter verkrijging van de graad van doctor \\ aan de Radboud Universiteit Nijmegen \\ op gezag van de rector magnificus prof. dr. Th.L.M. Engelen, \\ volgens besluit van het college van decanen \\ in het openbaar te verdedigen op maandag 15 december 2014 \\ om 14.30 uur precies \\ door \\ Annemieke Mol Lous \\ geboren op 23 december 1958 \\ te Delft
}




\section{Promotor:}

Prof. dr. J.M.A. Riksen-Walraven

\section{Copromotor:}

Dr. W.J. Burk

Manuscriptcommissie:

Prof. dr. R.H.J. Scholte (voorzitter)

Prof. dr. M.A.G. van Aken (UU)

Prof. dr. H.J.A. van Bakel (UvT) 
To Jeroen and all those children who have to give up their childhood too early. 



\section{Table of Contents}

$\begin{array}{ll}\text { Preface and acknowledgements } & 9\end{array}$

1. General Introduction 11

2. Depression and Play in Early Childhood 29

3. Depression Markers in Young Children's Play $\quad 5^{1}$

4. Teacher Ratings of Depression Markers in Young Children's Play 73

5. Summary, Conclusions, and General Discussion 91

$\begin{array}{ll}\text { Samenvatting en conclusies } & 101\end{array}$

$\begin{array}{ll}\text { Curriculum vitae } & 107\end{array}$ 



\section{Preface and acknowledgements}

During the past two decennia, this dissertation has influenced my life in different respects but with a huge impact. It was great to read, to research, to observe, to analyze, to discuss. Playing with thoughts, findings and numbers to gather more and new insights into the fascinating relationship between play and depression in young children. Also facing periods during which this creative process was blocked, doubting about everything and feeling insecure. A process that many of the readers will recognize. Doctoral theses or not, the art of living is the art of being able to play and to overcome periods in life that sometimes feel too hard to live....

I am very grateful for the support of all the people that have contributed to accomplish this dissertation. I will not mention everyone, just a selection of all those people that made it possible to reach this point in my life.

First, I would like to thank all the children, parents, clinicians, teachers and students who participated in these studies. Having a depressed child is one of the most challenging situations for parents. Thank you for your trust and for sharing your concerns and thoughts, providing us the opportunity to observe the play of your children.

There is one name that you will find throughout the whole dissertation, Marianne Riksen- Walraven. She bravely supported me throughout the whole period of working on this research. She encouraged me and took the challenge to help me finish this work. Even after a long period and quite some barriers. Without her unconditional trust, patience, critical feedback, encouragement and expertise this thesis would probably not have been finished. I also express my gratitude to Bill Burk for supporting me with all the methodological and statistical issues during the last part of my research.

Although I was not working in Nijmegen during the latest years, I acknowledge the colleagues from Nijmegen and beyond who have been supporting me especially during the first years of the research. I would like to express some special words of gratefulness to Eric De Bruyn and Henk Rost for their input and support, Marcel van Aken, Gerbert Haselager, Jessica van Mulligen and Ilse de Koeyer-Laros for sharing ideas and doubts and encouraging the intellectual challenge and the academic work. A special place in this thesis is reserved for Cees de Wit, who has always been involved in research and 
clinical work on depressed children and adolescents. Our endless talks and walks, wondering how emotion and cognition are influencing each other and how these processes may underlie depression; always insisting on taking these young depressed children seriously.

I thank Marjan Freriks from the Amsterdam University of Applied Sciences, Robert Viëtor, Paul van Maanen and Agnita Mur from the Leiden University of Applied Sciences and Dorothee van Kammen from the Thomas More University of Applied Sciences Rotterdam, giving me the opportunity to finish my dissertation and the trust that was needed to take up the challenge. You missed me a lot the last years, but I am back! My research team from Leiden and Rotterdam and my dear colleagues, Dieuwke Hovinga and Aziza Mayo, thank you for standing by me during the last period of the work. And of course Ingrid Walters, whose professional support in preparing the final texts, including all the tables and numbers, the art of APA etc. has been invaluable.

This kind of work does not end when you leave the office. Dear friends and family, thank you for your patience and words of trust (although sometimes you probably did not really think it was ever going to happen).

Hans, Niek, Tim and Louise:You are my life! Now, that this dissertation has been finished, a lot more of unconditional time has become available to spend together, to enjoy and to play around. 


\section{General Introduction}

\subsection{Depression in Early Childhood}

Of all mental disorders, depression in early childhood is an underestimated mental health problem (Berkhout, 2012; Beyer \& Furniss, 2007; Luby, 2010; Van Bakel, 2012). Despite the low prevalence of depression at early ages, depression in preschoolers is causing serious impairment in the child's functioning, is known for its endurance if manifested early in development, and is easy to miss for parents and caregivers (Ialongo, Edelsohn, \& Kelam, 2001; Luby, et al. 2002). Depression in preschoolers has been found to be related to increased occurrence of depression in later years (Luby, Si, Belden, Tandon, \& Spitznagel, 2009), low academic performance (Ialongo et al. 2001), and changes in neurobiological systems in children who have gone through an episode of Major Depressive Disorder (MDD) as a preschooler, indicating disruptions in emotion-related neural circuitry (Pagliaccio et al., 2013).

Early detection is needed in order to identify depression in young children as soon as possible. However, although the existence of preschool depression is generally acknowledged nowadays, discussions as how this disorder should be assessed at this age is still going on. Play assessment is a commonly used method to identify problem behavior in preschoolers and might also be useful for the early detection of depressive symptoms. This is especially because play inhibition (decreased quality and quantity of play) is regarded as one of the key markers of preschool depression (Kashani, \& Carlson, 1987; Kovacs, 1977; Nissen 1971; Ushakov \& Girich, 1972). The assumed relationship between depression and play in young children, however, has been hardly studied and questions remain about mechanisms that explain why depression is reflected in play behavior.

The present thesis concerns research about the relation between depression and play behavior in 3- to 7-year-old preschoolers and the possibility to use play observation for early detection and identification of depression in preschoolers. The main aim of this research is to detect differences in play behavior between depressed and non-depressed young children in order to get a clearer picture of how depression manifests itself in play.

In this introductory chapter the theoretical framework and perspectives underlying the research on the relation between play and depression will be elucidated. First, the definition and prevalence of depression will be addressed as well as the importance of early detection of depression in preschoolers. After that, we will discuss the assessment of preschool 
depression and especially the use of play observation for assessment. Next, findings of earlier research on depression and play in young children are summarized, followed by a discussion of how depression may theoretically manifest itself in play behavior. The introduction ends with an outline of the rest of the thesis.

\subsection{Depression: Definition and Prevalence in Adults and Children}

In the Diagnostic and Statistical Manual of Mental Disorders IV (4 ${ }^{\text {th }}$ ed., DSM-IV, American Psychiatric Association, 1994) depression is defined as a serious mood disorder causing serious impairment in cognitive, emotional, and social functioning. Depressed mood (or irritated mood in children) and/ or loss of interest or pleasure in activities (anhedonia) are core symptoms of Major Depressive Disorder (MDD). In addition, at least three of the following symptoms should be identified: 1) fatigue or loss of energy, 2) worthlessness or excessive or inappropriate guilt, 3) recurrent thoughts of death or suicidal thoughts or attempts, 4) diminished ability to think or concentrate, 5) indecisiveness, 6) psycho motoric agitation or retardation, 7) insomnia or hypersomnia, and 8) significant appetite loss and/or weight loss (DSM-IV; American Psychiatric Association, 1994).

According to the World Health Organization (WHO, 2012) depression is the fourth leading cause of disability and disease worldwide. Prevalence of depression in adults is around $6.7 \%$, with women having 1.7 times more chance to become depressed than men (Kessler, Berglund, Demler, Jin, \& Walters, 2005). In adolescence, about $8-11.2 \%$ is found to pass through a major depressive episode or dysthymia, and 3.3\% of adolescents suffer from a severe depressive disorder (Merikangas et al., 2010). In school-aged children (6 years and older), prevalence of depressive disorders is estimated about $2 \%$. Serious depression in children younger than 6 years old is estimated to appear in $0.5-2.1 \%$ of the population (Lavigne, LeBailly, Hopkins, Gouze, \& Binns, 2009; Trimbos Instituut, 2009; Egger \& Angold, 2006).

Empirical evidence for childhood depression as a clinically significant syndrome is relatively new. Since the mid-1980's a growing number of studies have become available showing that older children (6 years and older) not only demonstrate depressive symptoms but also could manifest MDD (Carlson \& Cantwell, 1980). In contrast to the earlier assumption that school-aged children would not show typical symptoms of depression but were more likely to instead manifest "masked" symptoms such as somatic 
complaints (e.g. head- and stomach aches) or disruptive behavior, several studies showed that children more frequently display typical symptoms of depression such as sadness, anhedonia, and excessive guilt. These symptoms are similar to those in the adult disorder as described in the DSM-IV (Egger \& Angold, 2006, Kovacs, Feinberg, Crouse-Novak, Palauskas, Pollock, \& Finkelstein, 1984; Stalets \& Luby, 2006).

Also for younger children empirical evidence for a clinical significant MDD has been found, demonstrating that children from age 3 onwards can manifest a valid and clinically significant depressive syndrome (Luby, Heffelfinger, Mrakotsky, Brown, Hessler, Wallis, et al., 2003; Luby, 2010). Typical $D S M-I V$ symptoms of MDD like sadness and/or irritability, associated with neurovegetative signs (elevated levels of stress) have been found to differentiate depressed preschoolers from non-depressed controls (Luby et al., 2002).

Thanks to the extensive research on early childhood depression conducted by Joan Luby and colleagues from the Department of Psychiatry, Washington University, St. Louis, data have become available from several independent study samples validating preschool depression (Luby, Si, et al. 2009), showing that MDD can be identified in preschool children when the diagnostic assessment is modified to account for age-adjusted symptom manifestations. The validity of this clinically significant preschool depressive syndrome has further been supported by empirical research that associated the syndrome with a unique symptom constellation, a family history of related disorders, social impairment, and severity and stability of depressive symptoms (Kovacs, 1996; Luby, Belden, et al., 2009; Stalets \& Luby, 2006). Preschool depression has even shown to display homotypic continuity with later childhood depression (Luby, Si, et al., 2009). That is, depressed preschoolers are much more likely to have depression at school age than preschoolers with other disorders and those who are healthy. Preschool depression is not a transient and clinically insignificant or nonspecific developmental phenomenon but an early manifestation of the same chronic and relapsing disorder known to occur in later childhood and adolescence (Luby, 2010). This underlines the importance of the earliest possible identification of MDD.

\subsection{The Importance of Early Identification of Preschool Depression}

Early identification of depressive disorders has been emphasized as a high public health priority (Costello et al., 2002; Luby 2010), given the known 
chronic and relapsing course of childhood mood disorders when identified after age 6 (Birmaher, Ryan, Williamson, Brent,\& Kaufman, 1996; Kovacs, 1996; McCauley et al., 1993, Harrington, Fudge, Rutter, Pickles, \& Hill, 199o). Early detection and early intervention may be helpful in order to prevent the development of a more serious and persisting later depression. Additionally, intervention may be more successful at early developmental stages, when neuroplasticity of the brain makes the young children more sensitive to psychosocial or psychotherapeutic interventions (Luby, 2010; Nelson, 2000; Schore, 2005).

Researchers and clinicians also point out the need for more research and empirical evidence regarding depressive symptoms in infants and children younger than three years old (Van Bakel, 2013; Luby, 2010). One of the reasons is the alarming increase in the off-label prescription of antidepressant medications to preschoolers for a variety of nonspecific conditions in the United States where in 1994 alone, 3,00o prescriptions for fluoxetine were written for infants under 12 months of age (Zito et al., 200o), while agespecific criteria and indications to guide the accurate identification and pharmacological treatment of depression in preschoolers are missing (Luby, Mrakotskty, et al., 2003).

\subsection{Assessment of Depression in Preschoolers}

Traditionally, the assessment of psychopathology in preschool-age children has relied mainly on adult informants as children have been widely regarded as developmentally unable to serve as valid reporters of their own mental state, due to their limited capacity to reflect and communicate about persistent depressive cognitions and feelings. Young children have trouble reporting time related events (like "how did you feel the last two weeks?") and show a tendency to underreport problems (Harter \& Pike, 1984; Maeselle, Ablow, John, Cowan, \& Cowan, 2005; Schwab-Stone, Failon, Briggs, \& Crowther, 1994).

Application of parent and teacher questionnaires for the assessment of internalizing problems in young children also has disadvantages. Parents and teachers are often not sufficiently aware of a child's depressive cognitions and feelings and may fail to recognize the symptoms of depression in young children (Briggs-Gowan, Horrowitz, Schwab-Stone, Leventhal, \& Leaf, 2000; Costello et al. 2002; Edelbrock, Costello, Dulcan, Conover \& Kalas, 1986; Harrington, 1993; Hinshaw, Han, Erhardt, \& Huber, 1992; Klein, 1991; Luby et al. 2006; Kolko \& Kazdin, 1993; Stevenson- Hinde \& Shouldice, 
1995; Wu et al. 1999). Furthermore, parents and teachers tend to focus on different aspects of behavior of the children according to their different roles and environments (Jensen, et al. 1999). Therefore it is not surprising that observations and reports from teachers and parents about problem behavior in children are not highly correlated (Achenbach, McConaughy \& Howell, 1987; Glover Gagnon \& Nagle, 2004; Hinshaw, Han, Erhardt, \& Huber, 1992; Maeselle, Ablow, John, Cowan, \& Cowan, 2005; Milfort \& Greenfield, 2002). This is not only a disadvantage, because the use of different informants from different contexts can supply additional information about the child. However, direct observation of children is still necessary to get a clear and more complete picture of the age-specific manifestation of preschool depression.

Age appropriate assessment is needed because unlike depressed adults, depressed preschoolers may not appear morbidly sad or withdrawn, and may have periods of apparently normal functioning during the day (Luby, 2010). Depressive symptomatology in preschoolers can therefore easily be missed. In the past, when investigators looked for depression in preschool children, they found many preschoolers with concerning symptoms but few who met full criteria for the disorder (Kashani, Holcomb, \& Orvaschel, 1986). More recently Luby, Heffelfinger, et al. (2003) found that standard criteria for $D S M$-IV only capture the most severely depressed preschoolers and miss a larger group ( $75 \%$ ) of less severely (but potentially clinically) depressed children. Luby, Mrakotsky, et al. (2003) therefore propose the use of developmental translations of specific symptoms of MDD, like focusing on behavioral changes in "activities and play" rather than in "work or school" for the assessment of preschool depression. Observation of play behavior offers the opportunity to observe quantity and quality of play as well as the specific manifestation of problem behavior during play.

\subsection{Play Observation as an Assessment Method for Preschoolers}

Play observation is considered to be an age appropriate assessment tool for preschoolers in general. Play, especially symbolic play (Piaget, 1951), also referred to as "fantasy play', "make-believe", or "pretend play", is a natural and developmentally important activity of preschoolers. Play observation is often used in assessment procedures in clinical settings for young children. That is not only because play, especially symbolic play, "represents a window to the child's mind" (Rubin, Fein, \& Vandenberg, 1983, p 756), 
but also because evaluations of children's play can provide indications of maturation, social, and cognitive development as play proceeds through a regular developmental sequence during childhood (Piaget, 1951; Fewell \& Rich, 1987; Van der Pol, 2005).

Although the importance of play observation has been emphasized by many researchers and clinicians, play observation procedures have been hardly standardized, which makes it difficult to compare studies. This might be due to the fact that few psychometrically sound and meaningful play behavior rating scales have been available for preschool children (Fantuzzo, Sutton-Smith, Coolahan, Manz, Canning, \& Debnam, 1995; Glover Gagnon, \& Nagle, 2004). Research on psychometric properties of play assessment measures is sparse and measures of play are hardly incorporated in standardized assessment batteries. Across the studies of play, minimal documentation and validity data are reported for the play measures used. Measures are often not described in detail, making replications quite difficult (Fisher, 1992; Van der Pol, 2005). One of the reasons might be that play-assessments are based on different theories about play.

For a considerable time, play research has been focusing on observation and interpretation of (symbolic) play contents (i.e. the themes that are expressed in children's play) with the play content and play behavior being interpreted in terms of specific theories like the psychoanalytic perspective. Empirical evidence about the assumed relation between play content and problem behavior is scarce, however. Other play procedures focus on observation of various types of play (e.g. manipulative play, constructive play, and symbolic play; Enslein \& Fein, 1981; Warren, Oppenheim, \& Emde, 1996). These play types are based on a categorization of play originally described by Piaget (1951). Differences in the occurrence, coherence, or sequencing of these types of play can be used to identify children with emotional and behavioral problems and disorders (Hartup, 1976; Hetherington, Cox, \& Cox, 1979; Singer, \& Singer, 1976; Sutton-Smith, 1980; Wainwright, \& Fein, 1996) and have been found associated with various forms of psychopathology in young children (McDonough, Stahmer, Schreibman, \& Thompson, 1997; Oppenheim, Nir, Warren, \& Emde, 1997; Van der Pol, 2005).

Promising results have been obtained in combining observation of play contents with observational categories of play behavior, following a standardized play procedure. One such procedure is the use of play narratives or story stems, such as the MacArthur Story Stem Battery (MSSB; Bretherton, Oppenheim, Emde, \& the MacArthur Narrative Working Group, 2003). This play-narrative approach presents standardized themes (story-stems) to the children and invites hem to complete the stories by 
playing with a combination of family dolls, including a mother, father and two same-sex children of different ages. Race and gender of the dolls are matched to that of the child. After presenting the stem for each story, the examiner prompts the child to "Show and tell me what happens now". Both quality of play and content and coherence of behavior are observed and coded in a standardized way (Toth, Cicchetti, McFie, Maughan, \& Van Meenen, 2000). Although the MSSB was originally designed to measure attachment security in young children (Bretherton, Ridgeway, \& Cassidy, 1990), several studies have documented links between a lower coherence of children's play behavior when completing the stories and more emotional/ behavioral problems (e.g. Oppenheim et al., 1997; Oppenheim, 2006; Von Klitzing, Kelsay, Emde, Robinson, \& Schmitz, 20oo; Warren, Emde, \& Sroufe, 200o). Substantial literature has emerged suggesting that MSSB is able to elicit information from the child that is related to both parent and teacher symptom reports (Beresford, Robinson, Holmberg, \& Ross, 2007; Macfie, Cicchetti, \& Toth, 2001).

In sum, there is evidence that play behavior (e.g. quality and quantity of symbolic play and coherence of play during play narratives) may reflect emotional and behavioral problems in young children. Whether this also holds for depression is addressed in the following section.

\subsection{Depression and Play: Earlier Research Findings}

Early publications on childhood depression already referred to play inhibition in depressed preschoolers and assumed that it was mainly the lack of motivation and loss of interest in general that was reflected in their play behavior (Nissen, 1971; Ushakov\& Girich, 1972). However, contrary to Nissen (1971). Kashani, Allan, Beck, Bledsloe, \& Reid (1997), however, did not find loss of interest and pleasure in a generalized way among depressed preschoolers. In another study, "changes in the quality and quantity of play activity" of depressed children (Kovacs, 1977, p. 157) are reported, but not clearly described. Overt behavioral symptoms over depression, such as psychomotor agitation and retardation, have been systematically observed in depressed preschoolers during standardized play procedures (Altmann \& Gottlib, 1988; Field et al. 1987; Kashani et al., 1997; Kazdin, 1990). More recently, Luby and colleagues observed depressed preschoolers to show more negative and less positive behaviors than their nondepressed peers, as well as lower levels of observed enthusiasm when interacting with caregivers in "playful" situations (Belden \& Luby, 2006; Luby et al., 2006). Research based 
on play narratives found that mood disordered children show less coherent play behavior during play narratives (Beresford et al., 2007), whereas manicdepressed children show substantially greater distress and disorganization during highly challenging play narratives (Miljikovitch, Pierrehumbert, \& Halfon, 2007).

As far as we know, there is only one earlier observational study that systematically compared play behavior of depressed children with play behavior of children with another disorder or children without a disorder in different play situations. In this study, Field et al. (1987) used a standardized play procedure and coded the videotaped play sessions using a standardized observation procedure with clearly defined play categories and trained observers. The children's play was observed in four situations, namely during 1) child-mother free play interaction, 2) a child-caregiver teaching task, 3) solitary free play, and 4) solitary puzzle completion. This study was the first to reveal less symbolic play in depressed children as compared to both conduct disordered and non-depressed children. The differences in symbolic play were most visible during the free interactive play conditions, but not in the solitary conditions. This study, however, also showed that behaviors and interactions of depressed and conduct-disordered children during the laboratory play sessions were "surprisingly 'normal' given their respectively high depression and behavior problem scores" (Field et al. 1987 , p 231). Based on the coders' ratings of videotaped play sessions, $50 \%$ of the depressed children and $62 \%$ of the conduct-disordered children were judged to be normal. Relatively little behavioral data reflected the depressed child's feelings of depression and low self-esteem. The affect and activity levels of depressed children did not differ from those of normal children. The authors recommend the use of more detailed and sensitive observation measures, as their behavioral measures may have been too "gross". They also recommend to include more challenging (stressful) play situations in order to provoke more problem behavior and thus to find more differentiating (play) behavior.

In sum, few clear data have yet become available about the exact manifestation of depression in preschoolers' play behavior. The number of studies is very limited and they are difficult to compare because they use a variety of theories and observation systems. The study of Field et al. (1987) as well as the later studies with play-narratives (Luby et al. 2006; Miljikovitch et al., 2007) underline the need for a clear theoretical framework and a standardized play observation system to examine the impact of preschool depression on symbolic play and the coherence of play narratives. 


\subsection{How Can Depression Affect Preschoolers' Play Behavior?}

This section summarizes how depression in preschoolers might theoretically affect different aspects of their play behavior. First we present the definition of play behavior that we used as a starting point of the studies in the present thesis. Next, we briefly outline the development of play and types of play as described by Piaget (1951), which underlies the play observation system used in the thesis. And finally, we summarize how depressive symptoms of MDD as described in DSM-IV might affect the play behavior of preschoolers -resulting in hypotheses to be tested in the observational studies in this thesis.

\subsubsection{Definition and characteristics of play}

Our definition of play departs from the assumption of play as a behavioral disposition, i.e., the motives and intentions behind the behavior that distinguish it from other behavior (Rubin et al., 1983). Based on a review of earlier studies and literature, Rubin et al. (1983) made a summary of six features that distinguish play from non-play behavior. These six features were summarized by Van der Poel (1994) into a set of three characteristic features of play. For the present thesis we adopted this definition by Van der Poel, implying that play is 1) autotelic by nature, 2) takes place within a frame of strictly binding but voluntarily accepted rules and meanings, and 3) implies active engagement, i.e., the player is actively involved in the activity. These features are assumed to distinguish play from non-play behaviors such as exploration, merely looking at an object, or unfocused and uninterested handling of play materials.

\subsubsection{Development and Types of Play}

The above definition applies to play behavior in general. In distinguishing different types of play we also followed Van der Poel (1994), by taking Piaget's (1951) categorization of play behavior as a starting point. The three reasons for this choice are the following:

First, Piaget's categorization has an extensive theoretical basis. Piaget categorized different types of play according to their order of emergence during ontogenetic development, paralleling stages of cognitive development. The types of play are described at the end of this section.

The second reason for choosing Piaget's categorization is that empirical evidence has been found for the developmental stages. Studies of the 
development of pretense or symbolic play tend to support the development sequence identified by Piaget (Belsky \& Most, 1981; Gown, Goldman, Johnson-Martin, \& Hussey, 1989).

The third reason for choosing this categorization system is that many later categorizations of play are at least partly deduced from this categorization (Belsky \& Most, 1981; Fein, 1981; Hellendoorn \& Van Berckelaer-Onnes, 1991; Hutt, 1979; McCune-Nicolich, 1980; Pellegrini, 1984; Rost, 1986; Rubin et al., 1983; Van der Poel, 1994; Van der Pol, 2005; Westby, 1991). However, sometimes the categorization was restricted to symbolic play only (Fein, 1975), or a strict distinction was not made between play and non-play behaviors such as exploration (Belsky \& Most, 1981).

As noticed above, Piaget described three types of play that arise during subsequent developmental stages, reflecting different cognitive structures:

1) Manipulative play (or "practice play" in Piagetian terms) refers to repeating actions for the sake of pleasure like repeatedly lifting up an arm of a doll without a specific meaning and will arise during the sensory-motor stage of cognitive development.

2) Symbolic play (also referred to as "pretend play", "fantasy play" or "makebelieve play") is the highest category of play in children aged 3-6 years. In this type of play children make use of symbolic representations, meaning that they actively verbalize and manipulate objects to make up a story. In symbolic play, children feel free and are intrinsically motivated to play about themes that are important to them. Symbolic play is also assumed to help children to express their worries and to find solutions for their worries in a playful way. Symbolic play is most often played in 3- to 6-year old children and more or less parallels the preoperational stage, during which a child is able to use symbolic schemes. However, the onset of the use of symbolic schemes starts before the onset of the pre-operational stage; in fact it reveals the transition from the sensory-motor to the pre-operational stage. Healthy preschoolers' play will dominantly consist of symbolic play, with some manipulative play.

3) Games with rules refer to creation of play frames where acting has to take place within strict rules that are accepted and agreed upon. Accepting the rules and trying to attain a certain goal (like winning a game) asks for more complicated cognitive and social capacities and will not take place before the concrete operational stage has been reached.

As symbolic play is supposed to be the dominant play category in preschoolers, we mainly focused on symbolic play and manipulative play. 


\subsubsection{Possible Effects of Depression on Preschoolers' Play}

How might various aspects of depression affect preschoolers' play? Based on the official symptoms of depression as recorded in DSM-IV, we will first list the possible effects of the depression symptoms that can influence quality and quantity of young children's play, like a general loss of interest and or pleasure, fatigue and/or loss of energy, loss of concentration, and psychomotor retardation or agitation. Next, the possible effects of more general features of depression, like developmental delays and affect regulation problems on play will be discussed.

Depressed children might lack the intrinsic motivation to engage in play as they are experiencing a general loss of interest and pleasure in activities, one of the core symptoms of MDD. Depressed children may play less or not at all because they do not experience pleasant feelings that normally arise from the experience of playing. Although Kashani and colleagues (1997) did not find loss of interest and pleasure in a generalized way among depressed preschoolers, such a loss may be reflected in deficits in certain types of play behavior. Depressed children might, for example, lack energy and/or concentration to actively engage in the more demanding categories of play, like symbolic play.

Depressive hypoactivity and psychomotor retardation may cause children to show little or no play behavior or to persevere with certain types of play while it may be more appropriate to move on to other types. Symptoms of psychomotor agitation and loss of concentration might also negatively affect the ability of depressed children to engage actively in play, especially in the more demanding, "higher" categories of play behavior. When children are easily distracted they might be unable to persist in the higher demanding category of symbolic play where roles and stories within the play demand active involvement of the child and a certain persistence to "finish' stories or solve problems. Psychomotor agitation might cause disruptions in the child's play and thus negatively influence its coherence.

It is also possible that depressed children show less symbolic play and more manipulative play because of a general developmental delay due to their disorder. Symbolic play requires a higher level of cognitive functioning which might not yet been reached by depressed children because of this delay (cf. Kovacs, 1996; Motti, Cicchietti, \& Sroufe, 1983; Nicolich, 1977; Piaget, 1951; Vandenberg, 1980; Westby, 1991).

Last but not least, the affect regulation problems of depressed children might impair the quality of their play behavior. It is possible that they engage less in symbolic play because they are not experiencing the expected 
amelioration of emotional discord in symbolic play. Symbolic play is assumed to help children to express their worries and to find solutions for their worries in a playful way. Since in play every thing can happen according to the player's wishes, the player will be able to master conflicts or fulfill wishes that (s)he may not be able to manage outside the play frame and in this way ameliorate emotional discord. This affect regulation function is mainly proposed in the psycho-analytic theories but also by other theorists, for example, Huizinga (1951), Piaget (1951), Vygotsky (1966), Garvey (1977), and Landreth, Homeyer, \& Morrison (2006). Affect regulation problems can influence quality of play in general but might also become more apparent after mood induction in play. It is possible that children play less symbolic play after mood induction with a sad mood because they cannot find solutions for their emotional discord. Another possibility is that depressed children "get lost" in their play about sadness and play more, because of their inability to find solutions for dealing with a sad mood. It is also possible that depressed children are not willing or able to play about happy mood, because they do not experience this happy mood. Induction of positive and sad mood during play situations might influence the quality and quantity of depressed preschoolers play.

In sum, from a theoretical point of view we can expect that depression might negatively affect quality and quantity of play in children, especially as it holds for the "higher" category of symbolic play and the coherence of play narratives. Depressed preschoolers probably show less play, especially less symbolic play, and more non-play and "lower" categories of play behavior, like manipulative play. It can be expected that play of depressed children shows less coherence, as reflected in more behavioral changes from one category to another. Finally, the effect of mood induction on the quantity and quality of play might reflect the impact of failing affect regulation mechanisms on preschoolers' play. The present thesis aimed to test these hypotheses about the inhibiting effect of depression on preschoolers ' play.

\subsection{Outline of the Present Thesis}

The main aim of this thesis was to find empirical evidence for the assumed differences in play behavior between depressed and non-depressed preschoolers summarized at the end of the former section. The thesis includes three empirical studies, consecutively conducted on three independent samples of children.

In the first study (described in Chapter 2) we compared the play behavior of seven depressed and seven nondepressed preschoolers in three different 
play situations, i.e. solitary free play, interactive free play, and play narratives. The children's behavior was extensively observed by trained observers using a standardized observation procedure that was developed for this study. Based on the promising results of this study, a second study (reported in Chapter 3) was designed to replicate the first study, using the same play observation procedure with some methodological improvements and using a larger sample and an extra control group: 30 depressed preschoolers were compared to 30 nondepressed clinical and 30 nondepressed nonclinical peers. The third and final study, reported in Chapter 4, was based on the results of the former study but was more practically oriented. The aim of this third study was to investigate whether teachers in regular and special schools can observe differences in play behavior between preschoolers who are and those who are at not at risk for depression. To that end, the teachers rated the play behavior of 135 preschool-aged children, based on their everyday observations in their classrooms and using a play observation questionnaire based on the outcomes of the former study. Finally, Chapter 5 summarizes the results of the three studies and closes with discussing the results and implications for further research and practice.

\section{References}

Achenbach, T.M., McConaughy, S.H., \& Howell, C.T. (1987). Child/adolescent behavioral and emotional problems: Implications of cross-informant correlations for situational specificity. Psychological Bulletin, 101, 213-232.

Altmann, E., \& Gottlib, H. (1988). The social behaviour of depressed children: An observational study. Journal of Abnormal Psychology, 95, 223-227.

American Psychiatric Association (1994). Diagnostic and Statistical Manual of Mental Disorders $\left(4^{\text {th }}\right.$ ed.). Washington D.C.: Author.

Belden, A.C., \& Luby, J.L. (2006). Preschoolers' depression severity and behaviors during dyadic interactions: The mediating role of parental support. Journal of the American Academy of Child and Adolescent Psychiatry, 45, 213-222.

Belsky, J., \& Most, R.K. (1981). From exploration to play: A cross-sectional study of infant free play behavior. Developmental Psychology, 17, 630-639.

Beresford, C., Robinson J.L., Holmberg J., Ross R.G. (2007). Story stem responses of preschoolers with mood disturbances. Attachment \& Human Development, 9, 255-270.

Berkhout, L. (2012). Play and Psycho-social health of boys and girls aged four to six (Doctoral Dissertation). Groningen: University of Groningen.

Beyer, T., \& Furniss, T. (2007). Child psychiatric symptoms in primary school. The second wave 4 years after preschool assessment. Social Psychiatry and Psychiatric Epidemiology, 42, 753-758.

Birmaher, B., Ryan, N.D., Williamson, D.E., Brent, D.A., \& Kaufman, J. (1996). Childhood and adolescent depression: A review of the past 10 years. Part II.Journal of the American Academy of Child and Adolescent Psychiatry, 35, 1575-1583. 
Bretherton, I., Ridgeway D., \& Cassidy, J. (1990). Assessing internal working models of the attachment relationship: An attachment story completion task for 3-year-olds. In M.T. Greenberg, D. Cicchetti, \& E.M. Cummings (Eds.), Attachment in the preschoolyears (pp. 273-310). Chicago: University of Chicago Press.

Bretherton, I., Oppenheim, D., Emde, R.N., \& the MacArthur Narrative Working Group (2003). The MacArthur Story Stem Battery. In R.N. Emde, D.P. Wolf \& D. Oppenheim (Eds.), Revealing the inner worlds ofyoung children: The MacArthur Story Stem Battery and parent-child narratives (pp. 381-396). New York: Oxford University Press.

Briggs-Gowan, M.J., Horrowitz, S.M., Schwab-Stone, M.E., Leventhal, J.M., \& Leaf, P.J. (20oo). Mental health in pediatric settings: distribution of disorders and factors related to service use. Journal of the American Academy of Child and Adolescent Psychiatry 39, 841-849.

Carlson, G.A., \& Cantwell, D.P. (1980). Unmasking masked depression from childhood through adulthood: Analysis of three studies. The American Journal of Psychiatry, 145, 1222-1225.

Costello, E.J., Pine, D.S., Hammen, C., March, J.S., Plotsky, P.M., Weissman, M.M., Biederman, J., Goldsmith, H.H., Kaufman, J., Lewinsohn, P.M., Hellander, M., Hoagwood, K., Koretz, D.S., Nelson, C.A., \& Leckman, J.F. (2002). Development and natural history of mood disorders. Biological Psychiatry 52: 529-542.

Edelbrock, C., Costello, A.J., Dulcan, M.K., Conover, N.C., \& Kalas, R. (1986). Parent-child agreement on child psychiatric symptoms via structured interview. Journal of Child Psychology and Psychiatry, 27, 181-190.

Egger, H.E., \& Angold, A. (2006). Common emotional and behavioral disorders in preschool children: Presentation, nosology, and epidemiology. Journal of Child Psychology and Psychiatry, 47, 313-337.

Enslein, J., \& Fein G.G. (1981). Temporal and cross-situational Stability of children's social and play behavior. Developmental Psychology, 17, 760-761.

Fantuzzo, J., Sutton-Smith, B., Coolahan, K.C., Manz, P.H., Canning, S., \& Debnam, D. (1995). Assessment of preschool play interaction behaviors in young low-income children: Penn Interactive Peer Play Scale. Early Childhood Quarterly, 10, 105-120.

Fein, G.G. (1975). A transformational analysis of pretending. Developmental Psychology, 11, 291-296.

Fein, G.G. (1981). Pretend play in childhood: an integrative review. Child Development, 52, $1095^{-1118 . ~}$

Fewell, R.R., \& Rich, J.S. (1987). Play assessment as a procedure for examining cognitive, communication, and social skills in multihandicapped children. Journal of Psychoeducational Assessment, 2, 107-118.

Field, T.M., Sandberg, D., Goldstein, S., Garcia, R., Vega-Lahr, N., Porter, K., \& Dowling, M. (1987). Play interactions and interviews of depressed and conduct disordered children and their mothers. Child Psychiatry and Human Development, 17, 213-231.

Fisher, E.P. (1992). The impact of play on development: A meta-analysis. Play and Culture, 5 , 159-181.

Garvey, C. (1977). Play. Glasgow: Fontana.

Glover Gagnon, S., Nagle, R.J. (2004). Relationships between peer interactive play and social competence in at-risk preschool children. Psychology in Schools, 41, 173-189.

Gowen, J.W., Goldman, B.D., Johnson-Martin, N., \& Hussey, B. (1989). Object play and exploration of handicapped and nonhandicapped infants. Journal of Applied Decelopmental Psychology, $10,53-72$.

Harrington, R. (1993). Depressive disorder in childhood and adolescence. Chichester: John Wiley and Sons. 
Harrington, R., Fudge, H., Rutter, M., Pickles, A., \& Hill, J. (1990). Adult outcome of childhood and adolescent depression I. Psychiatric status. Archives of General Psychiatry, 47, 465-473.

Harter, S., \& Pike, R. (1984). The pictorial scale of perceived competence and social acceptance for young children. Child Development, 55, 1969-1982.

Hartup, W.W. (1976). Peer interaction and the behavioral development of the individual child. In E. Schopler \& R.L. Reichler (Eds.), Psychopathology and child development (pp. 303-219). New York: Plenum Press.

Hellendoorn, J., \& Van Berckelaer-Onnes (Eds.) (1991). Speciaalspelvoor speciale kinderen [Special play for special children] (pp. 11-21). Groningen. Wolters-Noordhoff.

Hetherington, E.M., Cox, M., \& Cox, R. (1979). Play and social interaction in children following divorce. Journal of Social Issues, 35, 26-49.

Hinshaw, S.P., Han, S.S., Erhardt, D. \& Huber, A. (1992). Internalizing and Externalizing Behavior Problems in Preschool Children: Correspondence Among Parent ant Teacher Ratings and Behavior Observations. Journal of Clinical Child Psychology, 21, 143-150.

Hutt, C. (1979). Exploration and play. In B. Sutton-Smith (Ed.), Play and learning (pp. 175-194). New York: Academic Press.

Huizinga, J. (1951). Homo Ludens. Proeve eener bepaling van het spel-element der cultuur [A study of the play-element in culture] Haarlem: Tjeenk Willink.

Ialongo, N.S., Edelsohn, G., \& Kellam, S.G. (2001). A further look at the prognostic power of young children's reports of depressed mood and feelings. Child Development, 72, 736-747

Jensen, P.S., Rubio-Stipec, M., Canino, G., Bird, H.R., Dulcan, M.K., Schwab-Stone, M.E., \& Lahey, B.B. (1999). Parent and child contributions to diagnosis of mental disorders: are both informants always necessary? Journal of the American Academy ofChild and Adolescent Psychiatry, 38, 1569-1579.

Kashani, J.H., Allan, W.D., Beck, N.C., Bledsoe, Y., \& Reid, J.C. (1997). Dysthymic disorder in clinically referred preschool children. Journal of the American Academy of Child and Adolescent Psychiatry, 36, 1426-1433.

Kashani, J.H., \& Carlson, G.A. (1987). Seriously depressed preschoolers. American Journal of Psychiatry, 144: 348-350.

Kashani, J.H., Holcomb, W.R., \& Orvaschel (1986). Depression and depressive symptoms in preschool children from the general population. American Journal of Psychiatry, 143, 1138-1143.

Kazdin, A. (1990). Childhood depression. Journal of Child Psychology and Psychiatry, 31, 121-160.

Kessler, R.C., Berglund, P.A., Demler, O., Jin, R., \& Walters, E.E. (2005). Lifetime prevalence and age-of-onset distributions of DSM-IV disorders in the National Comorbidity Survey Replication (NCS-R). Archives of General Psychiatry,62, 593-602.

Klein, R. (1991). Parent-child agreement in clinical assessment of anxiety and other psychopathology: A review. Journal of Anxiety Disorders, 5, 187-198.

Kolko, D.J., \& Kazdin, A.E. (1993). Emotional/ behavioral problems in clinic and nonclinic children: correspondence among child, parent and teacher reports.Journal ofChild Psychology and Psychiatry, 34, 991-1006.

Kovacs, M. (1977). Conclusions and recommendations of the Subcommittee on Assessment. In J. Schulterbrandt \& A. Raskin (Eds.), Depression in childhood (pp. 155-162). New York: Raven Press.

Kovacs, M. (1996). Presentation and course of major depressive disorder during childhood and later years of the life span. Journal of the American Academy of Child and Adolescent Psychiatry, 35, 705-715. 
Kovacs, M., Feinberg, T.L., Crouse-Novak, M., Paulauskas, S.L., Pollock, M., \& Finkelstein, R. (1984). Depressive disorders in childhood. II. A longitudinal study of the risk for a subsequent major depression. Archives of General Psychiatry, 41, 643-649.

Landreth, G., Homeyer, L., \& Morrison, M. (2006). Play as the language of children's feelings. In D.P. Fromberg \& D. Bergen (Eds.), Play from Birth to Twelve. Contexts, Perspectives and Meanings (pp. 47-52). New York: Routledge.

Lavigne, J.V., LeBailly, S.A., Hopkins, J., Gouze, K.R., \& Binns, H.J. (2009). The prevalence of ADHD, ODD, depression, and anxiety in a community sample of 4-year-olds. Journal ofClinical Child \& Adolescent Psychology, 38, 315-328.

Luby, J.L. (2010). Preschool Depression: The importance of identification of depression early in development. Current Directions in Psychological Science, 19, 91-95.

Luby, J.L., Belden, A., Sullivan, J., Hayen, R., McCadney, A., \& Spitznagel, E. (2009). Shame and guilt in preschool depression: evidence for elevations in self-conscious emotions in depression as early as age 3. Journal of Child Psychology and Psychiatry, 50, 1156-1166.

Luby, J.L., Heffelfinger, A., Mrakotsky, C., Brown, K.M., Hessler, M.J., Wallis, J.M., \& Spitznagel, E.L. (2003). The Clinical Picture of Depression in Preschool Children.Journal of the American Academy of Child \& Adolescent Psychiatry, 42, 340-348.

Luby, J.L., Mrakotsky, C., Heffelfinger, A., Brown, K., Hessler, M., \& Hildebrand, T. (2002). Preschool major depressive disorder: Preliminary validation for developmentally modified DSM-IV criteria. Journal of the American Academy of Child and Adolescent Psychiatry, 41, 928-937.

Luby, J.L., Mrakotsky, C., Heffelfinger, A., Brown, K.M., Hessler, K., \& Spitznagel, E. (2003). Modification of DSM-IV criteria for depressed preschool children. American Journal of Psychiatry, 160, 1169-1172.

Luby, J.L., Si, X., Belden, A.C., Tandon, M., \& Spitznagel, E. (2009). Preschool Depression: Homotypic continuity

and course over 24 months. Archives of General Psychiatry, 66, 897-905.

Luby, J.L., Sullivan, J., Belden, A., Stalets, M., Blankenship, S., \& Spitznagel, E. (2006). An observational analysis of behavior in depressed preschoolers: Further validation of early-onset depression. Journal of the American Academy of Child \& Adolescent Psychiatry, 45, 203-212.

Macfie, J., Cicchetti, D., \& Toth, S. (2001). The development of dissociation in maltreated preschool-aged children. Development and Psychopathology, 13, 233-254.

Maeselle, J.R., Ablow, J.C., John, O.P., Cowan, P.A., \& Cowan, C.P. (2005). Can children provide coherent, stable and valid self-reports on the big five dimensions? A longitudinal study from ages 5 to 7. Journal of Personal Social Psychology, 89, 90-106.

McCauley, E., Myers, K., Mitchell, J., Calderon, R., Schloredt, K., Treder, R., (1993). Depression in young people: initial presentation and clinical course. Journal of the American Academy of Child \& Adolescent Psychiatry, 32, 714-722.

McCune-Nicolich, L. (1980). Manual for analyzing free play. New Brunswick NJ: Rutgers University.

McDonough, L., Stahmer, A., Schreibman, L., \& Thompson, S.J. (1997). Deficits, delays and distractions: an evaluation of symbolic play and memory in children with autism. Development and Psychopathology, 9, 17-44.

Merikangas, K.R., He, J., Burstein, M., Swanson, S.A., Avenevoli, S., Cui, L., Benjet, C., Georgiades, K., \& Swendsen, J. (2010). Lifetime prevalence of disorders in U.S. adolescents: Results from the National Comorbidity Study Adolescent Supplement (NCS-A). Journal of the American Academy of Child \& Adolescent Psychiatry, 49, 980-989.

Milfort, R., \& Greenfield, D.B. (2002). Teacher and observer ratings of head start children's social skills. Early Childhood Research Quarterly, 17, 581-595. 
Miljikovitch, R., Pierrehumbert, B., \& Halfon, O. (2007). Three-year-old's attachment play narratives and their associations with internalizing problems. Clinical Psychology and Psychotherapy, 14, 294-257.

Motti, F., Cicchetti, D., \& Sroufe, L.A. (1983). From infant affect expression to symbolic play: The coherence of development in Down syndrome children. Child Development, 54, 1168-1175.

Nelson, C.A. (2000). The neurobiological bases of early intervention. In J.P. Shonkoff and S.J. Meisels (Eds.), Handbook of early childhood intervention ( ${ }^{\text {nd }}$ ed., pp 204-227). Cambridge, MA: Cambridge University Press.

Nicolich, L. (1977). Beyond sensorimotor intelligence: assessment of symbolic maturity through analysis of pretend play. Merill-Palmer quarterly, 23, 89-99.

Nissen, G. (1972). Depressive Syndrome in Kindes- und Jugendalter. Berlin: Springer Verlag.

Oppenheim, D. (2006). Child, parent and parent-child emotion narratives: Implications for developmental psychology. Development and Psychopathology, 18, 771-79o.

Oppenheim, D., Nir, A., Warren, S.L., \& Emde R.N. (1997). Emotion regulation in mother-child co-construction: associations with children's narratives and adaptation. Developmental Psychology, 33, 284-294.

Pellegrini, A.D. (1984). The effects of exploration and play on young children's associative fluency: A review and extension of Training Studies. In Yawkey, T.D., \& Pellegrini, A.D. (Eds.), Child's Play: Developmental and Applied. (pp. 237-251). Lawrence Erlbaum Associates, Publishers, Hillsdale, New Yersey, London.

Piaget, J. (1951). Play, dreams and imitation in childhood. London: Routledge \& Kegan Paul.

Rost, H. (1986). Exploration and play: a micro-analysis. In R. van der Kooy \& J. Hellendoorn (Eds.), Play, play therapy and play research (pp. 233-245). Lisse: Swets \& Zeitlinger.

Rubin, K.H., Fein, G., \& Vandenberg, B. (1983). Play. In P.H. Mussen \& E.M. Hetherington (Eds.), Handbook of Child Psychology and Psychiatry, (vol. 4, pp. 693-774). New York: John Wiley and Sons.

Schore, A.N. (2005). Attachment, affect regulation and the developing right brain: linking developmental neuroscience to pediatrics. Pediatrics in Review, 10, 209-232.

Schwab-Stone, M., Failon, T., Briggs, M., \& Crowther, B., (1994). Reliability of diagnostic reporting for children aged 6-11 years: A test-retest study of the Diagnostic Interview Schedule for Children-Revised. American Journal of Psychiatry, 151, 1048-1054.

Singer, J.L., \& Singer, D.G. (1976). Imaginative play and pretending in early childhood: Some experimental approaches. In A. David (Ed.), Child personality and psychopathology: Current topics, Volume 3. New York: John Wiley and Sons.

Stalets, M.M., \& Luby, J.L. (2006). Preschool depression. Child and Adolescent Psychiatric Clinics of North America, 15, 899-917, viii-ix.

Stevenson-Hinde, J., \& Shouldice, A. (1995). 4,5 to 7 years: fearful behaviour, fears and worries. Journal of Child Psychology and Psychiatry, 36, 1027-1038.

Sutton-Smith, B. (1980). A syntax for play and games. In R. Herron \& B. Sutton-Smith (Eds.), Child's play, pp. 298-311. New York: John Wiley and Sons.

Toth, S.L., Cicchetti, D., McFie, J., Maughan, A., \& Van Meenen (2000). Narrative representations of caregivers and self in maltreated preschoolers. Attachment \& Human Development, 2, 271-305.

Trimbos Instituut (2009). Depressie bij jeugdigen (prevalentie).[Depression in young people] Retrieved from: http://www.ggzrichtlijnen.nl/index.php?pagina=/richtlijn/item/pagina. php\&id=1028\&richtlijn_id=85-ggz-richtlijnen-trimbos.

Ushakov, G.K., \& Girich, Y.P. (1972). Special features of psychogenic depression in children and adolescents. In A. Annell (Ed.) Depressive states in children and adolescents (pp. 510-516). Stockholm: Almqvist \& Wicksell. 
Van Bakel, H.J.A. (2012). Understanding infants: van schoot tot sofa. PrismaPrint, Tilburg University.

Vandenberg, B. (1980). Play, problem solving and creativity. In K.H. Rubin (Ed.), Children's Play. New directions for child development (pp. 49-68). San Fransisco: Jossey-Bass.

Van der Poel, P.A. (1994). Play. A study into the observation of play and the relationships between play, creativity, leisure and parental characteristics (Doctoral dissertation) Nijmegen: University of Nijmegen. Phaedon.

Van der Pol, P.J. (2005). Kracht en macht van spel en verbeelding [Force and power of play and imagination] (Doctoral dissertation). Leiden: University of Leiden. Optima.

Von Klitzing, K., Emde, R.N., Robinson, J., \& Schmitz, S. (2000). Gender-specific characteristics of 5-year-olds' playnarratives and associations with behavior ratings. Journal of the American Academy of Child and Adolescent Psychiatry, 39, 1017-1023.

Vygotsky, L. (1966). Play and its role in the mental development of the child. Soviet Psychology, $12,62-76$.

Wainwright, L. \& Fein, D. (1996). Play. In I. Rapin (Ed.). Preschool children with inadequate communication (pp. 173-19o). London: Mac Keith Press.

Warren, S.L., Emde, R.N., \& Sroufe, L.A. (2000). Internal; representations: predicting anxiety from children's play narratives. Journal of the American Academy of Child \& Adolescent Psychiatry, 39, 100-107.

Warren, S.L., Oppenheim, D., \& Emde, R.N. (1996). Can emotions and themes in children's play predict behaviour problems? Journal of the American Academy of Child and Adolescent Psychiatry, 35, 1331-1337.

Westby, C.E. (1991). A Scale for assessing children's pretend play. In C.E. Schaefer, K. Gitlin \& A. Sandgrund (Eds.), Play diagnosis and assessment (pp. 131-161). New York: Wiley.

World Health Organization (2012). Depression (Fact sheet no.369). Retrieved from: http://www. who.int/mediacentre/factsheets/fs369/en/index.html

Wu, P., Hoven, C.W., Bird, H.R., Moore, R.E., Cohen, P., Alegria, M., Dulcan, M.R., Goodman, S.H., Horwitz, S.M., Lichtman, J.H., Narrow, W.E., Roe, D.S., Regier, D.A., \& Roper, M.T. (1999). Depressive and disruptive disorders and mental health service utilization in children and adolescents. Journal of the American Academy of Child \& Adolescent Psychiatry, 38, 1081-1090.

Zito, J.M., Safer, D.J., DosReis, S., Gardner, J.F., Boles, M., \& Lynch, F. (200o). Trends in the prescribing of psychotropic medications to preschoolers. The Journal of the American Medical Association, 283, 1025-1030. 


\title{
2. Depression and Play in Early Childhood
}

\author{
Play Behavior of Depressed and Nondepressed 3- to 6-Year- \\ Olds in Various Play Situations ${ }^{1}$
}

\author{
Annemieke Mol Lous, Cees A. M. de Wit, Eric E. J. de Bruyn, \\ J. Marianne Riksen-Walraven, and Henk Rost
}

Summary The behavior of seven depressed and seven nondepressed 3 - to 6-year-olds was compared in three play situations: solitary free play, interactive free play, and play narratives. Depressed children played significantly less than their nondepressed controls. This was mainly due to differences in symbolic play. The groups did not differ with regard to manipulative play. The differences between depressed and nondepressed children varied across play situations. Depressed children showed significantly more nonplay behavior than their nondepressed counterparts. In addition, the behavior of depressed children showed less coherence than the behavior of the nondepressed children. Finally, mood induction proved to have no differential effect on the play behavior of depressed and nondepressed children.

\subsection{Introduction}

Although it is now generally recognized that children may become depressed at very early ages (e.g., Kashani, Allan, Beck, Bledsoe, \& Reid, 1997; Poznanski \& Mokros, 1994), adequate methods for diagnosing depression in preschoolers are lacking. Where self-report questionnaires and clinical child interviews have been found to play an important role in the assessment of depression in older children (Herjanic \& Reich, 1982; Ialongo, Edelsohn, WerthamerLarsson, Crocket, \& Kellam, 1995; Kashani, Orvaschel, Burk, \& Reid, 1985; Kovacs, 1986; Renouf \& Kovacs, 1994; Reynolds, 1994), these methods are not appropriate for children under 6 years of age. Young children have trouble reporting time-related events and show a tendency to underreport problems (Harter \& Pike, 1984; Schwab-Stone, Failon, Briggs, \& Crowther, 1994). Besides, children younger than 6 years usually are not able to read questionnaires.

1 Mol Lous, A., de Wit, C.A.M., de Bruyn, E.E.J., Riksen-Walraven, J.M., Rost, H. (200o). Depression and play in early childhood: play behavior of depressed and nondepressed 3- to 6-year-olds in various play situations. Journal of Emotional and Behavioral Disorders, 200o, 8, 249-26o. 
An alternative method might be to obtain information from parents by means of clinical interviews or questionnaires, but this procedure has disadvantages. Parents can report overt symptoms but are often not sufficiently aware of their child's depressive cognitions and feelings (Edelbrock, Costello, Dulcan, Conover, \& Kalas, 1986; Harrington, 1993; Klein, 1991; Stevenson-Hinde \& Shouldice, 1995). Therefore, other procedures are needed to assess depression in young children.

Outside the domain of childhood depression, several studies have used play behavior observation to assess emotional and behavioral problems in young children (Kashani \& Carlson, 1987; Oppenheim, Nir, Warren, \& Emde, 1997; Wainwright \& Fein, 1996; Warren, Oppenheim, \& Emde, 1996). Play behavior observation can focus on the play contents or on the types of play the child is showing (Rubin, Fein, \& Vandenberg, 1983; Slade, 1994). For a considerable time, observation and interpretation of play contents (i.e., the themes that are expressed in children's play) have been predominant in play assessment procedures. Empirical evidence in support of the assumed relation between play contents and problem behavior is scarce, however. Other procedures focus on the observation of various types of play (e.g., manipulative play; constructive play; and symbolic play, also referred to as fantasy play or pretend play; Enslein \& Fein, 1981; Warren, Oppenheim, \& Emde, 1996). Differences in the occurrence, the coherence, or the sequencing of these types of play can be used to help identify children with emotional and behavioral problems and disorders (Hartup, 1976; Hetherington, Cox, \& Cox, 1979; Singer \& Singer, 1976; Sutton-Smith, 1980; Wainwright \& Fein, 1996) and are found to correlate with various forms of psychopathology in young children (McDonough, Stahmer, Schreibman, \& Thompson, 1997; Oppenheim et al., 1997).

Recent articles report on the use of play narratives for the assessment of disorders in young children (Charman, 1997; McDonough et al., 1997; Warren et al., 1996). In play narratives, the child is presented with a set of dolls and is asked to complete both in words and in play a story that the experimenter starts (e.g., Bretherton, Ridgeway, \& Cassidy, 1990). Usually the object of investigation is the content of the child's play, but play narratives can also be used to study types of play behavior.

Assessment of children's play behavior thus appears to be useful for the assessment of some emotional and behavioral problems in young children. Whether this holds specifically for the assessment of depression in childhood is not yet resolved.

How depression manifests itself in children's play is unclear and scarcely studied. Early publications on childhood depression referred to play 
inhibition and the reflection therein of the depressed child's motivational problems and loss of interest (Nissen, 1971; Ushakov \& Girich, 1972) and to "changes in the quality and quantity of play activity" of depressed children (Kovacs, 1977, p. 157). More detailed specifications of depressed children's play behavior, however, have not become available since then. Play behavior idiosyncrasies as a criterion for young children's depression is not presented in DSM-IV (American Psychiatric Association, 1994) nor in a recent study on criteria for dysthymic disorder in preschool children (Kashani, et al., 1997) nor in recent review articles (Birmaher, Ryan, Williamson, Brent, \& Kaufman, 1996). We found only one study that characterized the play behavior of depressed children; it reported that a lower frequency of fantasy play during free play situations differentiates depressed from both nondepressed and conduct disordered children (Field et al., 1987).

How might various aspects of depression influence children's play behavior? Kashani and colleagues (1997) did not find loss of interest and pleasure in a generalized way among depressed preschoolers. However, such a loss may be reflected in depressed children's play behavior, in either play content or deficits in certain types of play behavior. Symptoms of psychomotor agitation, for example, might cause disruptions in the child's play and thus negatively affect its coherence. Depressive hypoactivity and psychomotor retardation may cause children to show little or no play behavior at all or to persevere with certain types of play when it would be more appropriate to move on to other types. Feelings of aggression may be reflected in types of play behavior. Depressed children may experience problems of affect regulation that might impair the quality of their play behavior. However, these and other possible speculations about the relation of play and depression have not been adequately researched. A prerequisite to the appropriate use of play behavior for the assessment of young children's depression is further investigation to empirically examine the way depression influences children's play behavior.

The present article reports an exploratory study carried out to examine how depressive young children's behavior in play situations differs from that of their nondepressed age-mates. We focused on three research questions:

(a) whether depressed and nondepressed children differ in the amount of play and related behavior exhibited in various play situations;

(b) whether they differ with regard to the coherence of their behavior in play situations and the influence of affect regulation problems on the play of depressed children (see Oppenheim et al., 1997; Warren et al., 1996), and

(c) whether inducing positive and negative moods during play differentially affects the play behavior of depressed and nondepressed children. 


\subsection{Method}

\subsubsection{Participants}

Sixteen children participated in this study, eight depressed and eight nondepressed. The nondepressed children served as a control group. The depressed children were selected from the residential and semiresidential units of two institutions for young children with somatic, somatoform, psychiatric, and psychosocial problems. The first step in the diagnostic selection of the depressed children was made by the institutions' clinical staff. They studied their patients' clinical files, using a checklist that was based on DSM-IV and ICD-1o criteria for major depressive episode. Only those children who fully met these depression criteria and whose diagnosis of depression was subsequently confirmed by an independent child psychiatrist were accepted as participants in the depressed group.

Two participants had another diagnosis comorbid with the depression diagnosis (attention-deficit/hyperactivity disorder, pervasive developmental disorder-not otherwise specified). In both cases the diagnosticians judged the depression diagnosis to be primary. We chose to include both purely and comorbidly depressed children in our study because in this phase of our investigation we were primarily interested in finding children with depressions, irrespective of further specifications, and we found it too early to make distinctions between both groups. However, we decided to exclude children with comorbid autism or mental retardation because these disorders can strongly affect children's play.

To be included in the study, children had to function at least at an average intelligence level, as determined by the staff of the institutions where the children lived. The children's socioeconomic status (SES) varied. SES was determined on the basis of the educational and employment level of the child's parent(s): The mother of one child had a university degree, two children came from a middle class family, and four children came from lower class families. The control group consisted of children from regular elementary schools. They were matched with the children in the depressed group by age, gender, and SES. Because the control children were not tested on intelligence, the match with respect to this variable was not complete and was based solely on teachers' reports with respect to the children's cognitive functioning. To be included, children had to be free of socialemotional problems, according to their teachers' verbal reports.

Due to videotaping problems, the observations of one depressed child could not be analyzed. The observations of the matched child of the 
nondepressed control group were deleted, too. The final sample consisted of seven depressed and seven nondepressed children. Both groups consisted of three girls and four boys, whose ages ranged from 3 years to 5 years 11 months, with a mean age of 4 years 11 months. In both groups, one child came from a high socioeconomic class, two from middle, and four from lower socioeconomic classes.

\subsubsection{Observation Procedure}

For each child of both groups, the observation procedure was carried out in a room at the child's own institution, school, or kindergarten. We chose not to bring all children to the same observation room because that would have caused too many transportation problems. Before starting the observation procedure, the experimenter visited the classes of the selected children to help them feel acquainted with her. Because an important condition for evoking play behavior is that the child feels at ease (Rost, 1986; Van der Poel, De Bruyn, \& Rost, 1994), the play observation procedure started with an introductory talk. The experimenter told the child that they were both going to play some games together and that some of these games would be videotaped. Then she continued to chat with the child about family, pets, favorite activities, and friends.

\subsubsection{Play Situations}

After this introduction, the child participated in three play situations: a solitary free play situation, an interactive free play situation with the experimenter, and a play narrative situation that was subdivided as to induction of positive, negative, and neutral mood.

Solitary Free Play. The solitary free play (SOIFP) situation was embedded in a larger interactive play situation in which the experimenter played two games with the child-a puzzle and a bowling game. The child was told that he or she was being videotaped and was thus given the impression that it was the games in which the experimenter was interested.

After each game, the experimenter pretended she needed time to prepare the next play episode. The child was asked to wait alone in a comer, left with some play objects (LegoTM dolls and accessories), and invited to play freely with these materials. This area was screened from the rest of the room and from the video camera. The experimenter could not see the child, but the child could see the experimenter through peepholes in the screen. 
These postgame waiting periods, each of which lasted 4 minutes, constituted the SolFP situation. It was the children's behavior during these periods in which the authors were actually interested, and their behavior was videotaped with a second camera hidden behind a one-way screen.

The SolFP situation was designed to make the child feel at ease while waiting in order to increase chances for spontaneous and intrinsically motivated play behavior in the children. This procedure has proven to yield reliable and valid measures of children's play behavior (Hammenecker, De Wit, \& Mol Lous, 1994; Rost, 1986; Van der Poel et al., 1994).

Interactive Free Play. In the interactive free play (IntFP) situation, the child was invited to play for 20 minutes with the experimenter. A diversity of play materials was present in the room, such as Legos, wooden blocks, clay, pencils, grocery store set, medical suitcase, doll, cars, farm, and accessories for dressing up. The choice of the play materials and activities was left to the child. The experimenter followed the child's initiatives. The entire 20-minute IntFP session was videotaped.

Play Narratives. During the play narratives (PNar) situation, the child was sitting at a table with the experimenter. The child was presented Lego dolls and props to be used during the PNar situation and asked to choose dolls that would represent the child and his or her family. The remaining figures were put aside.

Then the experimenter presented, one after another, four different standardized introductions to stories in which the doll chosen by the child to represent him or herself was the central figure. The themes of the four stories were ordinary activities in daily life: waking up in the morning, going to school or kindergarten, coming home after school, and going to bed in the evening. After each introduction, the experimenter invited the child to make the dolls act out "what would happen next."

Two stories (waking up, going to school) were presented within a mood induction (MI) procedure. Before the story introduction, the child was asked to choose whether the mood of the doll was to be happy or sad; pictures of happy and sad faces were shown in order to facilitate an adequate understanding of happy and sad. The chosen mood state was inserted in the story's introduction ("John is waking up, and he is feeling sad [happy] today..."), and then the child had to finish the story. After playing the story in the chosen mood, the story was started again with induction of the other mood ("John is waking up, and he is feeling happy [sad] today... "). The two other story themes (coming home after school, going to bed) were introduced neutrally, that is, without inducing mood states. 
Thus, each child was presented six stories in the PNar situation: two PNar-MI (happy mood), two PNar-MI (sad mood), and two PNar-Nt ("neutral" presentation, without MI). All PNar situations were videotaped in entirety.

\subsubsection{Order of Play Situations}

To control for order effects, the SoIFP, IntFP, and PNar situations were presented in four different sequences: A through D (see Table 1). A balanced order of play situation was followed for SolFP and IntFP, with respect to the first and the last position in the sequence. PNar was always presented between SolFP and IntFP. Within the PNar situation (see Table 1) a balanced order was followed in presenting the two neutral (PNar-Nt) and the two mood induction (PNar-MI) stories. However, because the children were free to choose the mood (either happy or sad) of the first PNar-MI story, happy and sad MI could not be balanced.

Table 1 Four Orders of Presentation of Play Situations

\begin{tabular}{|c|c|c|c|c|c|c|}
\hline \multirow[b]{2}{*}{ Sequence } & \multicolumn{4}{|c|}{ Order of presentation } & \multicolumn{2}{|c|}{ ns by group } \\
\hline & $1^{\text {st }}$ & $2^{\text {nd }}$ & $3^{\text {rd }}$ & $4^{\text {th }}$ & Depressed & Nondepressed \\
\hline A & SolFP & PNar-Nt & PNar-MI & IntFP & 2 & 2 \\
\hline B & SolFP & PNar-MI & PNar-Mt & IntFP & 1 & 2 \\
\hline C & IntFP & PNar-Nt & PNar-MI & SolFP & 2 & 2 \\
\hline D & IntFP & PNar-MI & PNar-Nt & SolFP & 2 & 1 \\
\hline \multicolumn{7}{|l|}{ Note: } \\
\hline \multicolumn{7}{|c|}{ SolFP = solitary free play $;$} \\
\hline \multicolumn{7}{|c|}{ IntFP = interactive free play; } \\
\hline \multicolumn{7}{|c|}{ PNar-Nt = play narratives neutral (without mood induction); } \\
\hline
\end{tabular}

Two matched children in the depressed group and their matches in the nondepressed group were randomly assigned to each sequence (A-D in Table 1). Because data from one depressed child and the nondepressed matching child were lost, groups and sequences are not completely crossed. For each child, all observations were carried out during the same day. In sequences $A$ and $B$ there was a rest break after the PNar situation; in sequences $C$ and $\mathrm{D}$ the break came before the PNar situation. 


\subsubsection{Behaviors Observed}

Play Behavior and Nonplay Behavior Categories. In each of the three play situations, nine behavior categories (three play and six nonplay; see Table 2) were coded. These categories were mutually exclusive; an observed behavior could be coded into only one of the categories (see Note).

Coding and Reliability. Table 2 behavior categories were observed and coded from videotape recorded during each of the play situations. Coding took place during the first $31 / \mathrm{z}$ minutes of each of the two SolFP sessions, the first 15 minutes of the single IntFP situation, and the first 3 minutes of each of the two PNar-Nt sessions (6 minutes in all), the two PNar-MI-happy sessions (6 minutes in all), and the two PNar-MI-sad sessions (6 minutes in all). Therefore, the maximum duration in seconds that any behavior category could be coded was as follows: SolFP situation, 420 seconds; IntFP situation, 900 seconds; PNar-MIhappy situation, 360 seconds; PNar-MIsad situation, 360 seconds; PNar-Nt situation, 360 seconds.

The occurrence and duration of these categories were observed and continuously coded from videotape by means of a computerized observation system, The Observer (Noldus, 1993). All videotapes were independently coded by three raters who were trained in the use of the coding scheme and blind with respect to each child's group status.

Interrater reliability was computed using the data coded by the three raters on all subjects. All behavior categories except one could be reliably scored (Cohen's kappa for pairs of raters ranged from .82 to .99). It was not possible to reliably distinguish ManPl-S from ManPl-C, so these were combined into one category of manipulative play (ManPl), which could be reliably scored (Cohen's kappa .95).

Play and Nonplay Behavior Scores. For each child, percentage duration scores were calculated for each of the remaining play behavior ( $\mathrm{ManPl}$, SymPl) and nonplay behavior (Expl, Hand, Look, Envi, Self, Adul) categories, in each play situation (SOIFP, IntFP, PNar-Nt, PNar-MI-happy, and PNarMI-sad). These scores were derived by obtaining the amount of time (in seconds) that a child exhibited each behavior in a given play situation, then dividing by the maximum duration of that situation.

For example, suppose that in the PNar-MI-happy situation, during the first positive mood story three separate episodes of SymPl were coded, lasting 39.6, 23.0, and 51.5 seconds, summing to 114.1 seconds. The same was done for the second positive mood story, with a sum of 135.8 seconds 
Table 2 Play and Nonplay Behavior Categories

\begin{tabular}{|c|c|c|}
\hline Code & Name & Activity \\
\hline \multicolumn{2}{|c|}{ Play Behavior } & \\
\hline ManPI-S & $\begin{array}{l}\text { Simple manipula- } \\
\text { tive play }\end{array}$ & $\begin{array}{l}\text { Repeating actions for the sake of pleasure, such as } \\
\text { repeatedly lifting up an arm of leg of a doll or repeatedly } \\
\text { opening and closing a medical kit. }\end{array}$ \\
\hline ManPI-C & $\begin{array}{l}\text { Combinatorial } \\
\text { manipulative play }\end{array}$ & $\begin{array}{l}\text { Combining actions and/or elements of the objects } \\
\text { evidently for the sake of play pleasure, such as moving } \\
\text { arms and legs of the doll at the same time or opening } \\
\text { the medical kit and taking out something without the } \\
\text { intention of representing a special action. }\end{array}$ \\
\hline SymPI & Symbolic Play & $\begin{array}{l}\text { Making objects, actions, and/or persons represent other } \\
\text { absent objects, actions, and/or persons, for example, } \\
\text { pretending that the doll is walking or talking and pretend- } \\
\text { ing that one is a doctor. }\end{array}$ \\
\hline \multicolumn{2}{|c|}{ Nonplay behavior } & \\
\hline Expl & Exploration & $\begin{array}{l}\text { Looking at, touching, and/or manipulating the play-object } \\
\text { or parts of them, evidently in order to find out how it works. }\end{array}$ \\
\hline Hand & Handling & Handling without any specific intention. \\
\hline Look & Looking & Looking or staring in a nonexplorative way. \\
\hline Envi & $\begin{array}{l}\text { Environment } \\
\text { oriented }\end{array}$ & Looking at, touching, or manipulating the environment. \\
\hline Self & Self-oriented & $\begin{array}{l}\text { Child is only interested in/or busy with him- or herself, for } \\
\text { example, looking at self in a mirror or manipulating own } \\
\text { clothes. }\end{array}$ \\
\hline Adul & $\begin{array}{l}\text { Experimenter } \\
\text { oriented }\end{array}$ & $\begin{array}{l}\text { Child is actively engaging with the oriented experimenter, } \\
\text { for example, asking him or her what they are going to } \\
\text { play afterwards or how long he or she has to remain in the } \\
\text { waiting room. }\end{array}$ \\
\hline
\end{tabular}

of SymPl coded. Summing across the two positive mood stories yields 249.9 seconds of SymPl.

The PNar-MI-happy situation lasted 2 X $180=360$ seconds, so this child exhibited a SymPl percentage duration of $69.4 \%$. In a similar way, percentage duration scores were obtained for all behavior categories in all five play situations.

Total Changes. To investigate the amount of coherence in the behavior of depressed and nondepressed young children, we computed for each child in each play situation the number of behavior changes, that is, the number of times the child's behavior changed from any category of play or nonplay behavior to another. These were summed across play situations to yield a total changes score. 


\subsection{Results}

Data were analyzed using a design with one between-subjects factor, group (depressed vs. nondepressed children), and three within-subjects factors, play situation (SOIFP, IntFP, PNar), type of play behavior (ManPl, SymPl), and type of nonplay behavior (Expl, Hand, Look, Envi, Self, Adul). ANOVAS and MANOV were executed using a general linear model procedure in SPSS 7.5.2. Table 3 provides descriptive data on each of the children, their percentage duration scores on the two play behavior categories, and total changes. Tables 4 through 7 summarize the means and standard deviations of the groups in various analyses and the outcomes of statistical tests in these analyses. With respect to the results that are described below,

Table 3 Percentage of Manipulative Play and Symbolic Play and Number of Behavior Changes

\begin{tabular}{|c|c|c|c|c|c|c|c|c|c|}
\hline \multirow[b]{3}{*}{ Group } & \multirow[b]{3}{*}{$\begin{array}{l}\text { Gen- } \\
\text { der }\end{array}$} & \multirow[b]{3}{*}{$\begin{array}{l}\text { Age } \\
\text { (Mo) }\end{array}$} & \multicolumn{6}{|c|}{ Play situation ${ }^{a}$} & \multirow[b]{3}{*}{$\begin{array}{c}\text { Total } \\
\text { changes }^{c}\end{array}$} \\
\hline & & & \multicolumn{2}{|c|}{ SolFP } & \multicolumn{2}{|c|}{ IntFP } & \multicolumn{2}{|c|}{ PNarb } & \\
\hline & & & $\begin{array}{c}\text { Man- } \\
\text { PI }\end{array}$ & $\begin{array}{c}\text { Sym- } \\
\text { PI }\end{array}$ & $\begin{array}{c}\text { Man- } \\
\text { PI }\end{array}$ & $\begin{array}{c}\text { Sym- } \\
\text { PI }\end{array}$ & $\begin{array}{l}\text { Man- } \\
\text { PI }\end{array}$ & SymPI & \\
\hline Depressed $^{d}$ & girl & 36 & 18.0 & 5.3 & 23.1 & 3.5 & 9.5 & 14.1 & 92 \\
\hline Nondepressed & girl & 36 & 0 & 47.5 & 1.6 & 16.2 & 10.6 & 62.8 & 52 \\
\hline Depressed & boy & 48 & 7.8 & 14.6 & 8.8 & 37.4 & 9.4 & 24.3 & 84 \\
\hline Nondepressed & boy & 48 & 0 & 40.1 & 5.1 & 67.0 & 0 & 92.3 & 49 \\
\hline Depressed & girl & 50 & 7.6 & 54.7 & 4.4 & 52.0 & 21.0 & 40.0 & 53 \\
\hline Nondepressed & girl & 50 & 10.7 & 7.8 & 0 & 55.1 & 1.2 & 95.7 & 45 \\
\hline Depressed & boy & 56 & 6.7 & 2.9 & 39.4 & 11.3 & 0 & 46.0 & 72 \\
\hline Nondepressed & boy & 56 & 26.6 & 52.8 & 9.5 & 25.9 & 1.9 & 93.0 & 57 \\
\hline Depressed & boy & 65 & 13.0 & 12.7 & 11.0 & 0 & 0 & 0 & 74 \\
\hline Nondepressed & boy & 65 & 0 & 85.5 & 0 & 72.7 & 0 & 94.5 & 39 \\
\hline Depressed & girl & 67 & 16.8 & 14.5 & 15.9 & 39.7 & 9.9 & 47.7 & 59 \\
\hline Nondepressed & girl & 67 & 22.4 & 71.4 & 10.2 & 63.2 & 0 & 98.9 & 32 \\
\hline Depressed & boy & 71 & 20.8 & 37.8 & 0 & 73.8 & 0 & 72.6 & 38 \\
\hline Nondepressed & boy & 71 & 33.0 & 35.1 & 14.0 & 72.1 & 0 & 100.0 & 38 \\
\hline
\end{tabular}

Note. SolFP = solitary free play situation; IntFP = interactive free play situation; PNar = play narrative situation (neutral and mood induction combined); $\mathrm{ManPI}=$ manipulative play behavior; SymPI = symbolic play behavior.

a Data represent the percentage of time during which each kind of play behavior occurred, for each play situation.

${ }^{\mathrm{b}}$ Mean of percentage durations from PNar-MI-happy, PNar-MI-sad, and PNar-Nt.

'Number of changes from one behavior category to another, summed over all play situations.

d This participant had comorbid Pervasive Developmental Disorder Not Otherwise Specified.

e This participant had comorbid Attention-Deficit/Hyperactivity Disorder. 
no statistically significant effects were found for age, gender, or order of presentation.

\subsubsection{Amount of Play and Nonplay Behavior}

Play Behavior. The first question we examined was whether depressed and nondepressed children differed with respect to amount of play behavior they exhibited. The dependent variable consisted of the combined scores for $\mathrm{ManPl}$ and SymPl (first summed within each play situation, then averaged across situations). ANOVA revealed that depressed children $(M=40.39, S D=$ 19.71) showed significantly less play than nondepressed children $(M=71.84$, $S D=14.77), F(1,12)=11.41 ; p<.005$. The percentage of variance explained $($ eta2 $)=.487$, and power was .872 .

To investigate whether this difference varied across play situations, we executed MANOVA with group and play situation as independent variables and play behavior (sum of $\mathrm{ManPl}$ and SymPl) as dependent variable (see Table 4). The interaction effect was statistically significant, Wilks's lambda $=.291, F(2,11)=13.43, p<.001$. The difference in amount of play behavior between depressed and nondepressed children was strongest in the PNar

Table 4 Play Behavior ${ }^{a}$ by Play Situation for Depressed and Nondepressed Young Children

\begin{tabular}{|c|c|c|c|c|c|c|c|c|c|}
\hline $\begin{array}{l}\text { Play } \\
\text { situation }\end{array}$ & Group ${ }^{b}$ & $M$ & $S D$ & Lambda & $F$ & $d f$ & $p$ & eta ${ }^{2}$ & power \\
\hline \multirow[t]{2}{*}{ SolFP } & Depressed & 33.34 & 19.66 & & 5.84 & 1,12 & .033 & .327 & .603 \\
\hline & $\begin{array}{l}\text { Non- } \\
\text { depressed }\end{array}$ & 63.59 & 26.66 & & & & & & \\
\hline \multirow[t]{2}{*}{ IntFP } & Depressed & 45.76 & 20.80 & & 1.18 & 1,12 & .298 & .090 & .171 \\
\hline & $\begin{array}{l}\text { Non- } \\
\text { depressed }\end{array}$ & 58.94 & 24.40 & & & & & & \\
\hline \multirow[t]{2}{*}{ PNar } & Depressed & 42.08 & 24.94 & & 25.80 & 1,12 & .000 & .683 & .996 \\
\hline & $\begin{array}{l}\text { Non- } \\
\text { depressed }\end{array}$ & 93.01 & 9.03 & & & & & & \\
\hline $\begin{array}{l}\text { Play } \\
\text { situation } \\
\text { by group }\end{array}$ & & & & .291 & 13.43 & 2,11 & .001 & & .985 \\
\hline
\end{tabular}

Note:

SolFP = solitary free play;

IntFP = interactive free play;

$\mathrm{PNar}=$ play narratives (happy and sad and neutral).

${ }^{\text {a }} \mathrm{ManPl}$ and SymPI Play Behavior combined (see Table 2).

${ }^{\mathrm{b}} \mathrm{n}$ for each depressed and nondepressed group $=7$. 
Table 5 Categories of Play Behavior of Depressed and Nondepressed Young Children

\begin{tabular}{|c|c|c|c|c|c|c|c|c|c|}
\hline $\begin{array}{l}\text { Play } \\
\text { behavior }\end{array}$ & Group $^{a}$ & $M$ & $S D$ & Lambda & $F$ & $d f$ & $p$ & eta ${ }^{2}$ & power \\
\hline \multirow[t]{2}{*}{ ManPI } & Depressed & 11.06 & 4.66 & & 3.15 & 1,12 & .101 & .208 & .372 \\
\hline & $\begin{array}{l}\text { Nonde- } \\
\text { pressed }\end{array}$ & 7.58 & 5.88 & & & & & & \\
\hline \multirow[t]{2}{*}{ SymPI } & Depressed & 29.34 & 20.27 & & 21.72 & 1,12 & .001 & .644 & .989 \\
\hline & $\begin{array}{l}\text { Nonde- } \\
\text { pressed }\end{array}$ & 64.27 & 14.59 & & & & & & \\
\hline $\begin{array}{l}\text { Play } \\
\text { behavior } \\
\text { categories } \\
\text { by group }\end{array}$ & & & & .467 & 13.72 & 1,12 & .003 & & .294 \\
\hline
\end{tabular}

situation, smaller but also statistically significant in the SolFP situation, and not significant in the IntFP situation.

Next we examined whether differences between depressed and nondepressed children in their amount of play depended on the type of play behavior. MANOVA with group as independent variable and play behavior as dependent variable revealed a significant interaction effect, Wilks's lambda $=.467, F(\mathrm{l}, 12)=13.72 ; p<.003$, power $=.924$. Nondepressed children showed significantly more SymPl than depressed children, whereas the two groups did not differ significantly in their amount of ManPl (see Table 5).

To investigate whether the interaction between play situation and play behavior was different for depressed and nondepressed children, we conducted MANOVA with group as between-subjects factor and play situation and play behavior as within-subjects factors. The interaction effect was statistically not significant.

Nonplay Behavior. Next we compared the depressed and nondepressed children in regard to their nonplay behavior. As Table 6 shows, depressed children showed significantly more orientation toward the environment in the SolFP and IntFP situations and more orientation toward the experimenter in the PNar situation. 
Table 6 Selected Nonplay Behavior by Play Situation for Depressed and Nondepressed Young Children

\begin{tabular}{llrrrrr}
\hline $\begin{array}{llrl}\text { Play situation/ } \\
\text { Nonplay behavior }\end{array}$ & Group & $\boldsymbol{M}$ & $\boldsymbol{S D}$ & $\boldsymbol{F}$ & $\boldsymbol{d f}$ & $\boldsymbol{p}$ \\
\hline SolFP/Envi & Depressed & 24.00 & 12.33 & 9.04 & 1,12 & .001 \\
& Nondepressed & 8.70 & 5.43 & & & \\
IntFP/Envi & Depressed & 4.41 & 2.49 & 8.54 & 1,12 & .013 \\
& Nondepressed & 1.31 & 1.30 & & & \\
PNar/Adul & Depressed & 47.38 & 25.22 & 20.30 & 1,12 & .001 \\
& Nondepressed & 3.87 & 4.12 & & & \\
\hline
\end{tabular}

Note:

SolFP = solitary free play;

IntFP = interactive free play;

$\mathrm{PNar}=$ play narratives (happy and sad and neutral);

Envi = environment-oriented behavior;

Adul $=$ experimenter-oriented behavior.

${ }^{a} n$ for each depressed and nondepressed group $=7$.

\subsubsection{Behavior Changes}

The second question in this study, involving coherence of behavior, was addressed by considering the number of behavior changes depressed and nondepressed children showed during the play situations. There proved to be a difference, Wilks's lambda $=.506, F(3,10)=3.25 ; p<.034$; power $=$ .564 . Depressed children showed significantly more behavior changes than nondepressed ones in the SolFP and IntFP situations but not in the PNar situation (see Table 7).

\subsubsection{Mood Induction}

In regard to our third question, we investigated whether mood induction during the PNar situation differentially affected play behavior. We found that mood induction did not have differential effects on the play behavior of depressed and nondepressed children. Depressed children showed less play behavior than nondepressed ones regardless of mood induction.

\subsection{Discussion}

To briefly recap findings, depressed 3- to 6-year-old children showed less play behavior than matched nondepressed children. They also exhibited 
Table 7 Behavior Changes by Play Situation for Depressed and Nondepressed Young Children

\begin{tabular}{|c|c|c|c|c|c|c|c|c|c|}
\hline $\begin{array}{l}\text { Play } \\
\text { situation }\end{array}$ & Group $^{a}$ & $M$ & $S D$ & Lambda & $\boldsymbol{F}$ & $d f$ & $p$ & eta ${ }^{2}$ & power \\
\hline \multirow[t]{2}{*}{ SolFP } & Depressed & 18.14 & 3.49 & & 6.57 & 1,12 & .025 & .354 & .654 \\
\hline & $\begin{array}{l}\text { Non- } \\
\text { depressed }\end{array}$ & 12.71 & 4.39 & & & & & & \\
\hline \multirow[t]{2}{*}{ IntFP } & Depressed & 36.43 & 13.89 & & 6.51 & 1,12 & .025 & .352 & .650 \\
\hline & $\begin{array}{l}\text { Non- } \\
\text { depressed }\end{array}$ & 22.00 & 5.54 & & & & & & \\
\hline \multirow[t]{2}{*}{ PNar } & Depressed & 12.86 & 7.11 & & .77 & 1,12 & .399 & .060 & .127 \\
\hline & $\begin{array}{l}\text { Non- } \\
\text { depressed }\end{array}$ & 9.86 & 5.64 & & & & & & \\
\hline $\begin{array}{l}\text { Changes } \\
\text { by group }\end{array}$ & & & & .506 & 3.25 & 3,10 & .034 & & .564 \\
\hline
\end{tabular}

Note:

SolFP = solitary free play;

IntFP = interactive free play;

$\mathrm{PNar}=$ play narratives (happy and sad and neutral).

${ }^{a} n$ for each depressed and nondepressed group $=7$.

more nonplay behavior, particularly more orientation toward the environment (in the solitary and in the interactive free play situations) and toward the experimenter (in the play narratives situation). Group differences in play varied by situation: larger in play narratives than in solitary free play, and nonsignificant in interactive free play. The depressed/nondepressed group play differences were specific to symbolic play rather than manipulative play. Depressed children showed less coherence of play, switching behaviors more often than nondepressed children. Mood induction during the play narrative situation did not have differential effects on the play of depressed and nondepressed children.

The present study's finding that depressed children play less than their nondepressed counterparts is in line with some theoretical-clinical ideas (Nissen, 1971; Ushakov \& Girich, 1972) and with the outcome of the empirical study of Field and colleagues (1987). One explanation for the differences in play behavior could be that depression involves a generally low level of activity, often referred to as retardation (see, e.g., $D S M-I V$ ). One of the clinically important findings of our study, however, is that we did not find depressed children to be less active. Indeed, they exhibited less play behavior but also more nonplay behavior (e.g., more orientation toward the environment and the experimenter) than the nondepressed children. Also, during the free 
play situations, depressed children showed more behavioral changes than the nondepressed children. These findings suggest that depressed children may not be behaviorally retarded, inactive, and aloof but "differently active." This may relate to Kashani and colleagues' (1997) findings that psychomotor agitation is reported in $75 \%$ of young depressed children, whereas decreased activity and retardation were found in only $25 \%$ of the cases.

The behavioral pattern of depressed children in our study is comparable with the behavior of children with a "disorganized" type of attachment, which has been related to childhood depression (Main, Kaplan, \& Cassidy, 1985; Main \& Solomon, 1990). Unfortunately, we could not examine this relationship further because we had no information about our participants' attachment history. But the suggestion is that depression at this early age can have a relationship with early attachment experiences; therefore, the interrelations among children's attachment quality, depression, and play behavior certainly deserve attention in future research.

Another explanation for the differences in both play and nonplay behavior between depressed and nondepressed children could be that the depressed children's orientation to the environment and to the experimenter, and the children's frequent behavioral changes, reflect the clinical feature of loss of concentration. This explanation assumes that in young children, play behavior requires more attention and internal control than nonplay behavior. Another hypothesis could be that nonplay behavior is exhibited more by depressed than by nondepressed children because depressive states are more likely to suppress play behavior than nonplay behavior. Such reasoning makes sense if we could argue that playing requires a level of effort and involvement that depressed children cannot bring themselves to.

These potential explanations distinguish play from nonplay behavior without specifying the type of play, but disregarding the type of play behavior may not be justified. At the manipulative play level, our depressed young children did not play less than the nondepressed children. Actually, they showed a higher level of manipulative play (although not statistically significant; see Table 5), but a markedly lower level of symbolic play $(p=.001$; power $=.99$ ). Therefore, a general explanation in terms of effort and attention regulation mechanisms seems not to hold.

On the other hand, in the development of play, manipulative play is assumed, and found, to emerge before symbolic play because it is thought that the latter requires a higher level of cognitive functioning.

Therefore, an alternative explanation for the low level of symbolic play of the depressed children may be that it signifies a kind of developmental 
delay of the depressed children (cf. Motti, Cicchetti, \& Sroufe, 1983; Nicolich, 1977; Piaget, 1962; Vandenberg, 1986; Westby, 1991).

The difference between the symbolic play levels of depressed and nondepressed children was least pronounced in the interactive free play situation. This result is partly in accordance with findings of Field and colleagues (1987), who also observed depressed and nondepressed children in various play situations (free play and puzzle completion tasks) and found that depressive children show less symbolic play than their nondisabled age-mates. However, in the Field et al. study the difference in the amount of symbolic play between depressed and nondepressed children was most evident in the interactive free play situation. This was not the case in the present study, in which the depressed children's amount of symbolic play was greater in the interactive free play situation than in the solitary free play situation; further, this difference was larger for the depressed than for the nondepressed group. Perhaps this point of dissimilarity in our results and those of Field et al. is due to differences in the interaction partners in the respective interactive free play situations. Our study involved play with friendly but unfamiliar adults, but in Field et al. the children were playing with their mothers. Conceivably, mothers may have a less facilitative effect on the play of depressed children than do sensitive strangers. Presence of the mother might even discourage depressed children's play behavior in cases of mother-child relationship problems, which can be associated with depression.

In this regard, affect regulation and dysregulation has been proposed as an important mechanism in depressed children's functioning (see Garber, Braaflandt, \& Weiss, 1995; Kovacs, 1997; Stegge, 1996).

Depressed children showed less symbolic play behavior than nondepressed children in all three play situations, but this difference was most pronounced in play narratives. This observation may strengthen the affectregulation hypothesis. In contrast to the task-orientation of manipulative play, the nature of symbolic play taps thoughts and related feelings, which in the case of the depressed child may distort the symbolic play process. Such a distortion should be highest in situations that elicit symbolic play, presumably such as the stories found in our play narrative situation. In the present study, the nondepressed children's level of symbolic play was much greater in play narratives than in interactive free play or solitary free play; in contrast, although depressed children showed less symbolic play in each of the play situations, it was the play narrative situation that had the strongest impact.

The interpretation that in young children depressive states have a dampening effect on symbolic play could explain why the mood induction 
procedure in the play narrative situation did not have a differential effect in depressed and nondepressed children. On the other hand, an alternative explanation could be that the mood induction procedure was ineffective in inducing mood changes. In future research, a stronger mood induction procedure may be able to clarify this issue, although caution is recommended in respect to ethical concerns.

The results of the present study may have important implications for clinical practice as well as theory in the measurement of depression in young children. As stated earlier, reliable assessment instruments for depression in young children are lacking. Our study showed that depression in young children can be reliably assessed by means of observation of various play characteristics and pointed to some important observational dimensions in this respect. However, the measurement procedure we used is rather extensive, which hampers its clinical applicability. Future research should investigate whether the relevant dimensions can be assessed via other procedures such as rating scales or observation in less complex settings. We are confident that depression criteria for preschool children, such as those proposed in DSM-IV and by Kashani and colleagues (1997), should incorporate play behavior characteristics.

Some issues and limitations in the design of the present study deserve special attention. First, the sample of the present study is small. However, note that the post hoc power of the statistical analyses with respect to differences in play and nonplay behavior of depressed and nondepressed children proved to be very satisfactory. This ranged from .87 to .92 for three of the most substantial effects: the difference in play behavior between depressed and nondepressed children, and interactions of the depressed versus the nondepressed group with type of play situation and with type of play behavior. We believe that this power can be attributed to the validity of the double-check depression identification procedure and to the reliability and scope of the observation procedure, as well as to the actual existence of differences in play behavior of depressed and nondepressed young children. Nonetheless, there is a need to replicate the study with larger samples to control the robustness of the findings.

Second, we investigated a very select sample of depressed children, whose problems were so serious that they were admitted to residential and semiresidential institutions. It may be that the children's developmental histories or their being institutionalized could have contributed to the differences found. Further, differences in play and nonplay behavior may not be as detectable in children who are less seriously depressed. Future research must bring more clarity to these issues. 
Furthermore, although comorbidity was not really an issue of importance in the present study, future research should address comorbidity. In larger samples of both purely and comorbidly depressed children, it should be possible to determine whether play behavior characteristics as they were found in the present study can be attributed to depression or to the comorbid condition.

Finally, although the present samples of depressed and nondepressed children were matched on age, gender, and SES and were roughly comparable on educational and cognitive levels, replication studies should focus attention on selection criteria and matching as to cognitive level. For example, present criteria for depression in young children are not agespecific. In the present study the diagnosis of depression carefully employed $D S M-I V$ and $I C D-10$ criteria based on clinical assessments made by the residential staffs and on the diagnosis of an independent child psychiatrist. It was only after the present study had begun that Kashani et al. (1997) appeared. We recommend that further studies in this field take into account the Kashani et al. criteria for depression in young children.

\section{Note 1}

The authors akcnowledge Dr. John van den Bercken for his assistance in statistical analyses.

\section{Note 2}

These categories were adapted from Rost (1986) and van der Poel et al. (1994). Differentiating criteria were derived from Piaget (1962), who held that as opposed to nonplay behavior, play behavior is characterized by intrinsic motivation, active engagement and positive affect. The three play categories (ManPl-S, ManPl-C, and SymPl) are assumed to represent increasingly complex levels of play (see Rost, 1986).

The nonplay behavior Expl has to be carefully distinguished from play behavior. The intention of Expl is to find out how play objects work; this makes Expl a form of goal-directed behavior and as such, opposed to play, which is intrinsically motivated, autotelic (Rubin et al. 1983), and not triggered by any stimulus other than the motivation to play (Van der Poel et al., 1994). 


\section{References}

American Psychiatric Association. (1994). Diagnostic and statistical manual of mental disorders (4th ed.) Washington, DC: Author.

Birmaher, B., Ryan, N. D., Williamson, D. E., Brent, D. A., Kaufman, J., Dahl, R. E., Perel, J., \& Nelson, B. (1996). Childhood and adolescent depression: A review of the past 10 years. Part I. Journal of the American Academy of Child and Adolescent Psychiatry, 35, 1427-1439.

Bretherton, I., Ridgeway, D., \& Cassidy, J. (1990). Assessing internal working models of the attachment relationship: An attachment story completion task for 3-year-olds. In M. T. Greenberg, D. Cicchetti, \& E. M. Cummings (Eds.), Attachment in the preschool years (pp. 273-310). Chicago: University of Chicago Press.

Charman, T. (1997). The relationship between joint attention and pretend play in autism. Development and Psychopathology, 9, 1-16.

Cicchetti, D., \& Schneider-Rosen, K. (1986). An organizational approach to childhood depression. In M. Rutter, C. E. Izard. \& P. B. Read (Eds.), Depression in young people: Developmental and clinical perspectives (pp. 71-134). New York: Guilford Press.

Edelbrock, C., Costello, A. J., Dulcan, M. K., Conover, N. C., \& Kalas, R. (1986). Parentchild agreement on child psychiatric symptoms via structured interview. Journal of Child Psychology and Psychiatry, 27, 181-190.

Enslein, J., \& Fein, G. G. (1981). Temporal and cross-situational stability of children's social and play behavior. Developmental Psychology, 17, 760-761.

Field, T. M., Sandberg, D., Goldstein, S., Garcia, R., Vega-Lahr, N., Porter, K., \& Dowling, M. (1987). Play interactions and interviews of depressed and conduct disordered children and their mothers. Child Psychiatry and Human Development, 17(4), 213-234.

Garber, J., Braaflandt, N., \& Weiss, B. (1995). Affect regulation in depressed and nondepressed children and young adolescents. Development and Psychopathology, 7, 93-115.

Hammenecker, C., De Wit, C. A. M., \& Mol Lous, A. (1994). Verhaalaanvullingsmethode voor toepassing binnen een depressiediagnostische spelprocedure [Story completion method for application in a depression assessment play procedure]. Unpublished manuscript, Department of Developmental Psychology, University of Nijmegen, The Netherlands.

Harrington, R. C. (1993). Depressive disorder in childhood and adolescence. Chichester, England: Wiley.

Harter, S., \& Pike, R. (1984). The pictorial scale of perceived competence and social acceptance for young children. Child Development, 55, 1969-1982.

Hartup, W. W. (1976). Peer interaction and the behavioral development of the individual child. In E. Schopler \& R. L. Reichler (Eds.), Psychopathology and child development (pp. 203-219). New York: Plenum Press.

Herjanic, B., \& Reich, W. (1982). Development of a structured psychiatric interview for children. Journal of Abnormal Child Psychology, 10, 107-130.

Herjanic, B., \& Campbell, W. (1977). Differentiating psychiatrically disturbed children on the basis of a structured interview. Journal of Abnormal Child Psychology, 5, 127-134.

Hetherington, E. M., Cox, M., \& Cox, R. (1979). Play and social interaction in children following divorce. Journal of Social Issues, 35, 26-49.

Ialongo, N., Edelsohn, G., Werthamer-Larsson, L., Crockett, L., \& Kellam, S. (1995). The significance of self-reported anxious symptoms in first grade children. Prediction to anxious symptoms and adaptive functioning in fifth grade. Journal of Child Psychology and Psychiatry, 38, 427-437.

Kashani, J. H., Orvaschel, H., Burk, J. P., \& Reid, J. C. (1985). Informant variance: The issue of parent-child disagreement. Journal of the American Academy of Child Psychiatry, 24, 437-441. 
Kashani, J. H., \& Carlson, G. A. (1987). Seriously depressed preschoolers. American Journal of Psychiatry, 144, 348-350.

Kashani, J. H., Allan, W. D., Beck, N. C., Bledsoe, Y, \& Reid, J. C. (1997). Dysthymic disorder in clinically referred preschool children. Journal of the American Academy of Child and Adolescent Psychiatry, 35 14265-1433.

Klein, R. (1991). Parent-child agreement in clinical assessment of anxiety and other psychopathology: A review. Journal of Anxiety Disorders, 5, 187-198.

Kovacs, M. (1977). Conclusions and recommendations of the Subcommittee on Assessment. In J. Schulterbrandt \& A. Raskin (Eds.), Depression in childhood (pp. 155-162). New York: Raven Press.

Kovacs, M. (1986). A developmental perspective on methods and measures in the assessment of depressive disorders: The clinical interview. In M. Rutter, C. E. Izard, \& P. B. Read (Eds.), Depression in young people: Developmental and clinical perspectives (pp. 399-433). New York: Guilford Press.

Kovacs, M. (1997). Depressive disorders in childhood: An impressionistic landscape. Journal of Child Psychology and Psychiatry, 38, 287-298.

Main, M., Kaplan, N., \& Cassidy, J. C. (1985). Security in infancy, childhood and adulthood: A move to the level of representation. In I. Bretherton \& E. Waters (Eds.), Growing points of attachment theory and research. Monographs of the Society for Research in Child Development, 50 (1-2, Serial No. 209), 66-104.

Main, M., \& Solomon, J. (1990). Procedures for identifying infants as disorganized/disoriented during the Ainsworth Strange Situation. In M. T. Greenberg, D. Cicchetti, \& M. Cummings (Eds.), Attachment in the preschool years: Theory, research and intervention (pp. 121-161). Chicago: University of Chicago Press.

McDonough, L., Stahmer, A., Schreibman, L., \& Thompson, S. J. (1997). Deficits, delays and distractions: An evaluation of symbolic play and memory in children with autism. Development and Psychopathology, 9, 17-44.

Motti, F., Cicchetti, D., \& Sroufe, L. A. (1983). From infant affect expression to symbolic play: The coherence of development in Down syndrome children. Child Development, 54, 1168-1175.

Nicolich, L. (1977). Beyond sensorimotor intelligence: Assessment of symbolic maturity through analysis of pretend play. Merril-Palmer Quarterly, 23, 89-99.

Nissen, G. (1971). Depressive Syndrome im Kindes undJugendalter [Depressive syndromes in child and adolescent age]. Berlin: Springer.

Noldus Information Technology. (1993). The observer: System for collection and analysis of observational data. Wageningen: Noldus.

Oppenheim, D., Nir, A., Warren, S. L., \& Emde, R. N. (1997). Emotion regulation in motherchild narrative co-construction: Associations with children's narratives and adaptation. Developmental Psychology, 33, 284-294.

Piaget, J. (1962). Play, dreams, and imitation in childhood. New York: Norton.

Poznanski, E., \& Mokros, H. B. (1994). Phenomenology and epidemiology of mood disorders in children and adolescents. In W. M. Reynolds \& H. F. Johnston (Eds.), Handbook of depression in children and adolescents (pp. 19-39). New York: Plenum Press.

Renouf, A. G., \& Kovacs, M. (1994). Concordance between mothers' reports and children's selfreports of depressive symptoms: A longitudinal study. Journal of the American Academy of Child and Adolescent Psychiatry, 33, 208-216.

Reynolds, W. M. (1994). Assessment of depression in children and adolescents by self-report questionnaires. In W. M. Reynolds \& H. F. Johnston (Eds.), Handbook of depression in children and adolescents (pp. 209-234). New York: Plenum Press. 
Rost, H. (1986). Exploration and play: a microanalysis. In R. van der Kooy \& J. Hellendoom (Eds.), Play, play therapy, and play research (pp. 233-245). Lisse: Swets \& Zeitlinger.

Rubin, K. H., Fein, G., \& Vandenberg, B. (1983). Play. In P. H. Mussen \& E. M. Hetherington (Eds.), Handbook of child psychology, Volume 4 (pp. 693-774). New York: Wiley.

Schwab-Stone, M., Failon T., Briggs, M., \& Crowther, B. (1994). Reliability of diagnostic reporting for children aged 6-11 years: A test-retest study of the Diagnostic Interview Schedule for Children-Revised. American Journal of Psychiatry, 151, 1048-1054.

Singer, J. L., \& Singer, D. G. (1976). Imaginative play and pretending in early childhood: Some experimental approaches. In A. David (Ed.), Child personality and psychopathology: Current topics. Volume 3. New York: Wiley.

Slade, A. (1994). Making meaning and making believe: Their role in the clinical process. In A. Slade \& D. P. Wolf (Eds.), Children at play (pp. 81-107). New York: Oxford University Press.

Stegge, H. (1996). De invloed van emoties op cognities en gedrag [The influence of emotions on cognitions and behavior]. In J. D. Bosch, H. A. Bosma, D. N. Oudshoorn, J. Rispens, \& A. Vyt (Eds.), Jaarboek ontwikkelingspsychologie, orthopedagogiek en kinderpsychiatrie 2 (pp. 163-183). [Annual developmental psychology, special education and child psychiatry 2]. Houten: Bohn Stafleu Van Loghum.

Stevenson-Hinde, J., \& Shouldice, A. (1995). 4, 5 to 7 years: Fearful behaviour, fears and worries. Journal of Child Psychology and Psychiatry, 36, 1027-1038.

Sutton-Smith, B. (1980). A syntax for play and games. In R. Herron \& B. Sutton-Smith (Eds.), Child's play (pp. 298-311). New York: Wiley.

Ushakov, G., \& Girich, Y. (1972). Special features of psychogenic depressions in children and adolescents. In A. Annell (Ed.), Depressive states in children and adolescents (pp. 510-516). Stockholm: Almqvist \& Wicksell.

Vandenberg, B. (1986). Play theory. In G. Fein \& M. Rivkin (Eds.), The young child at play: Reviews of research. Washington DC: National Association for the Education of Children.

Van der Poel, P. A., De Bruyn, E. E. J., \& Rost, H. (1994). Parental attitude and behavior and children's play. Play and Culture, 4, 1-10.

Wainwright, L., \& Fein, D. (1996). Play. In I. Rapin (Ed.), Preschool children with inadequate communication (pp. 173-190). London: Mac Keith Press.

Warren, S. L., Oppenheim, D., \& Emde, R. N. (1996). Can emotions and themes in children's play predict behavior problems? Journal of the American Academy of Child and Adolescent Psychiatry, 35, 1331-1337.

Westby, C. E. (1991). A scale for assessing children's pretend play. In C. E. Shaefer, K. Gitlin, \& A. Sandgrund (Eds.), Play diagnosis and assessment (pp. 131-161). New York: Wiley. 



\title{
3. Depression Markers in Young Children's Play
}

\author{
A Comparison between Depressed and Nondepressed \\ 3 - to 6-Year-Olds in Various Play Situations ${ }^{2}$
}

Annemieke Mol Lous, Cees A. M. de Wit, Eric E.J. de Bruyn and J. Marianne Riksen-Walraven

Summary The behaviour of 30 depressed 3 - to 6 -year-olds was observed in three play situations (solitary free play, interactive free play, and play narratives) and compared to the behaviour of 30 nondepressed clinical and 30 nondepressed nonclinical peers. Depressed children showed significantly less play, particularly less symbolic play, than nondepressed children. Instead, they exhibited more nonplay behaviours, such as exploration and undirected behaviours than the control children. Moreover, the behaviour of the depressed children was less coherent than that of the nondepressed children, as evident from a greater number of shifts from one type of behaviour to another. Differences between depressed and nondepressed children were most prominent during the play narratives and were particularly striking when a sad mood was presented.

\subsection{Introduction}

Although the existence of depressions in children younger than six years of age is generally acknowledged nowadays (Kashani, Allan, Beck, Bledsoe \& Reid, 1997; N.C.C.I.P., 1995), discussion as to how this disorder should be assessed at this age, is still going on. Commonly applied assessment procedures, such as clinical interviews and self-report questionnaires, are not suitable for young children due to their limited capacity to reflect and communicate about persistent depressive cognitions and feelings (Harter \& Pike, 1984; Schwab-Stone, Faillon, Briggs, \& Crowther, 1994; Verhulst \& Akkerhuis, 1989). Application of parent or teacher questionnaires for the

2 Mol Lous, A., de Wit, C.A.M., de Bruyn, E.E.J., Riksen-Walraven, J.M. (2002). Depression markers in young children's play: a comparison between depressed and nondepressed $3^{-}$to 6- year-olds in various play situations. Journal of Child Psychology and Psychiatry, 43, 1029-1038. 
assessment of internalising problems in very young children has disadvantages too. Parents and teachers are often not sufficiently aware of a child's depressive cognitions and feelings (Edelbrock, Costello, Dulcan, Conover \& Kalas, 1986; Harrington, 1993; Klein, 1991; Stevenson-Hinde \& Shouldice, 1995). Therefore, other procedures are needed to diagnose depression in very young children. In the present study we examined whether depression in young children can be assessed through observations of their play behaviour.

Play, particularly symbolic play -also referred to as pretend play or fantasy play- has always been a major point of interest for clinicians. Not only because play "represents a window to the child's mind" (Rubin, Fein \& Vandenberg, 1983, p 756), but also because symbolic play has been shown to reflect children's emotional and behavioural disorders (Singer \& Singer, 1976; Sutton-Smith, 1980; Warren, Oppenheim \& Emde, 1996). Disruptions of symbolic play have been found associated with a variety of emotional problems in children (Hartup, 1976; Hetherington, Cox \& Cox, 1979; Nader \& Pynoos 1991).

Play observation also seems a promising method to obtain direct and indirect information about affective, motivational and other behavioural symptoms of the depressive syndrome. Early publications on childhood depression referred to play inhibition and the reflection herein of the depressed children's loss of interest (Nissen, 1971; Ushakov \& Girich, 1972), and to "changes in the quality and quantity of play activity" of depressed children (Kovacs, 1977, p. 157). The results of recent observational studies on depressed children show that overt behavioural symptoms of depression such as psychomotor agitation and retardation, can indeed be systematically observed during standardized play procedures (Altman \& Gotlib, 1988; Field, Sandberg, Goldstein, Garcia, Vega-Lahr, Porter \& Dowling, 1987; Kashani et al., 1997; Kazdin, 1990). In addition, Field et al. (1987) reported a lower frequency of symbolic or fantasy play in free play situations to differentiate depressed from both normal and conduct disordered children.

In a former study (Mol Lous, De Wit, De Bruyn, Riksen-Walraven \& Rost, 2000), we compared the play behaviour of depressed and nondepressed 3- to 6-year-old children during solitary free play, interactive free play, and play narratives. The results of this study supported the findings of Field et al. (1987). As expected, depressed children were found to exhibit significantly less symbolic play than their matched nondepressed controls, especially in the play narratives situation, where the child was asked to play a story introduced by the experimenter. We also found the behaviour of depressed children to be more fragmented than the behaviour of their nondepressed 
peers, as evident from a larger number of switches from one type of play or nonplay behaviour to another.

In search of the mechanisms underlying the apparent effect of depression on the play behaviour of young children in our former study, our first conclusion was that the effect cannot be explained by a decrease or retardation in the activity level of the depressed children. After all, although the depressed children exhibited less play than the nondepressed ones, they showed significantly more nonplay behaviours such as self-oriented behaviour and exploration instead. Our findings thus suggest that depressed children may not be behaviourally retarded or sluggish, but rather "differentially active". The frequent behavioural changes we found in the depressed children may reflect psychomotor agitation, which Kashani et al. (1997) found characteristic of $75 \%$ of young depressed children.

The inhibition of symbolic play in depressed children may also be explained by affect regulation problems that characterise the depressed children's functioning (Cicchetti \& Toth, 1998; Field 1992; Garber, Braaflandt, \& Weiss, 1995; Kovacs, 1997; Sheeber, Allen, Davis, \& Sorensen, 200o). Symbolic play may elicit negative thoughts and feelings that can be threatening for depressed children, who might have experienced uncontrollable negative events and states, as is obvious e.g. from clinical literature (Ryan, 1999). The finding in our former study (Mol Lous et al., 200o) that symbolic play was most inhibited in depressed children during the play narratives, where the play themes are handed by the experimenter and thus are hard to escape from for the children, is in line with this interpretation. To examine the affect regulation hypothesis, the story beginnings in our former study were presented with various moods, viz., positive, negative, and neutral. Contrary to our expectation, however, we did not find negative mood presentation to negatively affect the depressed children's play. Because this finding might be due to the small sample size in our former study (seven depressed versus seven nondepressed children), the effect of mood presentation on depressed children's play was tested again in the present study with a larger sample.

Because our former study yielded clear and meaningful results, we decided to apply the same procedure in a new sample, while tackling two limitations of our previous study. The first limitation was that the sample of depressed children was rather small. The second was that the study did not include a nondepressed clinical control group. For that reason we could not exclude that the differences between the depressed and nondepressed children could be explained as an effect either of their being institutionalised, or of general conditions of psychopathology which contribute to 
children being clinically referred. Our present study therefore focused on a larger sample and included an extra clinical sample of nondepressed children as a second control group in addition to the group of nonclinical controls.

In this study, we compared the behaviour of depressed children with the behaviour of nondepressed clinical and nondepressed nonclinical control children in three play situations, viz., solitary free play, interactive free play, and play narratives. We tested the following hypotheses: (1) the depressed children exhibit less play and particularly less symbolic play than the nondepressed children in both control groups, across all play situations, (2) the differences in (symbolic) play among the depressed and the nondepressed children are largest in the play narratives situation, (3) the depressed children show more behavioural changes than the nondepressed children in both control groups, and (4) mood presentation during the play narratives differentially affects the play behaviour of depressed and nondepressed children; the largest differences in play between depressed and nondepressed children emerge when a negative mood is presented.

\subsection{Method}

\subsubsection{Participants}

Participants in this study were 30 depressed, 30 nondepressed clinical and 30 nondepressed nonclinical children. The latter two groups served as control groups. Children were between 3 and 6 years old. This age range was chosen for two reasons: since we wanted to use symbolic play as a variable of observation, children had to be older than 3 years of age; since the play observation procedure was meant to be applied in children who were too young for self-report assessment procedures, children had to be younger than 6 years of age.

The depressed and nondepressed clinical children were selected from twenty day-care units of clinical institutions for young children with somatic, somatoform, psychiatric, and psychosocial problems. Selection was carried out in three steps. The clinical staffs of the institutions made a first selection. For this purpose they used a checklist that comprised both the $D S M-I V$ and the $I C D$-10 criteria for major depressive episode, as they are described in the respective manuals. For each criterion, examples were added to help the clinical staffs in applying these criteria for the 
young age group under investigation. Subsequently, the checklist data were discussed with the first author in order to come upon a staff nomination of participants. Ultimately, the clinical files of the nominated children who fully met these depression criteria (i.e. the depressed group) or did not meet the depression criteria at all (i.e. the nondepressed clinical group), were judged by an independent child psychiatrist, who used the same checklist of depression criteria as the clinical staffs did. Only the children who passed the three steps of the selection procedure were included in the study. To be included in the sample, children had to function at least at a low average intelligence level, as judged by the staff of the institutions, and were not allowed to have an autism spectrum disorder, since these conditions can affect children's play. In all cases, appropriate informed consent was obtained from the children's parents or caregivers.

Within the depressed group, 10 children comorbidly had another disorder, viz., generalized anxiety disorder $(n=3)$, separation anxiety disorder $(n=1)$, language disorder $(n=2)$, obsessive-compulsive disorder $(n=1)$, oppositionaldefiant disorder $(n=2)$, or Cushing Syndrom $(n=1)$.

The children in the nondepressed clinical control group were matched with the depressed ones on age and socio-economic class. The nondepressed children met criteria for a variety of non-depressive disorders such as: ADHD, ADD, PDD-NOS, ODD, language disorder, CD-NOS, Asperger syndrome, post-traumatic stress disorder, and coordination disorder. Five children in the clinical control group did not meet the criteria for a specific $D S M-I V$ disorder, but were admitted to the institutions for more aspecific somatic, emotional and behavioural problems. Although the group was rather heterogeneous, all children concerned had in common that they were both institutionalised and nondepressed, and were for that reason included in this control group.

The nonclinical nondepressed control group consisted of children from five elementary schools and preschools, the first author had professional contacts with. They were matched with the children in the depressed group on age, gender and SES. To be included, children had to be free of socialemotional problems, and had to function at least at a low average level of intelligence, as judged by their teachers.

The final sample consisted of 30 depressed children (17 boys and 13 girls), 30 nondepressed clinical children (18 boys and 12 girls), and 30 nondepressed nonclinical children ( 17 boys and 13 girls). In all groups ages ranged from 36 months to 73 months (mean age 58.3 months). Twenty children came from lower class families, eight from middle class families, and two had at least one parent with a university degree. 


\subsubsection{Play Procedure}

The play procedure was carried out in a specially equipped room of the child's own institution or school. We preferred to observe the children in their own 'familiar' setting because feeling at ease is a main condition for eliciting play behaviour in children (Rubin, Fein, \& Vandenberg, 1983; Van der Poel, De Bruyn, \& Rost, 1991). The experimenters were graduate students with clinical experience in working with young children. They were trained for the play procedure and blind with respect to the clinical diagnoses of the children.

Before starting the play procedure, the experimenter visited the classes of the selected children, in order to make them feel acquainted with her. The play procedure started with an introductory talk, in which the experimenter explained that they were going to play some games together and that some of the games would be videotaped. Then she continued to chat with the child about family, pets, favorite activities and friends. After this introduction, the child participated in three different play situations: a solitary free play situation, an interactive free play situation with the experimenter, and a play narratives situation with and without mood-presentation.

Solitary free play. The Solitary free play (Solitary FP) situation was embedded in a larger interactive play situation in which the experimenter played two games with the child, viz. a puzzle and a bowling game. The child was told that these games were being videotaped and was thus given the impression that these were the play situations the experimenter was interested in.

After each game, the experimenter pretended she needed time to prepare the next play episode. The child was asked to wait alone in a corner, which was screened from the rest of the room and from the video camera. The experimenter could not see the child, but the child could see the experimenter through peep holes in the screen. In this waiting room some play objects were available (Lego "Belville" dolls and accessories), and the child was invited to freely play with these materials. The behaviour the child showed during these periods was the actual subject of the study and it was videotaped with a second camera hidden behind a one way screen.

Each of the two post-game waiting periods lasted 4 minutes. Together, these episodes constituted the Solitary FP situation.

The Solitary FP situation was designed to make the child feel at ease while waiting, in order to increase chances for spontaneous and intrinsically 
motivated play behaviour in the children to occur. This procedure has proven to yield reliable and valid measures of children's play behaviour (Mol Lous, et al., 2000).

Interactive free play. In the interactive free play situation (Interactive FP) the child was invited to play with the experimenter for 20 minutes. A diversity of play materials was present in the room, among which Lego Duplo, clay, pencils, a grocery store set, a medical suitcase, a doll, cars, a farm, and accessories for dressing up. The choice of the play materials and activities was left to the child. The experimenter followed the child's initiatives. The entire 20-minute IntFP session was recorded on videotape.

Playnarratives. During the play narratives situation (PlayNarr), the child was sitting at a table with the experimenter. The child was presented the Lego Belville dolls and props to be used during the play session and was asked to choose dolls that would represent the child and his/her family. The remaining figures were put aside.

Then the experimenter presented, one after another, four different standardized story beginnings, in which the doll which was chosen by the child to represent him or herself, was the central figure. The themes of the stories were ordinary activities in daily life: waking up in the morning, going to school or kindergarten, coming home from school, and going to bed in the evening. After each introduction, the experimenter invited the child to play with the toy subject "what would happen next".

Two stories (waking up; going to school) were offered with mood-presentation (MP). Both stories were presented twice, once with a 'happy' moodpresentation (PlayNarr Happy), and once with a 'sad' mood-presentation (PlayNarr Sad). Pictures of happy and sad faces were shown in order to facilitate an adequate understanding of the concepts 'happy' and 'sad'. The mood state was presented in the introduction of the story ("John is waking up, he is feeling sad (happy) today $\left.1 / 4^{\prime \prime}\right)$, and then the child had to finish the story. After playing the story in the selected mood, it was started again with presentation of the other mood ("John is waking up, he is feeling happy (sad) today $\left.1 / 4^{\prime \prime}\right)$. The two other story themes (coming home after school; going to bed) were introduced neutrally, that is, without presenting mood states.

Thus, each child was presented six stories in the PlayNarr situation: two PlayNarr Happy, two PlayNArr Sad, and two PlayNarr Neutral. The entire play narratives situation was recorded on videotape. 


\subsubsection{Design}

To control for order effects, the Solitary FP, Interactive FP, and PlayNarr situations were presented in six different sequences (Table 1). The children were randomly assigned to the sequences. For each child, the whole play procedure was carried out on one day. Halfway the procedure there was a 15 minutes break just before or after the interactive free play situation, depending on the sequence of the play situations.

Table 1 Order of Presentation of Play Situation Sequences

\begin{tabular}{llllll}
\hline Sequence & \multicolumn{5}{c}{ Order of presentation } \\
\cline { 2 - 6 } & $\mathbf{1}$ & $\mathbf{2}$ & $\mathbf{3}$ & $\mathbf{4}$ & $\mathbf{5}$ \\
\hline A & SFP & PN & PNs & PNh* & IFP \\
B & IFP* & SFP & PN & PNs & PNh \\
C & PN & PNs & PNh* & IFP & SFP \\
D & SFP & PN & PNh & PNs & IFP \\
E & IFP* & SFP & PN & PNh & PNs \\
F & PN & PNh & PNs* & IFP & SFP \\
\hline
\end{tabular}

Note:

SFP = solitary free play;

IFP = interactive free play;

$\mathrm{PN}=$ play narratives without mood-presentation;

PNs = play narratives with sad mood-presentation;

PNh = play narratives with happy mood-presentation;

* $=$ break.

\subsubsection{The Observation Procedure}

Observation Categories. In each of the three play situations, coding involved the same eight mutually exclusive and exhaustive behaviour categories (see Table 2), adapted from Rost (1986) and Van der Poel et al. (1991). Differentiating criteria were derived from Piaget (1962), who held that, as opposed to nonplay behaviour, play behaviour is characterized by intrinsic motivation, active engagement and positive affect. The two play categories (manipulative play and symbolic play) are assumed to represent increasingly complex levels of play (see Rost, 1986). Nonplay behaviour has to be carefully distinguished from play behaviour. Since exploration is an intentional activity, carried out to find out how play objects work; it is as such opposed to play, which is intrinsically motivated (Rubin, Fein \& Vandenberg, 1983). The observation system has been proven valid and reliable for the present play procedure (Mol Lous et al., 2000). 
Table 2 Play and Nonplay Categories

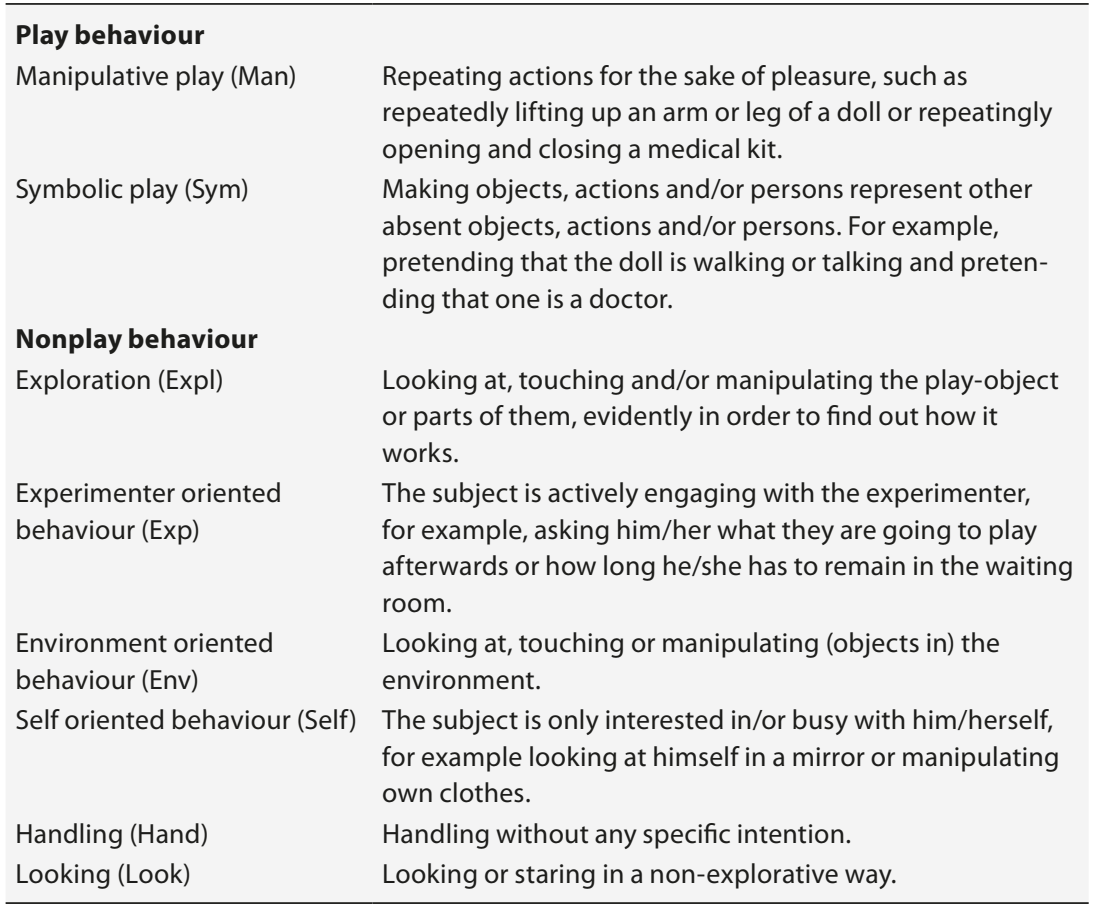

Coding and Reliability. For each play situation, the occurence and duration of each of the play and nonplay behaviour categories were coded from the videotapes. For each child the first $3^{1 / 2}$ minutes of each of the Solitary FP sessions, the first 15 minutes of the Interactive FP situation, and the first 3 minutes of each of the six play narratives were coded. The maximum duration in seconds that any behaviour category could be coded was as follows: Solitary FP situation, 420 seconds; Interactive FP situation, 900 seconds; PlayNarr Neutral situation, 360 seconds; PlayNarr Happy situation, 360 seconds; and PlayNarr Sad situation, 360 seconds.

The coding was executed using a computerized observation system The Observer (Noldus, 1993). Six raters (graduate students), who were blind with respect to the clinical diagnoses of the children, independently coded the videotapes. Raters were trained in couples, using videotapes from the former study as training material. Training continued until inter-rater reliability within the students' couples and between the students and the first author had reached values of .80 or more (Cohen's kappa), using time intervals of 5 seconds. This means that, within a margin of 5 seconds, the same observation category had to be coded by each rater. This time interval has 
been applied in our former study (Mol Lous et al., 2000), in which it proved to be adequate. Most of the play and nonplay behaviours we studied last longer than only a few seconds. Similar or even larger intervals have been reported in comparable observation studies (Van den Boom, 1994; Diener \& Mangelsdorf, 1999; Field et al., 1987).

By way of extra control, the first author coded at least 5 minutes of each play situation per child, independent of the other raters. In all except five of those 270 (90 children $\mathrm{x} 3$ situations) checks, Cohen's kappas of .80 to 1.00 were found. The five exceptions with lower Cohen's kappas were discussed until consensus was reached. At the end of the coding procedure, four randomly chosen videotapes were coded again by the first author. Inter-rater reliability proved to remain excellent (Cohen's Kappa .87 to 1.00$)$.

Play and Nonplay Behaviour Scores. For each child, percentage duration scores were calculated for each of the play (Man, Sym) and nonplay (Expl, Exp, Env, Self, Hand, and Look) behaviour categories, separately for each play situation (Solitary FP, Interactive FP, PlayNarr Neutral, PlayNarr Happy, PlayNarr Sad). These scores were obtained by calculating the amount of time (in seconds) that a child exhibited each behaviour in a given play situation, divided by the total duration of that situation.

For example, suppose that in the PlayNarr Happy situation, during the first positive mood story three separate episodes of Sym were coded lasting 39.6, 23.0, and 51.5 seconds, summing to 114.1 seconds. The same was done for the second positive mood story, with a sum of 135.8 seconds of Sym coded. Summing across the two positive mood stories yields 249.9 seconds of Sym. The PlayNarr Happy situation lasted 2x180 $=360$ seconds, so this child exhibited a Sym percentage duration of $69.4 \%$. In a similar way, percentage duration scores were obtained for all behaviour categories in all five play situations. Per play situation, the percentage scores of all behaviours counted up to $100 \%$.

Behavioural Changes. For each child in each play situation we computed the number of times the child's behaviour changed from any category of play or nonplay behaviour to another. These frequencies were summed across the play situations to yield a Total Changes score.

Data Analysis. In the data analysis we used a design with group (depressed vs. nondepressed clinical vs. nondepressed nonclinical children) as between-subjects factor and five within-subjects factors, type of play behaviour (Man and Sym), type of nonplay behaviour (Expl, Exp, Env, Self, Hand, and Look), play situation (Solitary FP, Interactive FP and PlayNarr), behavioural changes, and mood presentation (PlayNarr Happy, 
PlayNarr Sad and Play Narr Neutral). Most research questions are focusing on interaction effects. In general we want to know whether differences between groups (contrasts D vs. NDC, and D vs. NDNC) with respect to play behaviour, nonplay behaviour and behavioural changes vary according to play situation and mood induction procedure. ANOVAs and MANOVAs were executed using the SPSS procedures MANOVA and General Linear Model.

\subsection{Results}

Results will be described on the basis of the research questions. With respect to the results described below, no statistically significant effects were found for age, gender, and order of presentation.

\subsubsection{Differences in Amount of Play in the Various Play Situations}

First we examined whether depressed children differed from nondepressed clinical and nondepressed nonclinical controls in the total amount of play and in the amounts of manipulative and symbolic play exhibited in the various play situations.

As expected, depressed children proved to play significantly less than children in both the nondepressed clinical $(F(1,87)=51.61, p<.000$; eta sqd $=.37)$, and the nondepressed nonclinical group $(F(1,87)=103.30, p<.000$; eta sqd $=.54$ ), but this difference was due only to differences in the amounts of symbolic play. This result was found in two ANOVAs which were conducted with group as independent variable, and the total amounts of manipulative and symbolic play respectively, each summed across the three play situations, as dependent variables. With respect to symbolic play, a main effect was found, indicating that the depressed children showed significantly less symbolic play than both the nondepressed clinical group (Wilks' lambda = $.62, F(2,86)=26.56, p<.000$ ) and the nondepressed nonclinical group (Wilks' lambda $=.44, F(2,86)=55.88, p<.000)$. The three groups did not differ in the amount of manipulative play shown across the whole session (see Table 3 , panel 2).

We then investigated whether the differences between the groups with respect to each type of play varied across the three play situations (cfr. Table 3, panel 3). Two MANOVAs were conducted with group and play situation as independent variables, and the amounts of manipulative and symbolic play as dependent variables, respectively. For symbolic play 
significant interaction effects of group and play situation were found, both in the comparison of depressed and nondepressed clinical children (Wilks' lambda $=.71, F(2,86)=17.53, p<.000)$, and of depressed and nondepressed nonclinical children (Wilks' lambda $=.78, F(2,86)=12.37, p<.000$ ): in all play situations depressed children showed less symbolic play than the nondepressed clinical and the nondepressed nonclinical children. As expected, the difference in symbolic play between the three groups was strongest in the play narratives situation $(F(2,86)=110.93, p<.000)$, smaller in the solitary free play situation $(F(2,86)=16.88, p<.000)$, and still smaller but also statistically significant in the interactive free play situation $(F(2,86)=$ $10.81, p<.000)$. With respect to manipulative play no significant interaction effects were found.

\subsubsection{Differences in Nonplay Behaviour}

Because the scores on nonplay are complementary to those on play, since the amounts of play and nonplay behaviour add up to $100 \%$, it was not needed to examine whether depressed children differed from nondepressed controls in the total amount of nonplay behaviour shown during the session. The significant differences found in the amount of play behaviour among the groups already imply that the depressed children showed significantly more nonplay behaviour than the two groups of nondepressed children. But the question remains whether the differences between the three groups in the total amount of nonplay behaviour varied across the types of nonplay behaviour.

Therefore, a series of ANOVAs was executed with group as independent variable and the amounts of the various nonplay behaviours across the three play situations as dependent variables. As shown in Table 4, the differences among the groups were strongest for exploration, experimenter oriented behaviour, handling and looking. With respect to environment oriented behaviour the difference between depressed and non-depressed clinical children was small and non-significant, but between the depressed and the non-depressed non-clinical children it was larger and significant. The same holds for the differences found with respect to self oriented behaviour. 
Table 3 Mean Amounts of Play Behaviour and Standard Deviations in Seconds for the Three Groups in Three Play Situations

\begin{tabular}{|c|c|c|c|c|c|}
\hline & Type & Sit & Group & $M$ & $S D$ \\
\hline \multirow[t]{3}{*}{ 1. Play * group } & & & $\mathrm{D}$ & $118.8^{1,2}$ & 51.4 \\
\hline & & & NDC & 196.2 & 29.2 \\
\hline & & & NDNC & 228.3 & 41.7 \\
\hline \multirow[t]{6}{*}{ 2. Type of play * group } & Man & & $\mathrm{D}$ & 31.7 & 22.8 \\
\hline & & & NDC & 30.7 & 23.3 \\
\hline & & & NDNC & 23.6 & 27.6 \\
\hline & Sym & & $\mathrm{D}$ & $87.1^{1,2}$ & 45.9 \\
\hline & & & NDC & 165.6 & 37.6 \\
\hline & & & NDNC & 204.8 & 49.4 \\
\hline \multirow[t]{18}{*}{ 3. Play * sit *group } & Man & SFP & $\mathrm{D}$ & 14.9 & 19.1 \\
\hline & & & NDC & 17.8 & 21.9 \\
\hline & & & NDNC & 17.3 & 22.1 \\
\hline & & IFP & $\mathrm{D}$ & 8.0 & 9.8 \\
\hline & & & NDC & 7.8 & 11.7 \\
\hline & & & NDNC & 3.4 & 4.9 \\
\hline & & PN & $\mathrm{D}$ & 8.9 & 7.7 \\
\hline & & & NDC & 5.1 & 6.7 \\
\hline & & & NDNC & 3.0 & 6.1 \\
\hline & Sym & SFP & $\mathrm{D}$ & $13.3^{1,2}$ & 24.0 \\
\hline & & & NDC & 30.0 & 25.4 \\
\hline & & & NDNC & 53.8 & 31.5 \\
\hline & & IFP & $\mathrm{D}$ & $34.7^{1,2}$ & 19.0 \\
\hline & & & NDC & 51.1 & 20.8 \\
\hline & & & NDNC & 59.5 & 23.0 \\
\hline & & PN & $D$ & $39.2^{1,2}$ & 18.9 \\
\hline & & & NDC & 84.5 & 13.4 \\
\hline & & & NDNC & 91.5 & 11.0 \\
\hline
\end{tabular}

Note:

$\mathrm{D}=$ Depressed $(n=30)$;

NDC $=$ NonDepressed Clinical $(n=30)$;

NDNC $=$ NonDepressed NonClinical $(n=30)$;

Man = total amount of manipulative play;

Sym = total amount of symbolic play;

$\mathrm{SFP}=$ solitary free play situation;

IFP = interactive free play situation;

$\mathrm{PN}=$ Play narrative situation.

$1=\mathrm{D}$ vs NDC: $p=<.000$

${ }^{2}=$ D vs NDNC: $p=<.000$. 
Table 4 Mean Amounts of Nonplay Behaviour (Standard Deviations in Parentheses) in Seconds for the Three Groups Across the Three Play Situations

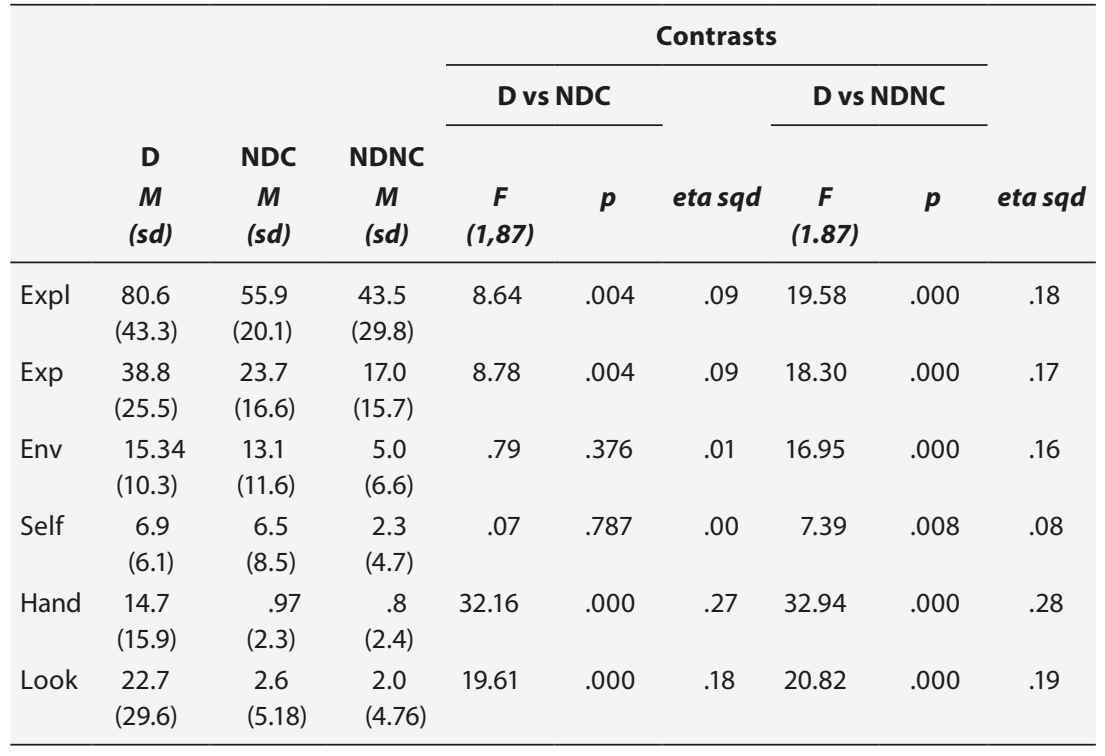

Note:

$\mathrm{D}=$ Depressed;

NDC = NonDepressed Clinical;

NDNC $=$ NonDepressed NonClinical;

Expl = exploratory behaviour;

Exp $=$ experimenter oriented behaviour;

Env = environment oriented behaviour;

Self = self oriented behaviour;

Hand = handling;

Look = looking;

Eta sqd (eta squared) $=$ the proportion of variance explained.

\subsubsection{Differences in the Number of Behavioural Changes}

Next we examined whether depressed children differed from their nondepressed controls in the number of behavioural changes and whether possible differences between the groups would vary across play situations. A MANOVA with group and play situation as independent variables and the number of behavioural changes as the dependent variable, revealed a significant main effect for both contrasts. Depressed children showed significantly more behavioural changes than both their nondepressed clinical controls $(F(1,85)=19.18, p<.000$, eta sqd $=.18)$ and the nondepressed nonclinical controls $(F(1,85)=5.20, p<.000$, eta sqd $=$ 
.38]. Significant interaction effects between group and play situation were found in the contrasts both of the depressed and the nondepressed clinical children (Wilks' lambda $=.86, F(2,84)=6.64, p<.002$ ) and of the depressed and the nondepressed nonclinical children (Wilks' lambda $=$ $.85, F(2,84)=7.42, p<.001)$. The difference between the groups in the number of behavioural changes was smallest but significant in the solitary free play situation $(F(2,86)=4.54, p=.013)$, larger in the interactive free play situation $(F(2,86)=13.50, p<.000)$ and largest in the play narratives situation $(F(2,86)=20.71, p<.000)$. Means and standard deviations are presented in Table 5 .

Table 5 Mean Numbers of Behavioural Changes and Standard Deviations for the Three Groups in the Three Situations

\begin{tabular}{llcc}
\hline Sit & Group & $\boldsymbol{M}$ & SD \\
\hline SFP & D & $12.4^{1,2}$ & 5.00 \\
& NDC & 11.6 & 6.60 \\
& NDNC & 8.4 & 4.72 \\
IFP & D & $32.2^{1,2}$ & 12.54 \\
& NDC & 22.2 & 10.66 \\
& NDNC & 17.8 & 9.20 \\
PN & D & $16.6^{1,2}$ & 6.12 \\
& NDC & 10.4 & 5.70 \\
& NDNC & 7.4 & 4.99 \\
\hline
\end{tabular}

Note:

$\mathrm{D}=$ Depressed $(n=30)$;

NDC $=$ NonDepressed Clinical $(n=30)$;

NDNC $=$ NonDepressed NonClinical $(n=30)$;

$\mathrm{SFP}=$ solitary free play situation;

IFP = interactive free play situation;

$\mathrm{PN}=$ Play narrative situation.

${ }^{1}=\mathrm{D}$ vs NDC: $p=<.000$

$2=$ D vs NDNC: $p=<.000$.

\subsubsection{Effects of Mood Presentation}

As a final research question we examined whether mood presentation differentially affected the play behaviour of depressed children as compared to the two groups of nondepressed controls. We conducted a MANOVA with group and mood presentation as independent variables and total amount of play behaviour in the play narratives situation as dependent variable. A main effect of mood was found, both in the contrast of depressed 
versus nondepressed children $(F(1,87)=144.61, p<.00$, eta sqd $=.62)$ as in that between depressed and nondepressed nonclinical children $(F(1,87)$ $=180.90, p<.00$, eta sqd $=.68)$. In addition, a significant interaction effect was found. The depressed children differed significantly in the effect of mood presentation both from the nondepressed clinical children (Wilks' lambda $=.57, F(2,86)=32.53, p<.000)$, and from the nondepressed nonclinical children (Wilks' lambda $=.45, F(2,86)=52.77, p<.000$ ). Table 6 shows that, as expected, the differences between depressed and nondepressed children are by far the greatest when a negative mood is presented. The effect of mood presentation was greater in the depressed group than in the two nondepressed control groups. The depressed children showed the largest amount of play behaviour in the positive mood presentation part, somewhat less in the neutral part and much less in the negative mood presentation situation, whereas in both control groups these differences were negligible.

Table 6 Mean Amounts of Play and Standard Deviations in Seconds for the Three Groups after Presentation of a Positive, Neutral, and Negative Mood during Play Narratives

\begin{tabular}{lllr}
\hline Mood & Group & \multicolumn{1}{c}{$\boldsymbol{M}$} & \multicolumn{1}{c}{ SD } \\
\hline Pos & D & $63.30^{1,2}$ & 25.31 \\
& NDC & 93.76 & 9.94 \\
\multirow{3}{*}{ Neut } & NDNC & 94.01 & 10.91 \\
& D & $54.66^{1,2}$ & 24.16 \\
& NDC & 87.49 & 11.85 \\
Neg & NDNC & 92.52 & 8.83 \\
& D & $26.01^{1,2}$ & 20.14 \\
& NDC & 87.32 & 19.32 \\
& NDNC & 96.79 & 9.02 \\
\hline
\end{tabular}

Note:

$\mathrm{D}=$ Depressed $(n=30)$;

$\mathrm{NDC}=$ NonDepressed Clinical $(n=30)$;

NDNC $=$ NonDepressed NonClinical $(n=30)$;

Neut $=$ neutral mood presentation;

Pos = positive mood presentation;

Neg = negative mood presentation .

$1=$ D vs NDC: $p=<.000$;

${ }^{2}=\mathrm{D}$ vs NDNC: $p=<.000$. 


\subsection{Discussion}

The present study shows significant and impressive differences in the behaviour of depressed and nondepressed 3- to 6-year-old children in various play situations. The results confirmed our hypotheses and replicated most of the results of our former study.

The depressed children showed less symbolic play than nondepressed clinical and nondepressed nonclinical children of the same age, level of cognitive competence, and socio-economic background. Instead, the depressed children exhibited more nonplay behaviours such as exploration and experimenter oriented behaviour. Moreover, the depressed children showed more shifts from one type of play or nonplay behaviour to another. The differences between depressed and nondepressed children were most prominent in the play narratives situation and were particularly striking when a negative mood was presented. In all analyses, the depressed children differed from both the nondepressed clinical and the nondepressed nonclinical control children.

The present study not only confirmed our hypotheses but also allows for stronger claims for generalization than our former study (Mol Lous et al., 2000). In contrast with the former study, our present study not only included a larger sample of depressed children (30 versus 7), it also included a nondepressed clinical control group in addition to a nondepressed nonclinical control group. What we found to be characteristic of the play behaviour of depressed children can therefore safely be conceived as typical of depressed children and not as descriptive of children with some type of psychopathology.

In contrast with our former study, the data of the present study showed a significant and strong negative effect of mood presentation on the play of depressed children. A clear drop in the amount of play was observed in the depressed children when a negative mood was presented in the play narratives situation. These findings support the hypothesis that the regulatory problems that characterize depressed children (Cicchetti \& Toth, 1998; Field 1992; Garber, Braaflandt, \& Weiss, 1995; Kovacs, 1997; Sheeber et al., 2000) have an inhibiting effect on these children's symbolic play. This type of play probably triggers thoughts and emotions that are difficult to control for depressed children, given their affect regulation problems. But what causes these apparent regulatory problems in depressed children?

There is increasing evidence that early interpersonal experience, particularly in parent-infant interactions, plays an important role in the development of affect regulation. The inhibition of symbolic play and the 
behavioural fragmentation of the depressed children in our study remind of children with disorganised attachments, who are characterized by behavioural disorganisation and disengaged states in stressful interpersonal situations (Main \& Solomon, 1990; Lyons-Ruth \& Jacobvitz, 1999). Although disorganised attachment has been found linked more often with externalising than with internalising disorders (Lyons-Ruth \& Jacobvitz, 1999; Van IJzendoorn, Schuengel, \& Bakermans-Kranenburg, 1999), disorganised attachment has been found associated with internalising problems in several studies (Carlson, 1998; Moss, Rousseau, Parent, St-Laurent, \& Saintong, 1998) and might theoretically cause such fragmented play behaviour as observed in our depressed pre-schoolers. Recent neurobiological research (Fox, 1994) suggests that frightening and traumatic experiences of disorganised children with their parents negatively affect the development of the major regulatory system in the brain, i.e., the orbital prefrontolimbic system. The impaired functioning of this system, in turn, contributes to the inability to cope with novel and stressful circumstances. It might, for example, preclude children to engage in dyadic play states that create high levels of arousal (Schore, 2001). In the present study we observed exactly this behaviour in a 3-year-old depressed girl who, when confronted by the experimenter with a narrative of herself waking up sadly, defensively extended her arms and hands and shouted "Stop it!". Because we have no information regarding the history of parent-child interaction and the attachment quality of the children in our present study, it is not possible for us to examine the presumed relations among children's interpersonal experience, attachment, affect regulation, depression, and play behaviour. In future studies of the behaviour of young depressed children, however, children's attachment histories certainly deserve attention, particularly since disorganised attachment has been found linked with externalising, rather than internalising disorders (Lyons-Ruth et al., 1999; Van IJzendoorn et al., 1999).

To our knowledge, our present and former studies (Mol Lous et al., 2000) and the study by Field et al. (1987) are the only ones in which a broad range of play activities of young children has been observed in various settings. Clearly, more studies are needed to unravel the intricacies and underlying mechanisms of the development of depression and play.

Finally, of course, markers like the ones found in this study cannot be conceived as diagnostic means in their own right, nor as indications of childhood psychopathology. Psychiatric diagnoses ask for more extensive assessment procedures than only play observation. Nevertheless, the procedure proved to allow reliable and valid observations of these 
depression markers. However, it must be stressed that the data of our former and present study were gathered and coded by trained observers using videotaped materials collected under standardized conditions. Moreover, videotaping and coding is time-consuming, a condition often contradictory to the case-load of many practicians. Further research is needed to see whether the same findings hold when less time consuming techniques are used by clinicians to observe the behaviour of children in their play rooms. Obviously the results concerning the mood presentation procedure are in need of replication, since now and for the first time we found differences as expected, whereas we did not find them in our former study. Future research should also compare the results of a more homogeneous depression sample with those of a heterogeneous one, as used in the present study, where depression co-occurs with other disorders. Also in future research, it might be meaningful to divide the heterogeneuos nondepressed clinical control group into various subgroups, such as to investigate whether different play behaviour patterns will be found in children with different nondepressive disorders.

\section{Note}

We acknowledge Dr. John van de Bercken from the Department of Educational Sciences, and Dr. Nol Bendermacher from the Research Technical Support Group of the Faculty of Social Sciences, both at Nijmegen University, for their assistance in the statistical analyses.

\section{References}

Altmann, E., \& Gottlib, H. (1988). The social behaviour of depressed children: An observational study. Journal of Abnormal Psychology, 95, 223-227.

Beck, A.T. (1976). Cognitive therapy and the emotional disorders. New York: International Universities Press.

Carlson, E.A. (1998). A prospective longitudinal study of disorganized/disoriented attachment. Child Development, 69, 1970-1979.

Cicchetti, D. \& Toth, S.L. (1998). The development of depression in children and adolescents. American Psychologist, 53, 221-241.

Diener, M.L., \& Mangelsdorf, S.C. (1999). Behavioral strategies for emotion regulation in toddlers: Associations with maternal involvement and emotional expressions. Infant Behavior and Development, 22, 569-583. 
Edelbrock, C., Costello, A.J., Dulcan, M.K., Conover, N.C., \& Kalas, R. (1986). Parent-child agreement on child psychiatric symptoms via structured interview. Journal of Child Psychology and Psychiatry, 27, 181-190.

Field, T. (1992). Infants of depressed mothers. Development and Psychopathology, 4, 49-66.

Field, T.M., Sandberg, D., Goldstein, S., Garcia, R., Vega-Lahr, N., Porter, K., \& Dowling, M. (1987). Play interactions and interviews of depressed and conduct disordered children and their mothers. Child Psychiatry and Human Development, 17, 213-231.

Fox, N.A. (1994). The development of emotion regulation: Biological and behavioral considerations. Monographs of the Society for Research in Child Development, 59 (2-3, Serial No. 240).

Garber, J., Braaflandt, N., \& Weiss, B. (1995). Affect regulation in depressed and nondepressed children and young adolescents. Development and Psychopathology, 7, 93-115.

Harrington, R. (1993). Depressive disorder in childhood and adolescence. Chichester: John Wiley and Sons.

Harter, S., \& Pike, R. (1984). The pictorial scale of perceived competence and social acceptance for young children. Child Development, 55, 1969-1982.

Hartup, W.W. (1976). Peer interaction and the behavioural development of the individual child. In E. Schopler \& R.L. Reichler (Eds.), Psychopathology and child development, pp. 203-219. New York: Plenum Press.

Hetherington, E.M., Cox, M., \& Cox, R. (1979). Play and social interaction in children following divorce. Journal of Social Issues, 35, 26-49.

Kashani, J.H., Allan, W.D., Beck, N.C., Bledsoe, Y., \& Reid, J.C. (1997). Dysthymic disorder in clinically referred preschool children.Journal of the American Academy of Child and Adolescents Psychiatry, 36, 1426-1433.

Kazdin, A. (1990). Childhood depression. Journal of Child Psychology and Psychiatry, 31, 121-160.

Klein, R. (1991). Parent-child agreement in clinical assessment of anxiety and other psychopathology: A review. Journal of Anxiety Disorders, 5, 187-198.

Kovacs, M. (1977). Conclusions and recommendations of the Subcommittee on Assessment. In J. Schulterbrandt \& A. Raskin (Eds.), Depression in childhood, pp. 155-162. New York: Raven Press.

Lyons-Ruth, K., \& Jacobvitz, D. (1999). Attachment disorganization: Unresolved loss, relational violence, and lapses in behavioral and attentional strategies. In J. Cassidy \& P.R. Shaver, Handbook of attachment: Theory, research, and clinical practice (pp. 520-554). New York: The Guilford Press.

Main, M., \& Solomon, J. (1990). Procedures for identifying infants as disorganized / disoriented during the Ainsworth strange situation. In M.T. Greenberg, D. Cicchetti, \& E.M. Cummings (Eds.), Attachment in the preschool years: Theory, research, and intervention (pp. 121-160). Chicago: University of Chicago Press.

Mol Lous, A., De Wit, C.A.M., De Bruyn, E.E.J., Riksen-Walraven, J.M., \& Rost, H. (200o). Depression and play in early childhood: Play behaviour of depressed and nondepressed 3 - to 6-year-olds. Journal of Emotional and Behavioural Disorders, 8, 249-26o.

Moss, E., Rousseau, D., Parent, S., St-Laurent, D., \& Saintong, J. (1998). Correlates of attachment at school age : Maternal reported stress, mother-child interaction, and behavior problems. Child Development, 69, 1390-1405.

Nader, K., \& Pynoos, R. (1991). Play and drawing techniques as tools for interviewing traumatized children. In C.E. Schaeffer, K. Gitlin \& A. Sandgrund (Eds.), Play diagnosis and assessment, pp. 375-389. New York: John Wiley and Sons.

N.C.C.I.P., National Center for Clinical Infant Programs, (1991). Zero to three. Asrlington: NCCIP. Nissen, G. (1971). Depressive Syndrome im Kindes- und Jugendalter. Berlin: Springer Verlag. 
Noldus Information Technology (1993). The Observer: System for collection and analysis of observational data. Wageningen: Noldus.

Piaget, J. (1962). Play, dreams and imitation in childhood. New York: Norton.

Rost, H. (1986). Exploration and play: A micro-analysis. In R. van der Kooy \& J. Hellendoorn (Eds.), Play, play therapy and play research, pp. 233-245. Lisse: Swets \& Zeitlinger.

Rubin, K.H., Fein, G., \& Vandenberg, B. (1983). Play. In P.H. Mussen \& E.M. Hetherington (Eds.), Handbook of child psychology, Volume 4, pp. 693-774. New York: John Wiley and Sons.

Ryan, V. (1999). Developmental delay, symbolic play and non-directive play therapy. Clinical Child Psychology and Psychiatry, 4, 167-185.

Schore, A.N. (2001). The effects of early relational trauma on right brain development, affect regulation, and infant mental health. Infant Mental Health Journal, 22, 201-270.

Schwab-Stone, M., Faillon, T., Briggs, M., \& Crowther, B. (1994). Reliability of diagnostic reporting for children aged 6-11 years: A test-retest study of the Diagnostic Interview Schedule for Children-Revised. American Journal of Psychiatry, 151, 1048-1054.

Sheeber, L., Allen, N., Davis, B., \& Sorensen, E. (2000). Regulation of negative affect during mother-child problem-solving interactions: Adolescent depressive status and family process. Journal of Abnormal Child Psychology, 28, 467-479.

Singer, J.L., \& Singer, D.G. (1976). Imaginative play and pretending in early childhood: Some experimental approaches. In A. David (Ed.), Child personality and psychopathology: Current topics, Volume 3. New York: John Wiley and Sons.

Stevenson-Hinde, J., \& Shouldice, A. (1995). 4,5 to 7 years: fearful behaviour, fears and worries. Journal of Child Psychology and Psychiatry, 36, 1027-1038.

Sutton-Smith, B. (1980). A syntax for play and games. In R. Herron \& B. Sutton-Smith (Eds.), Child's play, pp. 298-311. New York: John Wiley and Sons.

Ushakov, G.K., \& Girich, Y.P. (1972). Special features of psychogenic depression in children and adolescents. In A. Annell (Ed.), Depressive states in children and adolescents, pp. 510-516. Stockholm: Almqvist \& Wicksell.

Van den Boom, D.C. (1994). The influence of temperament and mothering on attachment: An experimental manipulation of sensitive responsiveness among lower-class mothers with irritable infants. Child Development, 65, 1457-1477.

Van der Poel, L., De Bruyn, E.E.J., \& Rost, H. (1991). Parental attitude and behaviour, and children's play. Play and Culture, 4, 1-10.

Van IJzendoorn, M.H., Schuengel, C., \& Bakermans-Kranenburg, M.J. (1999). Disorganized attachment in early childhood: Meta-analysis of precursors, concomitants and sequelae. Development and Psychopathology, 11, 225-249.

Verhulst, F.C., \& Akkerhuis, G.W. (1989). Agreement between parents' and teachers' ratings of behavioural/emotional problems in children aged 4-12. Journal of Child Psychology and Psychiatry, 30, 123-136.

Warren, S.L., Oppenheim, D., \& Emde, R.N. (1996). Can emotions and themes in children's play predict behaviour problems? Journal of the American Academy of Child and Adolescent Psychiatry, 35, 1331-1337. 



\title{
4. Teacher Ratings of Depression Markers in Young Children's Play ${ }^{3}$
}

\author{
Annemieke Mol Lous, J. Marianne Riksen-Walraven, William \\ J. Burk, Tim Theeboom, Joan, L. Luby
}

Summary This study investigated whether preschool teachers can observe differences in play behavior between preschoolers who are and those who are at not at risk for depression. Teachers rated the play behavior of 1354 - to 7-year-old children, based on everyday observations in their classrooms. Children at risk for depression showed less symbolic play, more behavioral changes (shifts in behavior), and more negative peer play interactions than their non-at risk peers. Being at risk for depression was also related to less motivation to engage in play, more negative affect during play, less comfort offering and seeking, and more disruptive behavior in reaction to negative mood in play. Multiple regression analyses showed that more disruptive reactions to negative emotions in play, and more behavioral changes uniquely predicted being at risk for depression.

\subsection{Introduction}

It has been assumed for many years that children are cognitively and emotionally too immature to experience clinical depression (Digdon \& Gotlib, 1985; Rie, 1966). In the last decades, however, the existence of depression in young children has become generally recognized (Kashani, Allan, Beck, Bledsoe, \& Reid, 1997; Luby, 2010; Luby, Heffelfinger, et al., 2003; Poznanski \& Mokros, 1995). Empirical studies have demonstrated that children from the age of 3 to 6 (preschool period) can manifest a valid and clinically significant depressive syndrome (Luby et al., 2002; Luby, Heffelfinger et al., 2003). Luby, Heffelfinger et al. (2003) identified sensitive and specific symptoms of preschool depression including sadness or irritability, anhedonia, whining and crying, and excessive self-blame. At these young ages, when children are not yet able to report on their own states and feelings, diagnosis of depression depends on systematic observations of the children's behavior, using age-appropriate measures. Play observation would seem 
to be a promising, age-appropriate method. Observation of play is also of special interest because from the earliest publications on childhood depression until recently, play inhibition has been mentioned as one of the core symptoms of depression in preschoolers (Kovacs, 1997, Luby, 2010; Luby, Mrakotsky et al., 2003; Nissen, 1971; Ushakov \& Girich, 1972). However, more detailed information and empirical evidence describing the relation between depression and changes in play behavior remains scarce.

In our former studies (Mol Lous, De Wit, De Bruyn, \& Riksen-Walraven, 2002; Mol Lous, De Wit, De Bruyn, Riksen-Walraven, \& Rost, 2000) we found clear differences in play behavior between depressed and nondepressed preschoolers as rated by trained observers using a standardized play situation in a lab setting. The aim of the present study was to examine whether teachers can rate the presence of these and other play characteristics in preschoolers' play behavior, based on their everyday observations of the children. This is an important issue as teachers may be the first to detect behavioral problems in young children.

\subsubsection{Play Characteristics of Depressed Young Children}

Early publications on childhood depression already referred to play inhibition and the reflection herein of depressed children's loss of interest and motivation (Nissen, 1971; Ushakov \& Girich, 1972) and decreased quality and quantity of play (Kovacs, 1977). One of the very few early observational studies that focused on the relation between depression and play found that depressed children show less fantasy play than nondepressed and conduct-disordered children during free play situations (Field et al., 1987). Other observational studies, focusing on more general behavioral symptoms of depression during play in school age children show that overt behavioral symptoms of depression, such as psychomotor agitation and retardation, can be observed during standardized play procedures (Altmann \& Gotlib, 1988; Kashani, Allan, Beck, Bledsloe, \& Reid, 1997; Kazdin, 1990). More recently, Luby and colleagues found that depressed preschoolers show more negative and less positive behaviors than nondepressed preschoolers, as well as lower levels of observed enthusiasm when interacting with caregivers in structured play observations (Belden \& Luby, 2006; Luby et al. 2006).

A relatively new way of observing play with a standardized procedure is the use of play narratives, where children are invited to complete story beginnings presented by an adult researcher, including emotionally evocative story stems (The MacArthur Story Stem Battery, MSSB; Bretherton, Oppenheim; Emde, \& The MacArthur Narrative Working Group, 2003; 
Robinson, 2007; Belden, Sullivan, \& Luby, 2007). These play narratives have been applied in scientific research and clinical assessments of disorders in young children. The play narratives method uses standardized play themes and play procedures. The observational categories focus both on content and coherence of children's story completions. Research based on play narratives found that mood disordered children showed less coherent play behavior during play narratives (Beresford, Robinson, Holmberg, \& Ross, 2007), whereas manic depressed children showed substantially greater distress and disorganization within high challenging play narratives (Luby, Sullivan, Belden, Stalets, Blankenship, \& Spitznagel, 2006; Miljikovitch, Pierrehumbert, \& Halfon, 2007).

In one of our own earlier studies (Mol Lous et al., 2002) we observed the behavior of 30 depressed preschoolers in three situations (solitary free play, free play in interaction with an experimenter, and play narratives) and compared it to the behavior of 30 nondepressed clinical and 30 nondepressed nonclinical peers. The results demonstrated that depressed children showed significantly less play, particularly less symbolic play, than their nondepressed peers. Instead, they exhibited more nonplay behaviors such as exploration and undirected behaviors. Play behavior of depressed children was also less coherent than that of the nondepressed children, as evident from a greater number of shifts from one type of behavior to another. The differences were most prominent in the play narratives situation and were particularly striking when a negative (i.e., sad) mood was presented (Mol Lous et al., 2002). The latter findings support the assumption that affect regulatory problems of depressed children have an inhibiting effect on their symbolic play (Cicchetti \& Toth, 1998; Field, 1992; Garber, Braaflandt, \& Weiss, 1995; Kovacs, 1997; Sheeber, Allen, Davis, \& Sorensen, 2000).

In sum, observational studies using standardized procedures have shown the play behavior of depressed preschoolers to clearly differ from that of nondepressed children in a number of respects. A next question is whether these results can be translated to an observation instrument applicable for preschool teachers, who have ample opportunities to observe children's play behavior over extended periods of time.

\subsubsection{Background of the Play Observation Questionnaire}

Play observation by teachers is a frequently used tool to obtain information about young children, and earlier research has provided empirical support for the reliability and predictive validity of teachers' play observations as 
a diagnostic tool (Milfort \& Greenfield, 2002; Webster-Stratton \& Lindsay, 1999). As there was no validated questionnaire readily available for observing a broad range of depression-related play characteristics in preschoolers, we designed a questionnaire to accomplish this goal. The questionnaire includes items in six domains, reflecting six dimensions of play behavior that could distinguish between preschoolers who are and preschoolers who are not at risk for depression. The first three domains, i.e., Symbolic play (also referred to as "Fantasy play" or "Pretend play"), Behavioral changes (shifts in behavior), and Exploration were based on the outcomes of our own study summarized above (Mol Lous et al., 2002).

The fourth domain, Peer play interaction, pertains to characteristics of play behavior in the context of peer interactions. In the preschool setting, there are many opportunities for children to play with peers, and the amount and characteristics of peer play might also reflect a risk for depression. Most items in this domain were adopted from the subscale "Play disconnection" from the Penn Interactive Peer Play Scale (PIPPS; Fantuzzo et al., 1995). This widely used play observation scale measures positive and negative aspects of children's play interactions. The PIPPS has been validated for the use with vulnerable children from the Head Start Program. Children from a representative sample of 800 Head Start children scoring high on the play disconnection subscale were described as "...quiet and withdrawn, and seemed depressed..." based on videotaped sessions of interactive school play (Fantuzzo et al., 1995, p.108).

The fifth domain of our play observation questionnaire, Motivation to play, reflects the loss of interest in and enthusiasm during play that has been found to characterize depressed young children. Based on our earlier finding that not only play in general, but especially symbolic play is negatively affected in depressed preschoolers (Mol Lous et al., 2002), we included items about Motivation to play in general and Motivation for symbolic play. Some of the items included in this fifth domain were also adopted from the "Play disconnection" subscale of the PIPPS.

The sixth domain in our questionnaire, Affect regulation, refers to the expression and regulation of emotions during play. Based on the findings of Luby et al. (2006) that depressed children show more negative and less positive behaviors during playful interactions we included items about expression of emotions in this domain. In line with our earlier findings that negative effects of depression are most visible in children's play when a negative mood is induced (Mol Lous et al., 2002), items reflecting disruptive behavior when confronted with negative mood in play were also included in this sixth domain. 


\subsubsection{The Present Study}

In sum, we designed a questionnaire for teachers to rate play behavior of young children in the above mentioned six behavioral domains that were hypothesized to differentiate depressed children from nondepressed children. In the present study we asked teachers to complete the questionnaire for preschoolers in their classes, and related the scores to the children's being at risk for depression as measured by the Preschool Feelings Checklist (PFC, Luby, Heffelfinger Koenig-McNaught, Brown, \& Spitznagel, 2004). Based on the above, we expected that teachers would rate children at risk for depression as 1) engaging less in symbolic play, 2) showing more behavioral changes during play, and 3) engaging more in exploration (reflecting less focused play) than children not at risk for depression. Furthermore, we expected children at risk for depression 4) to engage more in negative peer play interactions and 5) to be less motivated to engage in play. Children at risk for depression were also expected 6) to show low scores on affect regulation.

\subsection{Method}

\subsubsection{Participants}

Participants were contacted via their schools. Seven schools for special education for young children, located in large to middle sized urban areas in the Western part of the Netherlands, were randomly selected. In these special schools children indicated as being at risk for emotional and behavioral problems are placed in a separate setting with high expertise teachers and staff. School directors were addressed by phone to participate in research about play behavior of young children. Four schools agreed to take part. In the same areas where the special schools were located, six regular elementary schools were randomly approached. Four of them agreed to take part. All teachers $(N=19)$ who were teaching in the first two grades of the two types of schools (4- to 7-year-old children) participated in the research. To ensure enough variation in the sample, the teachers were asked to complete the play behavior questionnaire for three or four "troublesome children" ("children about whom you have serious concerns/ worries") and for three or four non-troublesome children, of about the same age, gender and developmental level. The teachers, in cooperation with their colleagues who worked with the same children and knew them well, made 
the judgment about a child being or not being "troublesome" and completed the questionnaire for these children.

The final sample consisted of 135 children ( 66 girls, 69 boys). From the special schools 48 children participated in the study. Of these children, 16 children had a diagnosis of a learning/ behavioral disorder or problem, (i.e., seven children with Attention Deficit Disorder with Hyperactivity (ADHD), two with severe language and speech difficulties (ESM), one Non Verbal Learning Disorder (NLD), one Asperger, one borderline, one Pervasive Developmental Disorder - not otherwise specified (PDD-NOS), one child with a kidney disease, one with combined disorder of ADHD and PDD-NOS, and one with undefined disorder of "regulation"). From the regular schools, 87 children were selected by the participating teachers conform the abovementioned principle and participated in this study. Four of these children had an official diagnosis of disorder or learning/ behavioral problems, (i.e., three ADHD, one child with a hearing impairment). One child was officially categorized as "gifted".

\subsubsection{Procedure}

Teachers were informed that the research aim was to find more evidence about the relationship between play and development of children and were kept blind to the study hypotheses.

The first author visited the school and asked the preschool teachers to fill in the two questionnaires for the selected children, i.e., the Play Observation Questionnaire and the translated PFC (Luby et al., 2004) to measure risk for depression. The teachers always filled in the questionnaire about play behavior before completing the PFC. To make sure that the items were well understood, the first author completed the questionnaires for the first two children together with every teacher separately during the first school visit. In the next two weeks, the teachers completed the remaining questionnaires and sent them to the first author. Their ratings were based upon their regular observations from the last three months, as part of their daily routine. All the children were rated in similar play situations. At the second school visit, about two weeks later, the first author asked about any changes the teachers wanted to make in the questionnaires they had completed, based on more detailed observations from the last two weeks. This was included in the procedure to make it possible for teachers to observe the child on items that they had not yet been able to score because of missing information. For example, teachers were often not aware of the children's reaction to emotionally charged 
play situations and planned extra observations in order to rate these items of the questionnaire.

After all the teachers had completed the questionnaires, the first author came to the school to provide information about research on play in general and specific outcomes for the targeted group of children that were part of the sample. This was part of the agreement to inform the teachers and schools about the latest insights in the relation between emotional problems and play behavior and to offer them the possibility to discuss the results and their concerns about the "troublesome" children.

\subsubsection{Measures}

Play Observation Questionnaire. As described in the introduction, the questionnaire was constructed from items reflecting six dimensions of play behavior that, based on earlier research, could distinguish between preschoolers who are and those who are not at risk for depression. Because the dimensions we aimed to measure were predefined, scale development proceeded in a rational two-step manner. First, preliminary scales were created using theoretically relevant items. After the initial selection of items for the six dimensions of the questionnaire, content and formulation of all dimensions and associated items was discussed with experts in the field and necessary adaptations were made based on this procedure. The original questionnaire consisted of six scales, reflecting the six dimensions of play behavior, i.e., Symbolic play (8 items); Behavioral changes (7 items); Exploration (2 items); Peer play interaction (16 items); Motivation to play (including 9 items, i.e., 4 items for Motivation to play in general and 5 items for Motivation to engage in symbolic play), and Affect regulation (12 items, i.e., 4 items for Expression of emotions and 8 items for Disruptive to negative mood). All items were rated on a 5 -point Likert-scale, ranging from $1=$ totally not applicable for this child to $5=($ almost $)$ completely applicable for this child . The second step in scale construction was based on the questionnaire data collected from the teachers in our sample, and is therefore described in the preliminary results section.

Preschool Feelings Checklist (PFC). The PFC (Luby et al., 2004) is a 16 -item parent/caregiver report checklist designed to identify preschoolers (aged 3.0 to 5.6 years) with symptoms of depression. It is a feasible yes/no checklist that takes 2 to 4 minutes to complete by a parent or caregiver. Symptoms of the checklist include "whines or cries a lot", "appears sad", "blames self". The two PFC items about play, "almost always wants to play" and "often 
plays about scary or sad themes", were not included in our study to prevent these play-related items to confound the outcomes of our analyses. Every symptom of the PFC, answered with "yes" is rated with one point, while a "no" is rated with zero points. The sum of all points is the final score for being at risk. The higher the score, the more a child is at risk. Being at risk for a major depressive disorder is measured if the PFC score of the child is equal to or higher than 3. In our analyses we used this as a cut-off score for rating children to be at risk for depression (PFC score 3 or higher) versus being not a risk for depression (PFC score 0-2).

Cognitive Level. Cognitive level was included as a control variable. Cognitive ratings were based on the judgments of the teachers about the children functioning below, average, or over average in cognitive tasks. For most of the children in the special schools, available scores on standardized tests could be used.

\section{3. $\quad$ Results}

The definitive scales and subscales that were used for the analyses were partly redefined, based on content and internal consistency of the preliminary designed scales.

One item from the Motivation scale (Hovers around aimlessly during play time) was removed, changing the internal consistency in the scale from .61 to .74. One item from the Peer play interaction scale (Directs others'actions politely) was removed, changing alpha from .71 to .86 . Two items from the Affect regulation scale (Often gets angry or irritated during play and Pouts for a considerable time if not allowed to join peer play) were removed, changing alpha from .62 to .72 .

Reliability analyses also indicated that creating subscales for the scale Motivation to play (Motivation for play in general and Motivation for pretend play) raised the internal consistency from .74 to .82 (motivation for pretend play) and .87 (motivation for play in general). Additionally, content and reliability analyses showed that the original Affect regulation scale (alpha: .72) could be divided into three subscales which resulted in higher internal consistency: Expression of emotions (4 items, alpha: .80), Comfort offering and seeking (3 items, alpha: .80), and Disruptive to negative mood (5 items, alpha:.93). Finally, all scales and subscales showed high alpha scores, varying between .80 and .94 . The results of the reliability analyses and score distributions for the definitive scales and subscales are presented in Table 1. The final items of the Play Observation Questionnaire are listed in Table 2. 
Table 1 Final Number of Items, Descriptive Statistics and Reliabilities per (Sub)Scale for the Play Observation Questionnaire Scales $(\mathrm{N}=135)$

\begin{tabular}{lccccc}
\hline Scales & Items & Range & SD & $\boldsymbol{M}$ & $\boldsymbol{a}$ \\
\hline Symbolic play & 8 & $1.1-5.0$ & 3.3 & 0.9 & .89 \\
Behavioral changes & 7 & $1.1-4.9$ & 2.4 & 0.9 & .94 \\
Exploration & 2 & $1.3-5.0$ & 3.5 & 0.9 & .81 \\
Peer play interaction & 14 & $2.0-5.0$ & 3.6 & 0.7 & .86 \\
Motivation & & & & & \\
$\quad$ - For play in general & 4 & $1.3-5.0$ & 3.8 & 0.9 & .87 \\
$\quad$ - For pretend play & 5 & $1.0-5.0$ & 3.2 & 0.9 & .82 \\
Affect regulation & & & & & \\
$\quad$ - Expression of emotions & 4 & $1.5-5.0$ & 3.4 & 0.9 & .80 \\
$\quad$ - Comfort offering/seeking & 3 & $1.3-5.0$ & 3.2 & 0.9 & .80 \\
$\quad$ - Disruptive to negative mood & 5 & $1.0-4.8$ & 1.8 & 1.0 & .93 \\
\hline
\end{tabular}

Table 2 Scales and Items of the Play Observation Questionnaire
Symbolic play
2. Able to play a role
4. Plays at a significant lower level than peers
6. Creative in making up play
29. Able to empathize for different roles
40. Comes up with happy endings for play
43. Plays at a significant higher level than peers
52. Chooses sad or aggressive endings for play/narratives
53. Not able to make up play

\section{Behavioral changes}

12. Volatile play

27. Difficult to keep attention to play

28. Only plays a short episode

58. Changes play activities quickly

61. Able to play concentrated

65. Easily distracted

69. Able to play for long episodes

\section{Exploration}

64. Active in exploring play material

66. Wants to try how new play materials work

\section{Motivation to play in general}

1. Engages with enthusiasm in playing games.

17. Plays enthusiastic

32. Tries to avoid play situations

37. Not interested in play materials 
Table 2 Scales and Items of the Play Observation Questionnaire, continued
Motivation to engage in pretend play/symbolic play
23. Likes to play dramatic pretend play
30. Loves to play about dramatic themes
31. Does not like to play about sad or anxious topics
48. Likes dressing up and face painting
57. Not to be induced to participate in role/pretend play

\section{Peer play interaction}
3. Invites other children to play
11. Watches other children play instead of participating in play
15. Rejects play ideas of others
18. Refuses to play when invited
19. Prefers to play alone, rather than to play with peers
24. Often plays alone
35. Tunes own role with peers
39. Does not count when peers are playing.
42. Plays its own part, separate from others (parallel play)
44. Breaks game if he/she does not like it
45. Joins play if invited
49. Is not part of the group during play
50. Tries to join play but is not accepted
59. Needs encouragement to join play
Affect regulation
Expression of Emotions
10. Shows no intense emotions during play
26. Not able to express feelings during play
33. Shows a variety of emotions during play
56. Laughs a lot during play
Comfort offering/seeking
20. Accepts comforting behavior from peers if upset
38. Comforts others when hurt or sad
55. Allows teacher to comfort, if sad
Disruptive to negative mood
9. Upset if sadness is expressed in play
16. Freezes if sad themes are addressed during play
25. Refuses to play about sad or frightening topics
46. Gets angry if play is about sad themes
60. Easily upset if emotions are expressed during play

Interrater reliability scores were obtained for $22(16.3 \%)$ of the children. For these children, two teachers or one teacher and one teacher assistant completed the Play Observation Questionnaire. Table 1 shows that interrater reliability was high across scale scores (Cohen's Kappa between 
.82 and .98). Chi-square tests and $t$-tests showed that the children from the two school types did not to differ in gender, cognitive development, and age. For the Preschool Feelings Checklist, the mean score across the whole sample was $2.55(S D=2.8$, Range $0-10)$. The association between being at risk for depression and school type was significant $\left(\chi^{2}(1, N=135)=\right.$ $7.84, p<.01)$. Based on the cut-off score $(\geq 3), 32$ of the 135 children $(23.7 \%)$ were classified as being at risk for depression $(M=5.94, S D=2.8$, Range $3-10)$, namely 18 out of 48 children (30.8\%) from the schools for special education, and 14 out of 87 children (15\%) from the regular elementary schools.

We also examined whether being at risk for depression was associated with one or more of the other diagnoses and with gender, cognitive level, and age. A significant association was found between being at risk for depression and having a comorbid diagnosis of Attention Deficit Disorder with Hyperactivity (ADHD). From the children at risk for depression, none of the children had a diagnosis of ADHD, while from the children not being at risk, eight had an official diagnosis of ADHD, based on a $D S M-I V$ clinician's diagnosis $\left(\chi^{2}(2, N=15)=7.3, p<.05\right)$. Being at risk for depression was not associated with the children's gender, cognitive level, and age.

\subsubsection{The Association Between Play Behavior and Being at Risk for Depression}

Table 3 (right hand panel) shows the means and standard deviations of the scores on the Play Observation Questionnaire separately for children who are and children who are not at risk for depression.

The $F$-values show that teachers rated children at risk for depression significantly lower on all of the scales of the Play Observation Questionnaire. According to the teachers' ratings, children at risk for depression showed less symbolic play, more behavioral changes, less positive and more negative peer play interactions, and less motivation to engage both in play in general and in symbolic or pretend play. Teachers also indicated children at risk for depression to express more negative affect and less positive affect during play, show less comfort offering and seeking, and more disruptive behavior if confronted with negative mood in play situations. Contrary to our expectation, teachers reported less (instead of more) exploration in children who were rated as being at risk for depression. 
Table 3 Means and Standard Deviations of the Play Behavior Scores, Separately for Children who are and Children who are Not at Risk for Depression, and F-Values for the Differences Between the Groups

\begin{tabular}{llllll}
\hline Scales/Subscales & \multicolumn{2}{c}{$\begin{array}{c}\text { At risk } \\
(\boldsymbol{n}=\mathbf{3 2})\end{array}$} & \multicolumn{2}{c}{$\begin{array}{c}\text { Not at risk } \\
(\boldsymbol{n}=\mathbf{1 0 3})\end{array}$} & $\boldsymbol{F}$ \\
& $\boldsymbol{M}$ & $\boldsymbol{S D}$ & $\boldsymbol{M}$ & $\boldsymbol{S D}$ & \\
\hline Symbolic play & 2.4 & 0.8 & 3.6 & 0.8 & $58.0^{*}$ \\
$\quad \begin{array}{l}\text { Behavioral changes } \\
\text { Exploration }\end{array}$ & 3.5 & 1.0 & 2.0 & 0.9 & $71.7^{*}$ \\
Peer play interaction & 2.8 & 1.0 & 3.8 & 0.8 & $32.9^{*}$ \\
Motivation & 2.9 & 0.8 & 3.9 & 0.6 & $57.0^{*}$ \\
$\quad$ - For play in general & & & & & \\
$\quad$ - For pretend play & 2.8 & 0.7 & 4.2 & 0.6 & $82.7^{*}$ \\
Affect regulation & 2.3 & 0.9 & 3.5 & 0.8 & $49.3^{*}$ \\
$\quad$ - Expression of emotions & & & & & \\
$\quad$ - Comfort offering/seeking & 2.6 & 0.7 & 3.6 & 0.9 & $45.5^{*}$ \\
$\quad$ - Disruptive to negative mood & 2.4 & 0.7 & 3.4 & 0.9 & $43.6^{*}$ \\
\hline
\end{tabular}

Note:

${ }^{*} p<.01$

To examine the joint and unique contribution of the children's scores on the different play (sub) scales to the prediction of being at risk for depression, logistic regression analysis was conducted with being at risk versus not being at risk for depression as the dependent variable and the nine play behavior scale scores as the predictors. School type (special versus regular) was entered as a control variable given its significant association with the dependent variable. In the initial regression model, the exploration subscale emerged as positively associated with greater risk for depression (bivariate associations indicated that exploration was negatively associated with depression). This so-called suppression effect (MacKinnon, Krull, \& Lockwood, 2000) was mostly due to the inclusion of the Behavioral changes subscale and, to a lesser degree, the Peer play interaction and Symbolic play subscales. To resolve this issue, the exploration subscale was excluded from the final regression model presented in Table 4.

The overall model was significant, $F(9,122)=44.4, p<.001$, with the scales together explaining $69 \%$ of the variance in being at risk for depression. As can be seen in Table 4, two play behavior scores uniquely predicted children to be rated as being at risk for depression. Showing more disruptive behavior to negative mood in play and more behavioral changes independently predicted being at risk for depression according to the Preschool Feelings Checklist. 
Table 4 Results of Logistic Regression Analysis for Predicting Being at Risk for Depression from the Play Behavior Scores, Controlling for School Type (Final Model)

\begin{tabular}{lcll}
\hline Predictor & B & SE B & exp B \\
\hline School type $^{\mathrm{a}}$ & -0.17 & 0.36 & 0.84 \\
Symbolic play & 0.45 & 0.81 & 1.56 \\
Behavioral changes & 1.25 & 0.48 & $3.51^{*}$ \\
Peer play interaction & 1.14 & 1.16 & 3.12 \\
Motivation & & & \\
$\quad$ - For play in general & -0.99 & 0.78 & 0.37 \\
$\quad$ - For pretend play & -0.49 & 0.63 & 0.61 \\
Affect regulation & & & \\
$\quad$ - Expression of emotions & -0.39 & 0.73 & 0.68 \\
$\quad$ - Comfort offering/seeking & 0.08 & 0.49 & 1.08 \\
$\quad$ - Disruptive to negative mood & 1.69 & 0.51 & $5.40^{*}$ \\
\hline
\end{tabular}

Note:

${ }^{*} p<.01$

${ }^{a}$ Regular school $=0$, special school $=1$

\subsection{Discussion}

The present study examined whether preschool teachers can observe differences in play behavior between children at risk for depression and children not at risk for depression. Teachers' ratings of the children's everyday play behavior indeed revealed significant differences between the two groups of children on all of the (sub)scales of our Play Observation Questionnaire. Eight of the nine differences were in the expected direction. Children who were considered at risk for depression were rated by their teachers as showing less symbolic play, more behavioral changes (as indicated by more shifts from one type of behavior to another), and more negative peer interactions during play than their non-at risk peers. Teachers also rated children at risk for depression to be less motivated to engage in play (both play in general and symbolic play), to offer and seek less comfort during play, and to react with more disruptive behavior to play situations where a negative mood is expressed. Finally, and contrary to what we expected, children who were considered as at risk for depression were rated as showing less (instead of more) exploration than their non-at risk peers. In multiple regression analysis, two of these play characteristics turned out to uniquely predict being at risk for depression, namely more disruptive reactions to negative emotions and more behavioral changes during play. 
The finding that disruptive behavior to negative mood in play was one of the unique predictors of being at risk for depression confirms the strong effect of negative mood induction in the play behavior of depressed children in an earlier study where the play behavior of depressed children was rated by trained observers using a standardized play situation in a lab setting (Mol Lous et al, 2002). It also supports the hypothesis that the affect regulatory problems that characterize depressed children (Cicchetti \& Toth, 1998; Field et al., 1987; Garber, Braaflandt, \& Weiss 1995; Kovacs, 1997; Sheeber, Allen, Davis,\& Sorensen, 200o) have an inhibiting effect on depressed children's symbolic play. Our findings underscore that this holds especially for the inability to regulate negative mood, because the other two indicators of affect regulation in this study were less strongly related to being at risk for depression; Expression of emotions and Comfort offering and seeking did not emerge as unique predictors, and the univariate effects of these indicators were less strong as well (see Table 3).

In the present study more behavioral changes constituted the second unique predictor of being at risk for depression. This is also in line with our former studies where depressed children were observed to show more behavioral changes than their non depressed controls in a standardized lab setting (Mol Lous et al, 2000, 2002). Theoretically, this could be explained by possible comorbidity of being at risk for depression with Attention Deficit Disorder with Hyperactivity (ADHD), since showing more behavioral changes is one of the characteristics ADHD. However, in this study, the relation between behavioral changes and being at risk for depression could not be explained by a higher percentage of children with comorbid ADHD in the group of children who were at risk for depression. Contrary, all eight children with an official diagnosis of ADHD were in the group not at risk for depression, while none of the children with ADHD were in the at risk group. This leads us to the conclusion that the high level of behavioral changes or switches from one type of activity to another as observed in depressed children in our former studies is indeed a serious marker of depression. This could be explained by poor concentration or agitation also known in depression and /or by an inability to engage in sustained meaningful productive play as a result of boredom, amotivation and anhedonia.

Our finding that both disruptive behavior in reaction to negative mood in play and a high level of behavioral changes were unique predictors of being at risk for depression is consistent with our earlier suggestion that the play behavior of depressed preschoolers looks quite similar to the behavior that children with a disorganized attachment show during play narratives (Mol Lous et al., 2002). In both groups of children, being 
confronted with threatening emotions seems to disturb the coherence of (play) behavior. It is possible that disorganized attachment plays a role in explaining the incoherent play behavior of depressed children in the present study. We cannot further examine this because attachment was not assessed in our group. But this would also be an interesting question for further research.

Although exploration could not be included in the multiple regression analysis, the unexpected bivariate relationship we found, i.e. more instead of less exploration in children at risk for depression, deserves some attention. Our expectation was based on the outcomes of a former controlled observational study (Mol Lous et al., 2002), where we found depressed children to show more non-play behaviors and especially more exploration in various play situations than their nondepressed peers. What might explain the present unexpected results? A possible explanation might be that the teachers did not distinguish between exploration and play in the way our trained observers did. Whereas the observers in our former study were trained to distinguish between exploration and play and score exploration as non-play behavior, it is possible that the teachers in our present study regarded exploration as a type of play behavior, which may have influenced their observations and ratings. In our former study we used mutually exclusive observational categories of play and non-play behaviors such as exploration, while the teachers in our present study could rate play and exploration as independent behavioral categories. So, in the former study a negative correlation between play and exploration was inherent to the observation system, and the outcomes of our former study may therefore have been an artifact of our observation system. In future studies with teachers, the concept of exploration versus play should be explicitly discussed with the teachers to clarify this question.

As described in the method section we left out two play-related items from the Preschool Feelings Checklist (PFC) to prevent possible confounding effects. This implies that the maximum possible score on the PFC was lower than in the original PFC version, while the same cut-off score was used to rate children at risk for depression. Therefore it should be kept in mind that the present "at risk for depression" score was conservative as compared to that for the original PFC version.

The results of the present study show that children who are at risk for depression have more negative and less positive peer play interactions than their non at risk peers. This puts these children even more at risk, especially if it leads to rejection by peers. Peer rejection has been shown 
to predict a broad range of negative outcomes, such as antisocial behavior, depression, poor school performance, school dropout, and substance abuse (e.g., Bagwell, Newcomb, \& Bukowski, 1998; Ladd \& Troop-Gordon, 2003). Although we did not include sociometric measurements in our study, future research should include such measures in order to shed more light on the relationship between negative play interactions, peer rejection and depression in young children. Not being able to handle negative mood, lacking quality of play, and peer rejection during preschool puts these young children at a threefold risk for (later) developmental psychopathology.

Our hypotheses about depression and play were based upon our former studies about play of officially diagnosed clinically depressed children while the present study incorporated children at risk, not officially diagnosed as depressed. We can conclude that not only depressive disorders but also milder levels of depression and depression related problems are visible in play behavior. Thus, play observation seems a promising tool for early detection of depression in preschoolers.

\subsubsection{Limitations and Implications for Further Research}

An important limitation of this study is that teachers who rated the children's play behavior also filled out the PFC to assess being at risk for depression. Although the teachers were blind to the study hypotheses and the PFC was always filled out after the rating of play behavior, the fact that both variables were rated by the same person may have inflated the associations between both measures. Furthermore, our request to the teachers to select "troublesome" children may have influenced the teachers' ratings of the children's play behavior. In future studies independent assessment of risk for depression is needed.

Another limitation is the relatively small sample size, especially with regard to the children at risk for depression. Because we also did not use a random sample, one should be careful with generalizations from the findings of this study and future research is needed with larger samples.

Despite these limitations, the results of this study are promising because despite the small sample of at risk children, we found meaningful outcomes and we may cautiously conclude that teachers can indeed observe play characteristics of children at risk for depression. This is an important finding for early detection of depression in preschoolers and clearly asks for replication. 


\section{References}

Altmann, E., \& Gottlib, H. (1988). The social behavior of depressed children: An observational study. Journal of Abnormal Psychology, 95, 223-227.

Bagwell, C. L., Newcomb, A. F., \& Bukowski, W. M. (1998). Preadolescent friendship and peer rejection as predictors of adult adjustment. Child Development, 69, 140-153.

Belden, A. C., \& Luby, J. L. (2006). Preschoolers' depression severity and behaviors during dyadic interactions: The mediating role of parental support. Journal of the American Academy of Child and Adolescent Psychiatry, 45, 213-222.

Beresford, C., Robinson, J. L., Holmberg, J., \& Ross, R. G. (2007). Story stem responses of preschoolers with mood disturbances. Attachment \& Human Development, 9, 255-270.

Bretherton, I., Oppenheim, D., Emde, R.N., \& The MacArthur Narrative Working Group (2003). The MacArthur Story Stem Battery. In R.N. Emde, D.P. Wolf, \& D. Oppenheim (Eds.), Revealing the inner worlds of young children: The MacArthur Story Stem Battery and parent-child narratives (pp. 381 - 396). New York: Oxford University Press.

Cicchetti, D., \& Toth, S. L. (1998). The development of depression in children and adolescents. American Psychologist, 53, 221-241.

Digdon, N., \& Gotlib, I.H. (1985). Developmental considerations in the study of childhood depression. Developmental Review, 5, 162-199.

Fantuzzo, J., Sutton-Smith, B., Coolahan, K. C., Manz, P. H., Canning, S., \& Debnam, D. (1995). Assessment of preschool play interaction behaviors in young low income children: Penn Interactive Peer Play Scale. Early Childhood Research Quarterly, 10, 105-120.

Field, T. M., Sandberg, D., Goldstein, S., Garcia, R., Vega-Lahr, N., Porter, K., \& Dowling, M. (1987). Play interactions and interviews of depressed and conduct disordered children and their mothers. Child Psychiatry and Human Development, 17, 213-231.

Field, T. (1992). Infants of depressed mothers. Development and Psychopathology, 4, 49-66.

Garber, J. Braaflandt, N., \& Weiss, B. (1995). Affect regulation in depressed and nondepressed children and young adolescents. Development and Psychopathology, 7, 93-115.

Kashani, J. H. Allan, W. D., Beck, N. C., Bledsoe, Y. \& Reid, J. C. (1997). Dysthymic disorder in clinically referred preschool children. Journal of the American Academy of Child and Adolescent Psychiatry, 35, 1426-1433.

Kazdin, A. (1990). Childhood depression. Journal of Child Psychology and Psychiatry, 31, 121-16o.

Kovacs, M. (1997). Depressive disorders in childhood: An impressionistic landscape. Journal of Child Psychology and Psychiatry, 38, 287-298.

Ladd, G. W., \& Troop-Gordon, W. (2003). The role of chronic peer difficulties in the development of children's psychological adjustment problems. Child Development, 74, 1344-1367.

Luby, J. L. (2010). Preschool depression: The importance of identification of depression early in development. Current Directions in Psychological Science, 19, 91-95.

Luby, J. L., Heffelfinger, A. K., Koenig-McNaught, A. L., Brown, K., \& Spitznagel, E. (2004). The preschool feelings checklist: A brief and sensitive screening measure for depression in young children. Journal of the American Academy of Child and Adolescent Psychiatry, 43, 708-717.

Luby, J. L., Heffelfinger, A. K., Mrakotsky, C., Brown, K. M., Hessler, M. J., Wallis, J. M., \& Spitznagel, E. L. (2003). The clinical picture of depression in preschool children. Journal of the American Academy of Child and Adolescent Psychiatry, 42, 340-348.

Luby, J. L., Heffelfinger, A. K., Mrakotsky, C., Hessler, M. J., Brown, K., \& Hildebrand, T. (2002). Preschool major depressive disorder: Preliminary validation for developmentally modified DSM-IV criteria. Journal of the American Academy of Child and Adolescent Psychiatry, 41, 928-937. 
Luby J. L., Mrakotsky, C., Heffelfinger, A. K., Brown, K., Hessler, M., \& Spitznagel, E.L. (2003). Modification of DSM-IV criteria for depressed preschool children. American Journal of Psychiatry, 160, 1169-1172.

Luby, J. L., Sullivan, J., Belden, A., Stalets, M., Blankenship, S., \& Spitznagel, E. (20o6). An observational analysis of behavior in depressed preschoolers: Further validation of early-onset depression. Journal of the American Academy of Child and Adolescent Psychiatry, 45, 203-212.

MacKinnon, D.P., Krull, J.L., \& Lockwood, C.M. (200o). Equivalence of the mediation, confounding and suppression effect. Prevention Science, 1, 173-181.

Milfort, R., \& Greenfield, D. B. (2002). Teacher and observer ratings of head start children's social skills. Early Childhood Research Quarterly, 17, 581-595.

Miljikovitch, R., Pierrehumbert, B., \& Halfon, O. (2007). Three-year-old's attachment play narratives and their associations with internalizing problems. Clinical Psychology and Psychotherapy, 14, 294-257.

Mol Lous, A., De Wit, C.A.M., De Bruyn, E.E.J., \& Riksen-Walraven, J.M. (2002). Depression markers in young children's play: a comparison between depressed and nondepressed 3- to 6-year-olds in various play situations. Journal of Child Psychology and Psychiatry, 43, 1029-1038.

Mol Lous, A., De Wit, C.A.M., De Bruyn, E.E.J., Riksen-Walraven, J.M., \& Rost, H. (200o). Depression and play in early childhood: Play behaviour of depressed and nondepressed 3 - to 6-year-olds. Journal of Emotional and Behavioural Disorders, 8, 249-26o.

Nissen, G. (1971). Depressive Syndrome im Kindes- und Jugendalter. Berlin. Springer Verlag.

Poznanski, E. O., \& Mokros, H.B. (1995). Children's Depression Rating Scale-Revised Manual. Los Angeles: Western Psychological Services.

Robinson, J. (2007). Story stem narratives with young children: Moving to clinical research and practice. Attachment \& Human Development, 9, $179-185$.

Sheeber, L., Allen, N., Davis, B., \& Sorensen, E. (2000). Regulation of negative affect during mother-child problem-solving interactions: Adolescent depressive status and family process. Journal of Abnormal Child Psychology, 28, 467-479.

Ushakov, G. K., \& Girich, Y. P. (1972). Special features of psychogenic depression in children and adolescents. In A. L. Annell (Ed.), Depressive states in children and adolescents (pp. 510-516). Stockholm: Almqvist \& Wicksell. 


\section{Summary, Conclusions, and General Discussion}

\subsection{Summary of the Research Project}

During the last decades evidence has been found for preschool depression as a clinically significant but underestimated disorder. It is known for its severe impact, endurance, and is easy to miss for caregivers and teachers. Early identification of the disorder is regarded as a public health priority, but age appropriate assessment instruments are lacking. Play observation is proposed as such an age appropriate assessment instrument for early detection of preschool depression. That is not only because play observation is a useful assessment tool in general, but also because play inhibition (i.e., decreasing quantity and quality of play) has been referred to as a core symptom of preschool depression from the earliest clinical and empirical studies on depression in preschoolers. To date, however, empirical evidence about the relationship between play and depression is scarce. The present thesis aims to contribute to filling this gap.

The thesis focused on the manifestation of depression in play behavior of both preschoolers with an official diagnosis of Major Depressive Disorder (MDD) and preschoolers at risk for depression but not (yet) officially diagnosed. Across the three studies included in this thesis, with three independent samples, information about play behavior of a total of 239 preschoolers from the western, middle-east and southern-east part of the Netherlands was collected.

The main aim of this thesis was to identify markers of depression in the play behavior of depressed preschoolers that differentiate them from nondepressed preschoolers. An additional goal was to investigate whether preschool teachers were able to identify specific play characteristics in children at risk for depression from their daily observations in the classroom. These research aims were addressed in three empirical studies that are presented in Chapters 2, 3, and 4 . The present $5^{\text {th }}$ and final Chapter presents a summary of the results of the three studies, followed by the main conclusions of the thesis and a general discussion.

Study 1. In the first (exploratory) study, described in Chapter 2, we observed the play behavior of seven children diagnosed by their institution's clinical staff with a major depressive disorder and compared it to the play behavior of seven matched nondepressed control children from mainstream 
elementary schools. We examined whether the depressed children differed from the nondepressed children in the amount and coherence of their play behavior in different play situations. We also examined whether mood induction during play narratives would differentially affect depressed children's play.

To examine this we videotaped the play behavior of the depressed and nondepressed preschoolers, using a standardized play procedure with different play situations (e.g. solitary play, interactive free play with an experimenter, and play narratives with and without mood induction). Children's behavior was rated from the videotapes using a coding system with mutually exhaustive play and nonplay observation categories.

The results showed that depressed children showed significantly less play than their nondepressed controls, especially less symbolic play. Their play was also less coherent, with more changes from one play or nonplay category to another. Differences between depressed and nondepressed children varied across play situations: they were larger in play narratives than in solitary play, and non significant in interactive free play. Depressed children showed significantly more nonplay behavior than their matched controls. This suggests that depressed children are not behaviorally retarded or sluggish, but rather 'differentially active'. The behavioral pattern of depressed children in our study is comparable with the behavior of children with a disorganized type of attachment, which has been related to childhood depression (Main \& Solomon, 1990). Contrary to our expectation, mood induction during play narratives had no differential effects on the play of depressed and nondepressed children.

In conclusion, this study was one of the first to reveal clear differences in observed play behavior between depressed preschoolers and nondepressed controls. Given the relatively small and select sample and some other methodological limitations of the study, we concluded that replication was needed.

Study 2. The second study, reported in Chapter 3, examined whether the results of our first study could be replicated in a larger sample and with some methodological improvements. The same play procedure was used to examine a larger group of depressed children $(n=30)$, selected with a more in-depth diagnostic procedure for assessment of depression. Furthermore, an extra non-depressed clinical sample $(n=30)$ was included as a second control group in addition to the nondepressed nonclinical controls $(n=30)$.

Results confirmed our findings from the first study that depressed children show less play, especially less symbolic play, and more behavioral changes than nondepressed children. In this second study this effect was also found when the depressed children were compared with nondepressed 
children from clinical childcare centers. Again the differences between depressed and nondepressed children were most prominent in the play narratives situation. Contrary to our first study, sad mood induction was found to have a strong negative impact on the play of depressed children. The latter result suggests that the regulatory problems that characterize depressed children have an extra inhibiting effect on these children's play.

In conclusion, this study confirmed our hypotheses that depressed children show less play, especially less symbolic play, and more fragmented behavior in play situations than nondepressed controls. The results of the present study also showed a significant and strong negative effect of sad mood induction on the play of depressed children.

Study 3. In the third study, presented in Chapter 4, we used the results of the former two studies in designing the $5^{2}$-item Play Observation Questionnaire for preschool teachers. We examined whether (non-trained) teachers could use the questionnaire to observe differences in play behavior between children at risk for depression and not at risk peers, based on their everyday observations of the children in the past three months.

Teachers from four regular elementary schools and four schools for special education used the play observation questionnaire to rate the behavior of a total of 1354 - to 7-year-old children. Afterwards, the teachers also completed the Preschool Feelings Checklist (PFC, Luby, Heffelfinger, Koenig-McNaught, Brown, \& Spitznagel, 2004) to identify children at risk for depression. The play behavior of children classified as being at risk for depression, based on the PFC $(n=32)$ was compared with the play behavior of peers who were not at risk for depression $(n=103)$.

According to the teachers' play observations, children at risk for depression showed less symbolic play, more behavioral changes, less motivation to engage in general and symbolic play, and more negative peer interactions during play. Teachers also indicated children at risk for depression to express more negative affect during play, show less comfort searching and offering behavior, and more disruptive behavior if confronted with negative mood during play. Multiple regression analyses showed that more disruptive behavior if confronted with negative mood, and more behavioral changes uniquely predicted children to be at risk for depression.

In conclusion, this study clearly reveals that teachers do recognize signs in children's everyday play behavior that might be indicative for being at risk for depression quite similar to the signs we found in our earlier observation studies in a standardized lab setting. The results suggest that teachers' reports on play behavior as observed during daily play situations in preschools can be useful for early detection of preschoolers being at risk for depression. 


\subsection{Conclusions}

The results of the three studies included in this thesis can be summarized in the following main conclusions:

- Depression in preschoolers has a negative effect on their play behavior. Depressed children show less play, particularly less symbolic play than nondepressed children. Their play behavior is also less coherent, showing more behavioral changes and fragmentation of play as compared to the play behavior of nondepressed children.

- The negative effect of depression on preschoolers' play behavior is most evident during play narratives with negative mood induction.

- Teachers can observe signs of depression in the play behavior of preschoolers, based on their daily, regular observations.

- As observed by teachers, the everyday play behavior of children at risk for depression differs in several respects from the play of children not at risk for depression. More behavioral changes and more disruptive behavior if confronted with negative mood are the most distinctive features of the everyday play behavior of preschoolers who are at risk for depression.

\section{5•3. General Discussion}

The present thesis has yielded new and interesting findings regarding play behavior of depressed preschoolers. In this general discussion we successively highlight some topics that deserve extra attention, as well as some clinical implications of our findings.

\subsubsection{Developments in the Field in the Past Decade}

The reader may have noticed that there is a substantial time lapse between publication of the first two studies in this thesis (Mol Lous, De Wit, De Bruyn, Riksen-Walraven \& Rost, 200o; Mol Lous, De Wit, De Bruyn, \& Riksen-Walraven, 2002) and the submission of the paper describing the third study (Mol Lous, Riksen-Walraven, Burk, Theeboom, \& Luby, 2014), which was based on the outcomes of the two earlier studies. This time lapse, which is the result of the author choosing for a career in teaching after the first studies and returning to finishing the thesis some years later, may raise the question of how developments in the relevant scientific field in the intermediate period were taken into account in finishing the thesis. This was done as follows. 
Before setting up the third study, the author performed an extensive literature search for possible new developments in the field of depression and play in young children; the results of this search are included in the General Introduction (Chapter 1) of this thesis. The literature search showed that relatively little new research had appeared in this field since publication of the earlier studies (Mol Lous et al., 2000, 2002) and that the conclusions drawn in those earlier studies were still valid. The most important contribution to the field of depression and play in young children since 2002 came from Joan Luby and colleagues, who demonstrated that children from age 3 onwards can manifest a valid and clinically significant depressive syndrome, which is predictive of depression in later childhood (e.g., Luby, 2010; Luby , Belden, et al., 2009; Luby, Mrakotsky, Brown, \& Spitznagel, 2004; Luby et al., 2003; Luby, Si, Belden, Tandon, \& Spitznagel, 2009; Luby et al., 2006). To further ensure that recent developments in the field of depression and play in preschoolers were sufficiently taken into account in the third and final paper, Joan Luby was contacted and acted as coauthor of the third paper.

In addition to including the most important recent developments in the field in the General Introduction (Chapter 1) of this thesis, we pay extra attention to three of these developments in the following subsections, namely the increasing use of play narratives as a diagnostic instrument for young children (5.3.2), recent findings regarding the neurobiological mechanisms that may underlie the development of early childhood depression (5.3.3), and the possible implications of the recent distinction among different subtypes of depression in young children (5.3.4).

\subsubsection{Play Narratives}

In our two standardized observational studies, we compared the play behavior of depressed versus nondepressed children in three different situations, namely solitary free play, interactive play with an experimenter, and play narratives. It is a remarkable finding that the negative effect of depression on play behaviour was most visible during the play narratives, and especially when a sad mood was induced. Our first two studies showed that depressed preschoolers engage less in play and show more behavioral changes. Moreover, we found that depression mainly affects symbolic play and becomes most apparent during play narratives with sad mood induction.

The latter finding suggests that the induction of sad mood is so challenging for depressed children that it severely affects their play. Being confronted 
with a sad mood might be so challenging for depressed young children because of the emotion regulation problems that have been found to characterize them. This is underscored by our casual observations of several children during play narratives with a sad mood induction. For example, Tom, a 3-year-old depressed boy, resisted playing a story with a puppet that represented himself as a sad person. He tried to escape from the play situation by stepping out of the "play frame" and kept on saying: "Is not Tom. Other Tom". He even wanted to throw away the puppet that was representing him. Our results with sad mood induction during play narratives suggest that this procedure might be a useful tool for detecting preschool depression.

The use of play narratives is also of special interest because they are used to measure attachment quality in young children. In the last decade, more evidence has been found for the use of play narratives as diagnostic instruments. The MacArthur Story Stem Battery (MSSB; Bretherton, Oppenheim, \& Emde, 2003) has been validated for both clinical and empirical research and has become a generally used assessment instrument for attachment quality (Beresford, Robinson, Holmberg, \& Ross, 2007; Robinson, 2007).

The trying to escape from the play situation and feeling unable to relieve distress during highly challenging play narratives that we observed in depressed preschoolers during play narratives with sad mood induction has also been found in the MSSB play narratives of maltreated, neglected, and abused children (Cicchetti et al. 1999), and in play narratives of children with mood disorders (Beresford et al., 2007; Robinson, 2007). The difference between the standard MSSB procedure and our sad mood induction procedure is that the MSSB uses story stems where a story content is presented that is expected to evoke specific distress (thereby uncovering attachment quality), whereas our procedure directly asks children to play themselves as a sad child without presenting a specific distressing story content. The MSSB measures disruptions in play behavior as an indication for insecure attachment. The fragmented play behavior that we found in depressed children's play narratives after sad mood induction shows striking similarities with the play behavior of children with a disorganized attachment. In the future, a combination of the standard MSSB procedure with sad mood induction might provide a more complete picture of depressed children's play and offers opportunities to measure possible relationships between depression and attachment.

\subsubsection{Possible Underlying Neurobiological Mechanisms}

Another topic that deserves attention lies in the possible neurobiological mechanisms that may underlie our research findings. At the time of our 
first observational studies not much was known yet about how the early negative experiences that are associated with early childhood depression (especially early life stress and a lack of adequate parental care) affect the development of certain parts young children's brains, and thereby the later behavior and functions that are mediated by those parts of the brain.

Recently, more neurobiological research has become available, showing that early negative experiences negatively affect those parts of the brain (e.g., the Prefrontal Cortex) that underlie children's later behavior and emotion regulation capacities. The impact of enduring high levels of stress and negative parent-child interactions in the very first years of life on the development of prefrontal regulatory systems, increasing the risk for both attention and emotion-regulatory problems has been hypothesized earlier (Fox, 1994; Schore, 2001) and is now supported by this more recent neurobiological research (for a review and model see Loman and Gunnar, 2010). This might explain our observations about the fragmented, incoherent play behavior that characterized depressed preschoolers in our studies, as well as the negative impact of sad mood induction in the play narratives that possibly reflects emotion regulation problems.

More recent research of Pagliaccio et al. (2012) supports this explanation, by showing that a history of depression during the preschool period is associated with decreased activity in prefrontal cortex during sad mood induction and regulation. Participants in this study observed a sad movie and were prompted to encourage active elaboration of the induced sad mood. MRI scans were used to examine the effects on parts of the brain like amygdala/ hippocampus, prefrontal cortex etc. Severity of current depressed mood in 7to 11-year-old children was found to be associated with increased activity in limbic regions such as the amygdala, particularly in children with a history of preschool depression, indicating disruptions in emotion-related neural circuitry associated with preschool-onset depression as found in depressed adults. These neurobiological studies provide more insight in the possible mechanisms underlying the effect of preschool depression on children's play behavior and underline the importance of early detection of depression.

\subsubsection{Subtypes of Depression}

In the studies in this thesis we did not distinguish among different subtypes of depression in young children, but there are indications that play inhibition might manifest itself differently in different subtypes. Since 2004, anhedonia has been found as a characteristic of a more severe and putative melancholic depressed subtype in young children showing alterations in 
cortisol reactivity, increased family history of major depressive disorder, and increased psychomotor retardations as well as other melancholic symptoms, such as lack of brightening in response to joyful events (Luby, Mrakotsky, et al., 2004; Luby, Si, et al., 2009; Luby et al. 2003; Luby et al. 2006). As early identification of this severe subtype of depression is extremely important for detection, diagnosis and treatment (Luby, 2010), more studies are needed to find out whether both play behavior and neurobiological markers can differentiate subtypes of depressed children, like the anhedonic subtype. Although we did find similar play characteristics in both clinically diagnosed children and children at risk for depression but not officially diagnosed, anhedonia might show a stronger negative effect on their play and more severe neurobiological deviations. Anhedonic children might even show no play behavior at all, which might have important consequences for the effectiveness of play therapy for intervention and prevention of depression. If children with anhedonia are unable to play, play interventions might not be effective. More research is needed to examine this.

\section{5·3.5. Implications for Practice}

Both our earlier laboratory studies and our more recent research on play behavior in the natural setting provide important information for clinical practice, i.e., assessment and treatment of depression in preschoolers. Decreased quantity and quality of play was not only observed in depressed children during the videotaped standardized play procedures with trained observers in our first studies. Teachers observed similar characteristics of play behavior in children at risk for depression in the natural preschool setting. Although the latter study had some methodological limitations that restrict the strength of the conclusions, the study results suggest that untrained teachers are able to detect children at risk for depression based on their play observations. If teachers are trained to observe emotion regulation problems and disruptions in play behavior they may be able identify children at risk for depression. Their observations can be used for the early detection of depression and add specific information to the observations of parents and other caregivers.

The results of the first to studies strongly suggest that standardized play observation procedures should be part of the diagnostic assessment procedures in clinical settings. More in particular, observations of the play behavior of referred children during play narratives can provide important information for clinical diagnosis of preschoolers. From our research it is clear that play narratives with sad mood induction are most effective in distinguishing 
among depressed and nondepressed preschoolers, and therefore deserve to be incorporated in such a clinical diagnostic assessment. The use of videotaped play sessions and objective observers during clinical assessments offers opportunities to observe both content and behavioral aspects of play behavior.

Future research should also focus on the possibilities to use interventions during play for improving emotion regulation in depressed children or children at risk. Our research clearly showed that sad mood has a disruptive effect on play behavior in these children. Recent research indicates that typical children make more use of positive coping strategies, such as introducing happy moods and smiling or helping the play figures to solve the problem in a positive way in play narratives than mood disturbed children. For typical children the use of positive coping strategies increased in more challenging stories, whereas mood disturbed children's positive coping markedly decreased (Beresford et al. 2007).

It is an important question whether the use of positive coping strategies can be taught to depressed children as intervention or treatment (Oppenheim, 2006). Luby, Lenze, \& Tillman (2012) found indications that it is indeed possible to improve depressed children's coping behavior during play interactions and direct communication. In using Parent Child Interaction Therapy with Emotion Development (PCIT-ED; Luby et al., 2012) found positive effects of teaching and in vivo coaching of parents to promote positive play techniques and emotion regulation competences in interaction with their children. Significant improvements were found in decreasing the severity of depression in general and specific symptoms like negativity and liability of the children. Improvements were also found for emotion regulation and emotion differentiation, as well as for executive functioning like memory and planning/ organizing. Although this pilot study was preliminary, in need for replications and follow-up of the effects, it offers promising possibilities to use play not only for detection of depression in preschoolers, but also as an intervention to work on the affect regulation problems and to improve depressed children's functioning in general.

\section{References}

Beresford, C., Robinson, J.L., Holmberg, J., \& Ross, R.G. (2007). Story stem responses of preschoolers with mood disturbances. Attachment \& Human Development, 9, 255-270.

Bretherton, I., Oppenheim, D., Emde, R.N., \& The MacArthur Narrative Working Group (2003). The MacArthur Story Stem Battery. In R.N. Emde, D.P. Wolf, \& D. Oppenheim (Eds.), Revealing the inner worlds of young children: The MacArthur Story Stem Battery and parent-child narratives (pp. 381-396). New York: Oxford University Press. 
Cicchetti, D. Macfie, J. Toth, S.L., Rogosch, F.A., Robinson, J., \& Emde, R.N. (1999). Effect of maltreatment on preschoolers' narrative representations of responses to relieve distress and of role reversal. Developmental Psychology, 35, 460-465.

Hood, K.K., \& Eyberg, S.M. (2003). Outcomes of parent-child interaction therapy: Mothers' reports of maintenance three to six years after treatment. Journal of Clinical Child and Adolescent Psychology, 32, 419-429.

Loman, M.M., \& Gunnar, M.R. (2010). Early experience, stress and the development of stress reactivity and regulation in children. Neuroscience Biobehavior Reviews, 34. 867-876.

Luby, J.L. (2010). Preschool depression: The importance of identification of depression early in development. Current Directions in Psychological Science, 19, 91-95.

Luby, J.L., Belden, A., Sullivan, J., Hayen, R., McCadney, A., \& Spitznagel, E. (2009). Shame and guilt in preschool depression: evidence for elevations in self-conscious emotions in depression as early as age 3. Journal of Child Psychology and Psychiatry, 50, 1156-1166.

Luby, J.L., Heffelfinger, A.K., Koenig-McNaught, A.L., Brown, K., \& Spitznagel, E. (2004). The preschool feelings checklist: A brief and sensitive screening measure for depression in young children. Journal of the American Academy of Child and Adolescent Psychiatry, 43, 708-717.

Luby, J.L., Heffelfinger, A.K., Mrakotsky, C., Brown, K.M., Hessler, M.J., Wallis, J.M., \& Spitznagel, E.L. (2003). The clinical picture of depression in preschool children.Journal of the American Academy of Child and Adolescent Psychiatry, 42, 340-348.

Luby, J.L., Lenze, S, Tillman, R. (2012). A novel early intervention for preschool depression: Findings from a pilot randomized controlled trial. The Journal of Child Psychology and Psychiatry, 53, 313-322.

Luby, J.L., Mrakotsky, C., Brown, K., \& Spitznagel, E. (2004). Characteristics of depressed preschoolers with and without anhedonia: evidence for a melancholic depressive subtype in young children. American Journal of Psychiatry, 2004, 161, 1998-2004.

Luby, J.L., Si, X., Belden, A.C., Tandon, M., \& Spitznagel, E. (2009). Preschool depression: Homotypic continuity and course over 24 months. Archives of General Psychiatry, 66, 897-905.

Luby, J.L., Sullivan, J., Belden, A., Stalets, M., Blankenship, S., \& Spitznagel, E. (2006). An observational analysis of behavior in depressed preschoolers: Further validation of early-onset depression. Journal of the American Academy of Child and Adolescent Psychiatry, 45, 203-212.

Mol Lous, A., De Wit, C.A.M., De Bruyn, E.E.J., \& Riksen-Walraven, J.M. (2002). Depression markers in young children's play: a comparison between depressed and nondepressed 3 - to 6-year-olds in various play situations. Journal of Child Psychology and Psychiatry, 43, 1029-1038.

Mol Lous, A., De Wit, C.A.M., De Bruyn, E.E.J., Riksen-Walraven, J.M., \& Rost, H. (200o). Depression and play in early childhood: Play behaviour of depressed and nondepressed 3 - to 6-year-olds. Journal of Emotional and Behavioural Disorders, 8, 249-26o.

Mol Lous, A., Riksen-Walraven, J.M., Burk, W.B., Theeboom, T., Luby, J.L. (2014). Teacher ratings of depression markers in young children's play.Journal of Emotional and Behavioral Disorders (submitted).

Oppenheim, D. (2006). Child, parent and parent-child emotion narratives: Implications for developmental psychopathology. Development and Psychopathology, 18, 771-79o.

Pagliaccio, D., Luby, J.L., Gaffrey, M., Belden, A., Botteron, K., Gotlib, I.H., \& Barch, D.M. (2012). Anomalous functional brain activation following negative mood induction in children with pre-school onset major depression. Developmental Cognitive Neuroscience, 2, 256-267.

Robinson, J. (2007). Story stem narratives with young children: Moving to clinical research and practice. Attachment \& Human Development, 9, 179-185.

Schore, A.N. (2001). The effects of early relational trauma on right brain development, affect regulation, and infant mental health. Infant Mental Health Journal, 22, 201-207. 


\section{Samenvatting en conclusies}

\section{Samenvatting van het onderzoek}

In de afgelopen twintig jaar is duidelijk geworden dat depressie bij jonge kinderen wel degelijk onderscheiden kan worden als een klinisch significante stoornis die bovendien vaak wordt onderschat. Het doormaken van depressie op jonge leeftijd blijkt een zeer grote impact te hebben die ook op de langere termijn doorwerkt in het functioneren van kinderen. Depressie op jonge leeftijd wordt echter vaak niet onderkend door ouders en verzorgers. En hoewel vroege signalering van depressie wordt beschouwd als een prioriteit op het terrein van de volksgezondheid, ontbreekt het nog aan ontwikkelingsadequate onderzoeksinstrumenten. Spelobservatie wordt genoemd als zo'n ontwikkelingsadequaat onderzoeksinstrument. Niet alleen omdat spelobservatie in het algemeen een geschikt diagnostisch instrument is voor jonge kinderen. Maar ook vanwege het feit dat vanuit de vroegste klinische en empirische onderzoeken inhibitie van spel wordt genoemd als kernsymptoom van depressie bij jonge kinderen. Er is echter nauwelijks empirische evidentie voor deze veronderstelde relatie tussen spel en depressie. Dit proefschrift heeft als doel om een bijdrage te leveren aan het opvullen van deze lacune.

In dit proefschrift is onderzocht hoe depressie zich manifesteert in het spel van zowel kinderen met een officiële diagnose van Major Depressive Disorder (MDD) als kinderen waarbij een duidelijk vermoeden is van een depressieve stoornis zonder dat de depressie officieel gediagnosticeerd is. Het proefschrift omvat drie empirische studies, bij drie verschillende onderzoeksgroepen, waarbij gegevens zijn verzameld over het spelgedrag van in totaal 239jonge kinderen tussen 3 en 7 jaar uit het westelijk, middenoostelijk en zuidoostelijk deel van Nederland.

Het belangrijkste doel van dit proefschrift was om te onderzoeken of depressieve kinderen specifieke spelkenmerken laten zien die hen onderscheiden van niet-depressieve leeftijdgenoten. Daarnaast wilden we ook onderzoeken of leerkrachten in de onderbouw van het basisonderwijs op basis van hun dagelijkse observaties in de klas ook specifieke spelkenmerken herkennen bij kinderen bij wie een depressieve stoornis vermoed wordt. In de hoofdstukken 2, 3 en 4 van dit proefschrift zijn de drie empirische studies beschreven die zijn uitgevoerd om dit te onderzoeken. In het vijfde en laatste hoofdstuk wordt een overzicht gegeven van de bevindingen van de drie studies, gevolgd door de belangrijkste conclusies, een algemene discussie en aanbevelingen voor verder onderzoek. 
Studie 1. In de eerste (exploratieve) studie, beschreven in hoofdstuk 2, is het spelgedrag van zeven kinderen geobserveerd en vergeleken met het spelgedrag van zeven niet-depressieve kinderen. De depressieve kinderen waren door de klinische staf van de instelling waar zij verbleven als depressief gediagnosticeerd. De niet-depressieve kinderen waren afkomstig van reguliere basisscholen. We onderzochten of het spelgedrag van depressieve kinderen verschilde van het spelgedrag van de niet-depressieve kinderen wat betreft de hoeveelheid en coherentie van hun spelgedrag in diverse spelsituaties. Hierbij hebben we ook inductie van emoties toegepast om te kijken of dit een specifiek effect zou hebben op de verschillen in spelgedrag tussen beide groepen kinderen.

Om dit te onderzoeken hebben we video-opnames gemaakt om het spelgedrag van de depressieve en niet-depressieve kinderen te kunnen vergelijken tijdens een gestandaardiseerde spelprocedure met verschillende spelsituatie (solitair spel, vrij spel met de proefleider en spel-narratieven met inductie van emoties). Het gedrag van de kinderen werd gecodeerd met behulp van elkaar uitsluitende observatiecategorieën voor spel- en niet-spelgedrag.

Uit de resultaten bleek dat depressieve kinderen significant minder speelden dan hun niet-depressieve leeftijdsgenootjes. Dit verschil was vooral zichtbaar bij het symbolisch spel. Het spel van de depressieve kinderen was ook minder coherent; hun spel vertoonde meer wisselingen van de ene naar de andere observatiecategorie. De verschillen tussen depressieve en niet-depressieve kinderen varieerden per spelsituatie: de verschillen tijdens de spel-narratieven waren groter dan tijdens de solitaire spelsituatie en niet significant tijdens interactief spel met de proefleider. Depressieve kinderen vertoonden ook meer niet-spelgedrag dan hun niet-depressieve leeftijdgenoten. Dit suggereert dat depressieve kinderen niet zozeer inactief, traag of "sloom" zijn in hun gedrag, maar dat ze eerder "anders actief" zijn. Het gedrag van de depressieve kinderen uit dit onderzoek vertoont gelijkenis met het gedrag van kinderen met een gedesorganiseerd gehechtheidstype, dat ook wel geassocieerd wordt met depressie bij kinderen (Main \& Solomon, 1990). In tegenstelling tot onze verwachtingen had inductie van emoties tijdens spel-narratieven geen verschillend effect op het spel van depressieve en niet-depressieve kinderen.

Concluderend kunnen we stellen dat dit het eerste onderzoek is waarin duidelijke verschillen in spelgedrag konden worden vastgesteld tussen depressieve kinderen en hun niet-depressieve leeftijdsgenoten. Gezien de geringe omvang en specificiteit van de onderzoeksgroep, alsmede enkele andere methodologische beperkingen, is het aan te bevelen om het onderzoek te herhalen om sterkere uitspraken te kunnen doen. 
Studie 2. In de tweede studie, beschreven in hoofdstuk 3, is onderzocht of de resultaten van het eerste onderzoek bevestigd konden worden door hetzelfde onderzoek uit te voeren met een grotere onderzoeksgroep en een aantal methodologische aanpassingen. In deze studie werd dezelfde spelprocedure gehanteerd om een grotere groep depressieve kinderen $(n=30)$ te onderzoeken. Voor de selectie van deze groep kinderen werd ook een strengere diagnostische procedure gehanteerd om de depressie te kunnen vaststellen. Ook werd een extra controlegroep samengesteld van niet-depressieve kinderen uit een klinische setting $(n=30)$ aanvullend op een niet-depressieve, niet klinische controlegroep $(\mathrm{n}=30)$.

De resultaten bevestigden onze eerdere bevindingen dat depressieve kinderen minder spelen, met name minder symbolisch spel spelen en dat ze vaker wisselen van gedragscategorie. In deze tweede studie bleek dat deze verschillen ook gevonden werden als depressieve kinderen werden vergeleken met niet-depressieve kinderen uit een klinische setting. Ook bij deze studie waren de verschillen het meest zichtbaar tijdens de spelnarratieven. In tegenstelling tot ons eerste onderzoek bleek inductie van een verdrietige stemming een sterke negatieve invloed te hebben op het spel van depressieve kinderen. Dit laatste doet veronderstellen dat het vooral de affect-regulatie problemen van de depressieve kinderen zijn die een belemmerend effect hebben op hun spel.

Concluderend kunnen we stellen dat deze studie onze hypotheses bevestigde dat depressieve kinderen minder spel vertonen, vooral minder symbolisch spel spelen en dat hun spelgedrag meer gefragmenteerd is dan bij niet-depressieve leeftijdsgenootjes. In dit onderzoek vonden we dat inductie van een verdrietige stemming een significant en sterk negatief effect had op de kwaliteit en hoeveelheid spel van depressieve kinderen.

Studie 3. Voor de derde studie, beschreven in hoofdstuk 4, hebben we de resultaten van de eerste twee onderzoeken gebruikt om een spelobservatievragenlijst met $5^{2}$ items te ontwikkelen voor leerkrachten in de onderbouw van de basisschool. We onderzochten of (ongetrainde) leerkrachten deze vragenlijst konden gebruiken om, op basis van hun dagelijkse (routinematige) observaties in de afgelopen drie maanden, verschillen in spelgedrag te kunnen observeren tussen kinderen die mogelijk "at risk" zijn voor depressie en kinderen die dat niet zijn.

Leerkrachten van vier reguliere basisscholen en vier scholen voor speciaal basisonderwijs hebben de spelvragenlijst ingevuld van in totaal 135 vier tot zeven jaar oude kinderen. Na het invullen van deze lijst hebben de leerkrachten ook de Preschool Feelings Checklist (PFC, Luby, Heffelfinger, Koenig-McNaught, Brown, \& Spitznagel, 2004) ingevuld om kinderen te kunnen identificeren 
die mogelijk at risk waren voor een depressieve stoornis. Vervolgens is het spelgedrag van leerlingen die at risk waren voor depressie $(n=32)$ vergeleken met het spelgedrag van kinderen die niet at risk waren $(n=103)$.

Uit de spelobservaties van de leerkrachten bleek dat kinderen die at risk zijn voor depressie minder symbolisch spelen, meer gedragswisselingen laten zien, minder gemotiveerd zijn om te participeren in algemeen en symbolisch spel en dat ze meer negatieve interacties met leeftijdsgenootjes vertonen tijdens het spelen. Leerkrachten gaven ook aan dat kinderen die at risk zijn voor depressie meer negatieve emoties laten zien tijdens hun spel, minder troost zoeken en bieden en dat ze meer verstorend gedrag vertonen als ze geconfronteerd worden met negatieve stemmingen tijdens het spel.

Uit meervoudige regressie analyses bleek dat verstorend gedrag als reactie op negatieve stemmingen en meer gedragswisselingen beide unieke voorspellers waren voor het at risk zijn voor depressie.

Concluderend kan gezegd worden dat leerkrachten op basis van hun dagelijkse spelobservaties specifieke kenmerken van spelgedrag zien bij kinderen die at risk zijn voor depressie; deze spelkenmerken zijn vergelijkbaar met de kenmerken van spelgedrag die wij vonden in onze eerdere observatiestudies in een gestandaardiseerde laboratoriumsetting. Op basis hiervan kunnen we verwachten dat spelobservaties door leerkrachten tijdens dagelijkse spel situaties in de klas gebruikt kunnen worden voor vroegsignalering van jonge kinderen die at risk zijn voor depressie.

\section{Conclusies}

De resultaten van de drie empirische studies in dit proefschrift kunnen worden samengevat in de volgende belangrijkste conclusies:

- Depressie bijjonge kinderen heeft een negatief effect op hun spelgedrag. Depressieve kinderen spelen minder. Ze laten vooral minder symbolisch spel zien dan niet-depressieve kinderen. Hun spelgedrag is ook minder coherent, met meer gedragswisselingen en gefragmenteerd spel in vergelijking tot niet-depressieve leeftijdgenootjes.

- Het negatieve effect van depressie op het spel van jonge kinderen is het meest zichtbaar tijdens spelsituaties waarbij gebruik wordt gemaakt van spel-narratieven met inductie van een negatieve (verdrietige) stemming.

- Leerkrachten kunnen kenmerken van depressie observeren in het spelgedrag van jonge kinderen, gebaseerd op hun dagelijkse routinematige observaties. 
- Het alledaagse spelgedrag van jonge kinderen die at risk zijn voor depressie verschilt van het spelgedrag van niet-depressieve kinderen, zoals geobserveerd door leerkrachten. De grootste verschillen tussen kinderen die wel en kinderen die niet at risk zijn voor depressie worden gevonden voor gedragswisselingen en de confrontatie met negatieve emoties in spel. Het meest kenmerkende voor het alledaagse spelgedrag van kinderen die at risk zijn voor depressie is dat zij meer gedragswisselingen en meer verstorend gedrag vertonen wanneer zij geconfronteerd worden met negatieve (verdrietige) emoties. 



\section{Curriculum vitae}

Annemieke Mol Lous werd op 23 december 1958 te Delft geboren. In 1977 behaalde ze het Gymnasium diploma aan het Hugo Grotius te Delft. Na haar opleiding tot leerkracht basisonderwijs aan de Pedagogische Academie voor het Basisonderwijs H. Bouman in Amsterdam, werkte ze enkele jaren in het vernieuwingsonderwijs in Almere. In 1988 startte zij de MO-A opleiding orthopedagogiek aan het Nuts seminarium te Amsterdam waar ze in 1990 haar diploma behaalde. Haar doctoraal orthopedagogiek rondde zij in 1993 af aan de Vrije Universiteit in Amsterdam. Tijdens deze studies werkte zij parttime als leerkracht in het speciaal onderwijs in de kinderpsychiatrie.

Van 1994 tot 1999 was zij als AIO werkzaam bij de vakgroep ontwikkelingspsychologie van de Katholieke Universiteit Nijmegen. In haar onderzoek richtte ze zich op de relatie tussen spel en depressie bij jonge kinderen van drie tot zes jaar. Van 1999 tot 2009 was zij als hoofddocent en onderzoeker verbonden aan het domein onderwijs en opvoeding van de Hogeschool van Amsterdam. Vanaf 2009 is Annemieke als lector passend onderwijs/ inclusive education verbonden aan de Hogeschool Leiden en de Thomas More Hogeschool te Rotterdam. Als lector stuurt zij een onderzoeksteam aan dat onderzoek doet naar succesfactoren voor passend onderwijs en de UNESCO doelen van 'Inclusive education' en 'Education for All' en op basis hiervan (na) scholing ontwikkelt. In deze periode heeft zij ook haar eerdere onderzoek naar de relatie tussen spel en depressie weer opgepakt. Zij startte een derde onderzoek naar de vraag of leerkrachten in het basisonderwijs ook relaties zien tussen depressie en spel op basis van hun dagelijkse reguliere observaties in de klas. Dit laatste onderzoek en de eerdere onderzoeken zijn in dit proefschrift beschreven.

Naast haar werk als lector bij de hogescholen is zij verbonden aan (editorial) boards van diverse (inter)nationale organisaties zoals o.a. de Vereniging voor Leraren Opleiders Nederland (VELON), Association for Teachers Education Europe (ATEE, chair of the Research and Development Community on Inclusion and Special Needs), European Network on Social and Emotional Competence in School (ENSEC), Bahir Dar University in Ethiopië en de Universiteit van Malta. Ook heeft zij diverse andere (advies) functies, o.a. bij de Ambulante Educatieve Dienst (AED) Leiden, Dutch Coalition on Disability and Development (DCDD), USAID en de werkgroep buitenland van Kinderpostzegels Nederland. 
